\title{
ANAEROBIC FERMENTATION OF FOOD WASTE AND GLYCEROL TO HYDROGEN
}

\author{
A Thesis \\ presented to \\ the Faculty of California Polytechnic State University, \\ San Luis Obispo
}

\begin{abstract}
In Partial Fulfillment
of the Requirements for the Degree

Master of Science in Civil and Environmental Engineering
\end{abstract}

by

Eric Robert Krikorian

June 2017 
(C) 2017

Eric Robert Krikorian

ALL RIGHTS RESERVED 
COMMITTEE MEMBERSHIP

TITLE: $\quad$ Anaerobic Fermentation of Food Waste

and Glycerol to Hydrogen

AUTHOR: Eric Robert Krikorian

DATE SUBMITTED: June 2017

COMMITTEE CHAIR: Tryg Lundquist, Ph.D.

Professor of Environmental Engineering

COMMITTEE MEMBER: Rebekah Oulton, Ph.D.

Professor of Civil and Environmental

Engineering

COMMITTEE MEMBER: Chris Kitts, Ph.D.

Professor of Biological Sciences 


\begin{abstract}
Anaerobic Fermentation of Food Waste and Glycerol to Hydrogen

Eric Krikorian
\end{abstract}

Hydrogen has several well-known advantages as a fuel and chemical feedstock, but current methods of hydrogen production are costly and energy intensive. A potentially advantageous source of hydrogen is fermentation of organic wastes, especially any abundant, low-cost wastes with a high content of simple sugars. Molar hydrogen yields from fermenters (aka digesters) are affected by $\mathrm{pH}$, organic loading rate (OLR), hydraulic residence time (HRT), and substrate type. A less studied process to increase yield is sparging with low- $\mathrm{H}_{2}$ content gas to strip $\mathrm{H}_{2}$ from the digester liquid. The present study optimized the levels of each of these variables for hydrogen production from glycerol and food waste, building on previous proof-of-concept studies that used glucose as the substrate.

Six bench-scale, semi-continuously fed, stirred, anaerobic digesters were constructed and fed glycerol or food waste as a substrate. In a series of experiments, $\mathrm{pH}, \mathrm{HRT}, \mathrm{OLR}$, and gas sparging rate were tested over a range of values. $\mathrm{pH}$ levels were controlled by use of phosphate buffers. In an envisioned process, low- $\mathrm{H}_{2}$ content from a second-stage methane digester would be used as the sparging gas, allowing subsequent combustion of a high- $\mathrm{H}_{2}$ content biogas with low NOx formation potential. $\mathrm{N}_{2}$ was used as a surrogate for biogas in one set of experiments. 
The main conclusions are based on data from periods of steady-state digester performance and daily measurements of $\mathrm{pH}$, alkalinity, biogas production, biogas composition, total and volatile suspended solids, and chemical oxygen demand (COD). COD balances were measured for all experiments and generally showed recoveries of $>85 \%$.

With glycerol substrate, the highest molar hydrogen yield $(0.071 \pm 0.0100 \mathrm{~mol}$ $\mathrm{H}_{2} /$ mol glycerol $)$ and volumetric hydrogen production $\left(0.281 \pm 0.0395 \mathrm{~L}_{\mathrm{H} 2} / \mathrm{L}_{\text {Reactor- }}\right.$ day) were achieved with the following: pH 6.51, OLR $18.8 \mathrm{~g}$ COD/L-day, HRT 12 hours, and sparging rate of $3.2 \mathrm{~mL} / \mathrm{min}$, and 1-L working volume. Gas type $\left(\mathrm{N}_{2}\right.$ or biogas) used in sparging did not influence hydrogen production.

The best results with food waste $\left(0.021 \pm 0.0013 \mathrm{~mol} \mathrm{H}_{2} / \mathrm{mol} \mathrm{COD}\right.$ and $0.478 \pm$

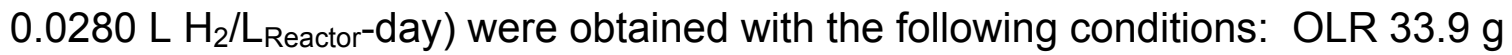
$\mathrm{COD} / \mathrm{L}$-day and nitrogen sparging rate of $1.0 \mathrm{~L} \mathrm{~N}_{2} /$ hour, and 1-L working volume. $\mathrm{pH}$ and HRT were not optimized for food waste substrate, but the best values from the glycerol experiments were adopted.

Sparged glycerol and food waste digesters had molar hydrogen yields at least $40 \%$ greater than controls. Nonetheless, molar hydrogen yields in the present study were lower than in those reported by other authors, for unknown reasons. Yields from food waste might be improved by optimizing $\mathrm{pH}$ and HRT 
levels. Alkalinity sources need to be identified to replace the non-scalable phosphate buffers of the present research. Lastly, long-term experiments should consider whether attached growth of hydrogen-consuming methanogens develops in hydrogen fermentation reactors. 


\section{ACKNOWLEDGMENTS}

I would like to thank,

Carol and Jacques Krikorian for working two jobs, and sacrificing so much for me to get an excellent education and further my dreams, for teaching me the values of a hard work ethic, and responsibility, and for supporting me and my endeavors every step of the way

Tyler Deitz for putting up with an irritated Eric whose just spent hours and hours in a stinky lab, for being someone I look forward to seeing every single day, for somehow making even the worst of situation better, and for helping me to become a better person every day

Ruth Spierling for two years of answering my relentless phone calls and emails, supporting me every step of the way, teaching me everything I know about the world of anaerobic digestion, and inspiring me every day to become a better scientist and engineer

Tryg Lundquist for his ability to make even the most scientific of discussions humorous, and for inspiring me to work harder and harder every day to pursue one of the most important and extraordinary fields of engineering

Shelley Blackwell for her support in scheduling ENVE 405 students and taking care of my many emergency shipping orders

Christopher O'Connor, Emma Hennig, and Daniel Covarrubias for their hours of hard work and support in the lab, and for allowing me to have an occasional weekend

ENVE 405 students, for collecting much of my data

Rebekah Oulton for being in my thesis committee and teaching me the value of project management

Chris Kitts for being in my thesis committee

California Energy Commission for financial support in a project grant through the Energy Innovation Small Grants program

Tracy Thatcher for lending me the air flow meter

San Luis Obispo Water Reclamation Facility for allowing me to pick up gallons and gallons of sludge 
California Polytechnic State University, San Luis Obispo for allowing me to learn about the joys of anaerobic digestion

And everyone else who was instrumental to my success in this project 


\section{TABLE OF CONTENTS}

Page

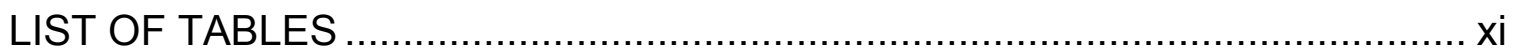

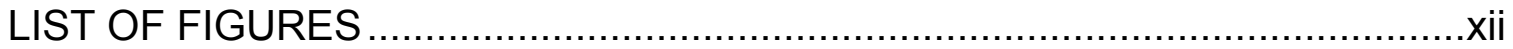

CHAPTER

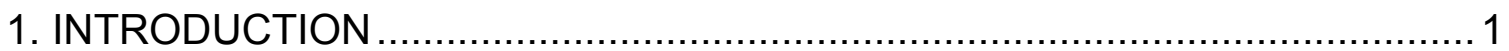

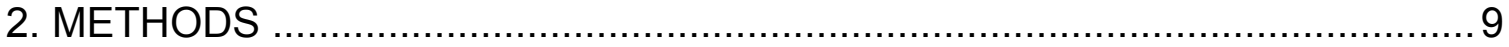

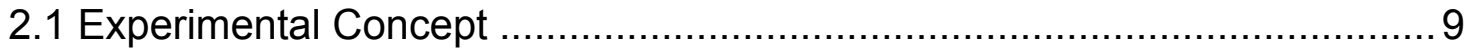

2.2 Bench-Scale Anaerobic Digesters Design ......................................... 11

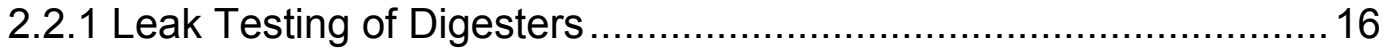

2.2.2 Feedstock Reservoir Design .............................................. 17

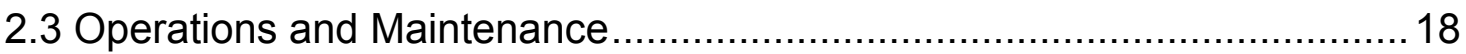

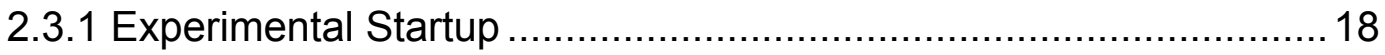

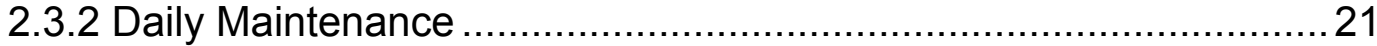

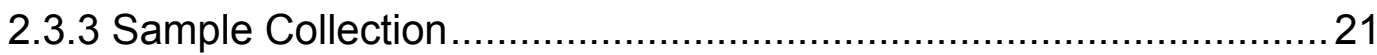

2.3.4 Definition of Steady State Digester Performance .........................22

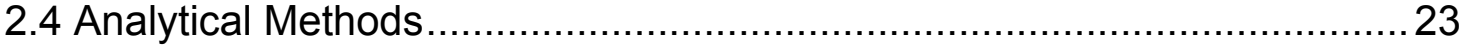

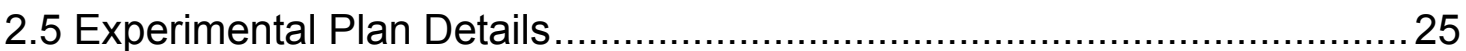

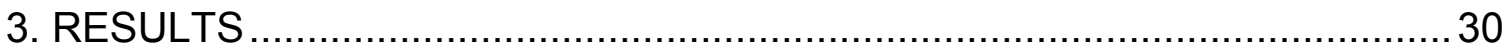

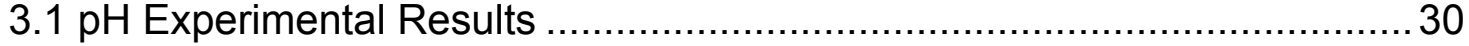

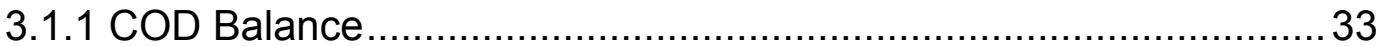

3.1.2 Molar Hydrogen Yields and Volumetric Hydrogen Production ........ 36

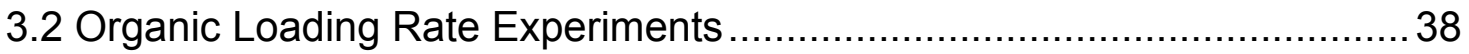

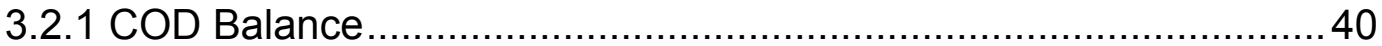

3.2.2 Molar Hydrogen Yields and Volumetric Hydrogen Production ........ 43

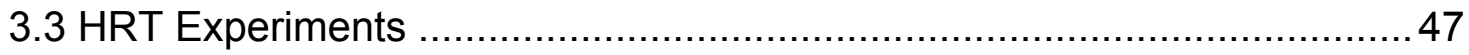

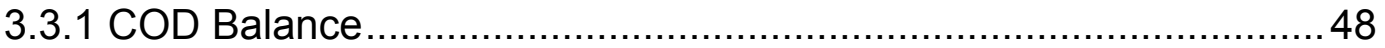

3.3.2 Molar Hydrogen Yields and Volumetric Hydrogen Production ........51

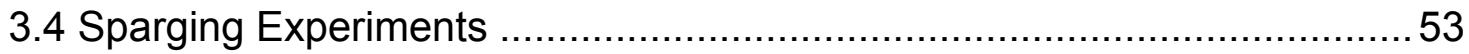

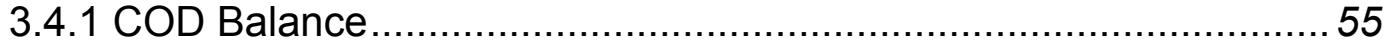


3.4.2 Molar Hydrogen Yields and Volumetric Hydrogen Production ........56

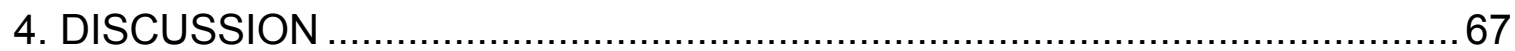

4.1 Comparisons to Literature …...................................................... 70

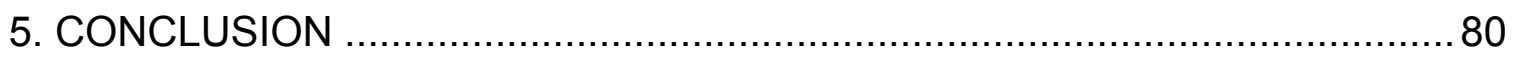

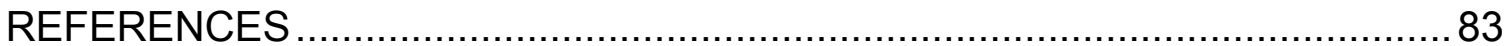




\section{LIST OF TABLES}

Table 1. Operational variables, either treatment variables or constant variables, for each experiment. The stepwise optimization experiments were conducted in the order listed.

Table 2. Constituents added to the 10-L feedstock reservoirs

Table 3. The various operational conditions and values tested for food waste and glycerol substrates

Table 4. Target operational variables for $\mathrm{pH}$ Experiment 1 and $\mathrm{pH}$

Experiment 2

Table 5. Target OLRs for food waste in concentration units of glucose and COD

Table 6. Molar yields observed at the optimal operational conditions with respect to COD and glycerol

Table 7. Molar hydrogen yields obtained from various experiments using pure glycerol as a substrate. Each yield was generally higher than what was observed in this experiment.

Table 8. Molar hydrogen yields produced by food waste substrate at varying operational conditions and cultures. 


\section{LIST OF FIGURES}

Page

Figure 1. Schematic cross section of a typical digester used in the hydrogen optimization experiments. The lower end of the temperature port tube was sealed and filled with water. A temperature probe was sealed in this tube.

Figure 2. Digester inlets and outlets. Pictured at 1 o'clock is the gas outlet, 3 o'clock is the compression fitting and $\mathrm{pH}$ probe, 5 o'clock is the digestate outlet, 7 o'clock is the feed inlet, 9 o'clock is the sealed temperature probe, and 11 o'clock is the base addition line. Pictured in the center is the sealed lid and sparging gas inlet fitting. Also shown is the reflective heat mat wrapped around the digester.

Figure 3. Outlet gas appurtenances

Figure 4. One of the tipping gas meters (not filled with water). Top: plan view. Bottom: side view.

Figure 5. One of three filled digester feedstock reservoir atop a stir plate and located in a refrigerator.

Figure 6. Components of food waste (in \% wet mass) obtained from a dining hall at California Polytechnic State University, San Luis Obispo, and used as digester feed.

Figure 7. Time-series $\mathrm{pH}$ readings for replicate digesters D1 and D2 (target $\mathrm{pH}$ 6.2). The mean $\mathrm{pH}$ of the duplicate digesters was 6.08 during the steady-state period (within the vertical lines). On Day 3, D2 stopped mixing and was dosed with $\mathrm{KOH}$, raising the $\mathrm{pH}$ to 6.50 . HRT was 12 hours.

Figure 8. Mean of duplicates $\mathrm{pH}$ readings during $\mathrm{pH}$ Experiment 1. The steady state period is depicted as the days between the vertical lines.

Figure 9. COD balance for $\mathrm{pH}$ Experiment 1 where digesters were operated at $\mathrm{pH}$ values of $6.08,6.47$, and 6.83 , during the steady state performance period. The means of steady-state performance periods by duplicate digesters were used to calculate the standard errors $(n=2)$ shown on the digester effluent and biogas bars. The influent standard errors were based on measurements during the steady state performance period $(n=5)$... 
Figure 10. COD balance for $\mathrm{pH}$ Experiment 2 where digesters were operated at pHs of $6.21,6.54$, and 6.84 during the steady state performance period. The means of steady-state performance periods by duplicate digesters were used to calculate the standard errors $(n=2)$ shown on the digester effluent and biogas bars. The influent standard errors were based on measurements during the steady state performance period $(n=5)$.

Figure 11. Molar hydrogen yields for mean $\mathrm{pH}$ values of $6.15,6.51$, and 6.84 . The means of steady state performance periods by replicate experiments were used to calculate the standard errors shown on the molar yield bars $(n=2)$. Molar hydrogen yields are based on influent COD.

Figure 12. Volumetric hydrogen production for mean $\mathrm{pH}$ values of 6.15 , 6.51 , and 6.84 . The means of steady state performance periods by replicate experiments were used to calculate the standard errors shown on the volumetric hydrogen production bars $(n=2)$.

Figure 13. COD balance for digesters operated at mean OLRs of 18.8, 24.0, and $28.8 \mathrm{~g} \mathrm{COD/L-day.} \mathrm{OLR} \mathrm{values} \mathrm{were} \mathrm{calculated} \mathrm{as} \mathrm{the} \mathrm{mean} \mathrm{over} \mathrm{the}$ course of the steady state period. The means of steady-state performance periods by duplicate digesters were used to calculate the standard errors ( $\mathrm{n}$ $=2$ ) shown on the digester effluent and biogas bars. The influent standard errors were based on measurements during the steady state performance period $(n=5)$.

Figure 14. COD balance for digesters operated at mean OLRs of 12.7, 17.6, and $23.1 \mathrm{~g} \mathrm{COD/L-day.} \mathrm{OLR} \mathrm{values} \mathrm{were} \mathrm{calculated} \mathrm{as} \mathrm{the} \mathrm{mean} \mathrm{over} \mathrm{the}$ course of the steady state period. The means of steady-state performance periods by duplicate digesters were used to calculate the standard errors ( $\mathrm{n}$ $=2$ ) shown on the digester effluent and biogas bars. The influent standard errors were based on measurements during the steady state performance period $(n=5)$.

Figure 15. COD balance for food waste-fed digesters operated at mean OLRs of $25.8,31.2$, and $33.9 \mathrm{~g} \mathrm{COD/L-day.} \mathrm{OLR} \mathrm{values} \mathrm{were} \mathrm{calculated} \mathrm{as}$ the mean over the course of the steady state period. The means of steadystate performance periods by duplicate digesters were used to calculate the standard errors $(n=2)$ shown on the digester effluent and biogas bars. The influent standard errors were based on measurements during the steady state performance period $(n=5)$. 
Figure 16. Molar hydrogen yields for OLRs of $12.7,18.2,23.6$, and $28.8 \mathrm{~g}$ COD/L-day. OLRs of 18.2 and $23.6 \mathrm{~g}$ COD/L-day were calculated mean OLRs between replicate experiments. Standard error bars for those OLRs represent the error between replicate experiments $(n=2)$. OLRs of 12.7 and 28.8 were tested once, so standard error bars represent the error among duplicate digesters $(n=2)$.

Figure 17. Volumetric hydrogen yields for OLRs of $12.7,18.2,23.6$, and $28.8 \mathrm{~g} \mathrm{COD/L-day.} \mathrm{OLRs} \mathrm{of} 18.2$ and $23.6 \mathrm{~g} \mathrm{COD/L-day} \mathrm{were} \mathrm{calculated}$ mean OLRs between replicate experiments. Standard error bars for those OLRs represent the error between replicate experiments $(n=2)$. OLRs of 12.7 and 28.8 were tested once, so standard error bars represent the error among duplicate digesters $(n=2)$.

Figure 18. Molar hydrogen yields for food waste-fed digesters at OLRs of 25.8, 31.2, and $33.9 \mathrm{~g} \mathrm{COD/L-day.} \mathrm{OLR} \mathrm{values} \mathrm{represent} \mathrm{the} \mathrm{average} \mathrm{OLR}$ over the steady state period. The means of steady-state performance periods by duplicate digesters were used to calculate the standard errors shown $(n=2)$

Figure 19. Volumetric hydrogen production for food waste-fed digesters at OLRs of 25.8, 31.2, and $33.9 \mathrm{~g} \mathrm{COD/L-day.} \mathrm{OLR} \mathrm{values} \mathrm{represent} \mathrm{the}$ average OLR over the steady state period. The means of steady-state performance periods by duplicate digesters were used to calculate the standard errors shown $(n=2)$.

Figure 20. COD balance for HRT Experiment 1 with digesters operated at HRTs of 6,12 , and 18 hours. The means of steady-state performance periods by duplicate digesters were used to calculate the standard errors (n $=2$ ) shown on the digester effluent and biogas bars. The influent standard errors were based on measurements during the steady state performance period $(n=5)$.

Figure 21. COD balance for digesters operated at HRTs of 3,6 , and 9 hours. The means of steady-state performance periods by duplicate digesters were used to calculate the standard errors $(n=2)$ shown on the digester effluent and biogas bars. The influent standard errors were based on measurements during the steady state performance period $(n=5)$.

Figure 22. COD balance for digesters operated at HRTs of 6,12 , and 18 hours. The means of steady-state performance periods by duplicate digesters were used to calculate the standard errors $(n=2)$ shown on the 
digester effluent and biogas bars. The influent standard errors were based on measurements during the steady state performance period $(n=5)$

Figure 23. Molar yields for HRTs of 3, 6, 9, 12, and 18 hours. Standard error bars for HRTs of 6,12 , and 18 hours represent the standard error between replicate experiments $(n=2)$. Standard error bars for 3- and 9-hour HRTs represent the error between duplicate digesters $(n=2)$.

Figure 24. Volumetric hydrogen production for HRTs of $3,6,9$, 12, and 18 hours. Standard error bars for HRTs of 6,12 , and 18 hours represent the standard error between replicate experiments $(n=2)$. Standard error bars for 3- and 9-hour HRTs represent the error between duplicate digesters $(n=2)$.

Figure 25. COD balance for sparged and unsparged digesters. Digesters were operated at a mean OLR of $17.8 \mathrm{~g} \mathrm{COD/L-day,} \mathrm{pH}$ of 6.46 , and HRT of 12 hours. The means of steady-state performance periods by duplicate digesters were used to calculate the standard errors $(n=2)$ shown on the digester effluent and biogas bars. The influent standard errors were based on measurements during the steady state performance period $(n=5)$.....

Figure 26. COD balance for food waste-fed digesters that were sparged or unsparged. Digesters were operated at a mean OLR of $32.9 \mathrm{~g} \mathrm{COD/L-day,}$ $\mathrm{pH}$ of 6.40 , and HRT of 12 hours. The means of steady-state performance periods by duplicate digesters were used to calculate the standard errors ( $\mathrm{n}$ $=2$ ) shown on the digester effluent and biogas bars. The influent standard errors were based on measurements during the steady state performance period $(n=5)$

Figure 27. Molar yields for unsparged (US), nitrogen sparged (NG), and biogas sparged (BG) digesters during the steady state period. Digesters operated at a pH of 6.46, HRT of 12 hours, and an OLR of $17.8 \mathrm{~g} \mathrm{COD/L-}$ day. The sparging rate for NG and BG was $3.2 \mathrm{~mL} / \mathrm{min}$. The means of steady-state performance periods by duplicate digesters were used to calculate the standard errors shown $(n=2)$.

Figure 28. Volumetric hydrogen production for unsparged (US), nitrogen sparged (NG), and biogas sparged (BG) digesters during the steady state period. The sparging rate for NG and BG was $3.2 \mathrm{~mL} / \mathrm{min}$. Digesters operated at a pH of 6.46, HRT of 12 hours, and an OLR of $17.8 \mathrm{~g} \mathrm{COD/L-}$ day. The means of steady-state performance periods by duplicate digesters were used to calculate the standard errors shown $(n=2)$. 
Figure 29. Molar hydrogen yields for unsparged (US), nitrogen sparged (NG), and biogas sparged (BG) digesters at various sparging rates. Digesters operated at a pH of 6.46, HRT of 12 hours, and an OLR of $17.8 \mathrm{~g}$ COD/L-day. The means of steady-state performance periods by duplicate digesters were used to calculate the standard errors shown $(n=2)$. The leftmost bar in each set of sparging rates represents the steady state molar hydrogen yield of an unsparged digester running under the same conditions. ...59

Figure 30. Molar hydrogen yields for digesters sparged with nitrogen gas (NG). The linear fit produced an $R^{2}$ value of 0.93 , and error bars depict the standard error produced between duplicate digesters $(n=2)$.

Figure 31. Molar hydrogen yields for digesters sparged with biogas (BG). The linear fit produced an $R^{2}$ value of 0.95 , and error bars depict the standard error produced between duplicate digesters $(n=2)$.

Figure 32. Volumetric hydrogen production for unsparged (US), nitrogen sparged (NG), and biogas sparged (BG) digesters at varying sparging rates. Digesters operated at a pH of 6.46, HRT of 12 hours, and an OLR of $17.8 \mathrm{~g}$ COD/L-day. The means of steady-state performance periods by duplicate digesters were used to calculate the standard errors shown $(n=2)$. The leftmost bar in each set of sparging rates represents the steady state volumetric hydrogen production of an unsparged digester running under the same conditions.

Figure 33. Volumetric hydrogen production for digesters sparged with nitrogen gas (NG). The linear fit produced an $R^{2}$ value of 0.94 , and the means of steady-state performance periods by duplicate digesters were used to calculate the standard errors shown $(n=2)$.

Figure 34. Volumetric hydrogen production for digesters sparged with biogas (BG). The linear fit produced an $R^{2}$ value of 0.95 , and the means of steady-state performance periods by duplicate digesters were used to calculate the standard errors shown $(n=2)$.

Figure 35. Molar hydrogen yields for food waste-fed digesters that were either unsparged (US) or sparged at flowrates of 0.5 and $1 \mathrm{~L} \mathrm{~N} / \mathrm{hr}$. All digesters operated at a mean OLR of $32.9 \mathrm{~g} \mathrm{COD/L-day,} \mathrm{pH}$ of 6.40 , and HRT of 12 hours. The means of steady-state performance periods by duplicate digesters were used to calculate the standard errors shown $(n=2)$.....64 
Figure 36. Molar hydrogen yields for food waste-fed digesters sparged with nitrogen gas. The linear fit produced an $R^{2}$ value of 0.99 , and the means of steady-state performance periods by duplicate digesters were used to calculate the standard errors shown $(n=2)$.

Figure 37. Volumetric hydrogen production for nitrogen-sparged and food waste-fed digesters operating at a mean OLR of $32.9 \mathrm{~g} \mathrm{COD/L-day,} \mathrm{pH}$ of 6.40 , and HRT of 12 hours. The means of steady-state performance periods by duplicate digesters were used to calculate the standard errors shown ( $\mathrm{n}$ $=2$ ).

Figure 38. Volumetric hydrogen production for food waste-fed digesters sparged with nitrogen gas. The linear fit produced an $R^{2}$ value of 0.93 , and the means of steady-state performance periods by duplicate digesters were used to calculate the standard errors shown $(n=2)$.

Figure 39. Molar hydrogen yields as a function of HRT and OLR within a $\mathrm{pH}$ range of 6.35 to 6.58 . The optimal molar hydrogen yield is the peak of the surface plot ( $\left.0.012 \mathrm{~mol} \mathrm{H}_{2} / \mathrm{mol} \mathrm{COD}\right)$ at an OLR value of $18.2 \mathrm{~g} \mathrm{COD/L-day}$ and HRT of 12 hours.

Figure 40. Volumetric hydrogen production as a function of HRT and OLR within a $\mathrm{pH}$ range of 6.35 to 6.58 . The optimal volumetric hydrogen production is the peak of the surface plot $\left(0.156 \mathrm{~L} \mathrm{H}_{2} / \mathrm{L}_{\text {Reactor }}\right.$-day $)$ at an OLR value of $18.2 \mathrm{~g} \mathrm{COD/L-day} \mathrm{and} \mathrm{HRT} \mathrm{of} 12$ hours. 


\section{CHAPTER 1: INTRODUCTION}

The future of energy production lies not in the use of fossil fuels, rather the more sustainable use of renewable energy including renewable hydrogen. Hydrogen energy is expected to become one of the dominant sources of energy due to its abundance of environmental applications, high energy yield $(142.3 \mathrm{~kJ} / \mathrm{g})$, and formation of water as its only combustion product (Seifert, Waligorska, Wojowski, \& Laniecki, 2009). Hydrogen is a promising alternative to fossil fuels because the energy yield $(\mathrm{kJ} / \mathrm{g})$ of hydrogen is 2.75 times higher than that of traditional fossil fuels (Maru, Bielen, Constanti, Medina, \& Kengen, 2013, Han et al., 2016, Sharma, Parnes, \& Li, 2011). The microbial conversion of organic waste substrates has proven itself as a promising means of producing hydrogen gas (Lo, Chen, Huang, Yuan, \& Chang, 2013; Seifert et al., 2009).

Hydrogen use is currently centered around its many industrial applications like refining, metallurgy, and electronics (Ramachandran \& Menon, 1998). However, its use as a source of energy is slowly gaining ground, especially in applications like hydrogen fuel cells and fuel hydrogenation. Hydrogen fuel cells are being studied extensively as an option for transportation systems because they do not produce greenhouse gasses, and their energy conversion efficiency is generally greater than the Carnot efficiency limit of traditional internal combustion engines (Ahmadi \& Kjeang, 2017). Concurrently, a series of hydrogen refueling stations along what is being called the "California Hydrogen Highway" is being considered to support the future of transportation (Romm, 2006). Hydrogen gas is also being 
studied as a possible additive to biogas in biogas energy generators. Hydrogen has been shown to reduce harmful pollutants like nitrogen oxides when mixed with biogas and combusted in lean air to fuel ratios (Liang \& Pirnie, 2009; Wilson, 2012; Choudhuri \& Gollahalli, 2000). Even so, hydrogen storage, transportation, and production issues have presented difficulties for implementation (Kornbluth, Greenwood, Jordan, McCaffery, \& Erickson, 2012). Ahmadi and Kjeang note the lack of hydrogen production infrastructure as being the major drawback to its potential energy uses (2017).

Hydrogen is most commonly produced by means of steam reforming natural gas, thermochemical and radiolytic processes, and water electrolysis (Dempartment of Energy, 2014; Maru et al., 2013). However steam reforming is three times more expensive per energy unit than gasoline, and water electrolysis is only feasible in areas where electricity is inexpensive (Florida Solar Energy Center, 2014). Most importantly, electro- and thermo-chemical hydrogen production is dependent on fossil fuel energy, and the means of production are energy inefficient (Maru et al., 2013). Fermentative hydrogen production, or the anaerobic digestion of organic waste substrates to hydrogen, may pose a solution to these problems by utilizing natural, low energy input microbial processes (Chong et. al. 2008, Tapia-Venegas et al., 2015).

Fermentative hydrogen production has many benefits over traditional and nonmicrobial forms of hydrogen production. First, fermentative hydrogen production can use carbon-rich and abundant wastes like glycerol and food waste to 
produce hydrogen gas. Rather than being sent to the landfill, these wastes can be used for hydrogen production, and in the process become stabilized and minimized before being disposed of or used in other potential applications (Kumar et al., 2017). If produced on site with existing methanogenic digesters, hydrogen digesters can work in series with the methanogenic digesters, creating a two-phase system resulting in hydrogen and methane gas mixtures for combustion. Furthermore, fermentative hydrogen production can be a low-cost and environmentally friendly process when organic waste substrates are used.

One of the most important factors in producing hydrogen by microbial processes is the substrate fed to the microorganisms. For substrates to be feasible for fermentative hydrogen production, they must be simple sugars, low-cost, present in large quantities, and the nature of carbon in the substrate must be highly reduced (Maru et al., 2013). Glycerol and food waste are two wastes that meet these criteria. However, a large amount of hydrogen research uses glucose substrate. Glucose is the ideal substrate for hydrogen production, and it is good for demonstrating the process, but it is bad for real world applications because it is not a waste.

Glycerol is produced, in large amounts, during the transesterification of vegetable oils, and animal fats for biodiesel and bioethanol production. For every 100 pounds of biodiesel produced, roughly 10 pounds of crude glycerol is produced (Yazdani \& Gonzalez, 2007). Due to the accelerated growth of biodiesel and bioethanol industries, glycerol is being produced in surplus, resulting in a 10-fold 
decrease in glycerol prices (Maru et al., 2013; Yazdani \& Gonzalez, 2007) Because of the highly-reduced carbon in glycerol, microbial fermentation to more valued products like 1,3-propandiol, ethanol, acetic and butyric acid, and hydrogen makes glycerol a promising substrate for fermentative hydrogen production (Yazdani \& Gonzalez, 2007).

Stoichiometrically, 1 mole of hydrogen can be produced per mole of glycerol consumed (Equation 1-1). However, actual hydrogen yields are expected to be much less than the stoichiometry indicates due to reactions that produce other desired compounds (Yazdani \& Gonzalez, 2007; Hallenbeck \& Benemann, 2002). Even if the reactions were controlled in a way to produce only hydrogen and ethanol, heat losses would prevent the reaction from reaching full stoichiometric yields.

$\mathrm{C}_{3} \mathrm{H}_{8} \mathrm{O}_{3}+3.5 \mathrm{O}_{2} \rightarrow 3 \mathrm{CO}_{2}+4 \mathrm{H}_{2} \mathrm{O}$

Every year the United States disposes 32.2 million tons of food waste, or about $0.279 \mathrm{~kg}$ per person, per day (Krista, Tonjes, Gurevitch, 2015). Food waste is present in large quantities, and accounts for roughly $40 \%$ of municipal solid waste (Han et al., 2016). Food waste varies by source, but is generally comprised of simple sugars, fats, carbohydrates, and proteins - compounds that have a great potential for hydrogen production (Curry \& Pillay, 2012). One source found the hydrogen production potential of post-consumer food waste mixed with $3 \%$ wastewater sludge to be $121.6 \mathrm{~mL} / \mathrm{g}$ carbohydrate COD (Kim, Han, \& Shin, 2004). 
One of the drawbacks to fermentative hydrogen production is that there are no accepted and commercialized means to producing hydrogen because of an issue of low molar hydrogen yields. This is an issue if the substrates are not wastes, but if organic waste substrates are used and are available at low or no cost, then the molar yield should be less important. Most experiments test fermentative hydrogen production in batch reactors. However, further examination of continuously stirred tank reactors with organic waste substrates is needed.

Operational conditions including $\mathrm{pH}$, organic loading rate, hydraulic residence time and gas sparging have been found to significantly affect hydrogen production in CSTR anaerobic digesters (Pakarinen, Kaparaju, \& Rintala, 2011; Olivas, 2015). Two useful output metrics for determining the optimal conditions, especially for biogas studies, are molar fuel yield and volumetric fuel production. Molar hydrogen yield is a useful output metric because it allows for the comparison of hydrogen yields from different substrates. It can also be a measure of substrate utilization efficiency, a way to determine how efficiently substrates are converted to desired products. The molar hydrogen yield is the moles of hydrogen gas produced by the digesters per mole of substrate COD introduced $\left(\mathrm{mol} \mathrm{H}_{2} / \mathrm{mol} \mathrm{O}_{2}\right)$. For pure substrates, molar hydrogen yields can be expressed as moles of hydrogen per mole of substrate. This allows for the comparison to stoichiometric yields. While stoichiometric yields are not practical to achieve in biological systems, they are a good benchmark (Hallenbeck \& Benemann, 2002). The volumetric hydrogen production is the volume of 
hydrogen produced per time per liquid volume in the digester $\left(\mathrm{L} \mathrm{H}_{2} / \mathrm{L}_{\text {Reactor }}\right.$-day). Volumetric hydrogen production is the volume of hydrogen produced per volume of digester which is proportional to the capital cost.

The anaerobic digestion process consists of multiple stages where substrate is degraded to other products: (1) hydrolysis, (2) fermentation, (3) acetogenesis, (4) methanogenesis (Cooke, 2014). In fermentative hydrogen production, anaerobic digesters are operated in a way that prevents methanogenesis from occurring. The methanogenic bacteria work against hydrogen production and reduce hydrogen yields by utilizing hydrogen to produce methane (Gunaseelan, 1997; Nallathamb, Thompson, 2008). In methane-producing digesters, the methanogenic bacteria flourish within a $\mathrm{pH}$ range of 6.6-7.6, yet they can grow and survive at lower pH values (McCarty, 1964). Hydrogen-producing bacteria, in contrast, typically thrive within a pH range of 5.0-6.5 (Valdez-Vazquez \& Poggi-Varaldo, 2009). Consequently, pH can be a key parameter in optimizing hydrogen production.

The hydraulic residence time (HRT) of a CSTR is modeled as the volume of the reactor over the volumetric flow rate. The HRT of hydrogen-producing anaerobic digesters is generally a matter of hours, while for methane-producing digesters, HRT is usually days or weeks (Kuruti et al., 2017). As a rough comparison, the specific growth rate of hydrogen-producing bacteria is $0.215 / \mathrm{hr}$, while methanogenic bacteria have a specific growth rate that is 4 -times lower, $0.05 / \mathrm{hr}$ (Ruggeri, Tommasi, \& Sanfilippo, 2015). Due to their faster growth rate, 
hydrogen-producing bacteria can be selected over methanogens by operating with an HRT that is short enough to wash-out the methanogenic bacteria.

Further, methanogen inhibition can occur at lower HRTs due to the accumulation of volatile fatty acids which cause a decrease in the $\mathrm{pH}$ of the reactor (ValdezVazquez \& Poggi-Varaldo, 2009).

The organic loading rate $(\mathrm{OLR})$ is the mass of substrate entering the digester per volume of digester per day ( $\mathrm{g}$ COD/L-day). Substrate is typically expressed in terms of COD as both pure and unidentified substrates can be expressed as COD. Past studies have achieved molar hydrogen yields ranging from 0.38-0.50 $\mathrm{mol} \mathrm{H}_{2} / \mathrm{mol}$ glycerol at OLRs ranging from $12.2 \mathrm{~g} \mathrm{COD} / \mathrm{L}$-day to $24.3 \mathrm{~g} \mathrm{COD/L-}$ day. Food waste OLRs ranging from $28 \mathrm{~g}$ COD/L-day to $50 \mathrm{~g} \mathrm{COD/L-day} \mathrm{have}$ produced molar hydrogen yields of $0.04-0.05 \mathrm{~mol} \mathrm{H}_{2} / \mathrm{mol}$ COD (Li et. al. 2008b, Lee et. al. 2010a).

High partial pressures of hydrogen inside anaerobic digesters result in the dissolution of gases into the liquid phase, reducing overall hydrogen production and substrate conversion efficiency (Beckers et al., 2015). To reduce the partial pressure of hydrogen inside the digesters, and thus release the gas from the liquid phase, the digesters can be mixed and sparged with an inert gas (Das, Khanna, \& Dasgupta, 2014; Beckers et al., 2015). Lamed, Lobos, and Su found that the dissolved hydrogen concentration in liquid digestate was decreased three-fold when mixed, suggesting a three-fold increase in overall hydrogen production (1988). A continuously stirred anaerobic digester fed glucose 
increased its molar hydrogen yield from $0.85 \mathrm{~mol} \mathrm{H}_{2} /$ mol glucose to $1.43 \mathrm{~mol} \mathrm{H}_{2} /$ mol glucose when sparged with nitrogen gas at $2.9 \mathrm{~L} \mathrm{~N} / \mathrm{L}-\mathrm{hr}$ (Mizuno, Dinsdale, Hawkes, Hawkes, \& Noike, 2000).

With future process feasibility in mind, these experiments are an attempt to address many of the problems facing fermentative hydrogen production. First, continuously stirred tank reactors, rather than batch reactors, were used to perform digestion experiments. Low molar hydrogen yields will be addressed by determining the optimal $\mathrm{pH}, \mathrm{HRT}$, OLR, and gas sparging rates. Finally, the use of waste substrates, food waste and glycerol, will be studied in an attempt to determine their feasibility. 


\section{CHAPTER 2: METHODS}

Laboratory digesters were used in this study to determine the optimal operational conditions for producing hydrogen in semi-continuously fed, stirred anaerobic digesters, as described in detail below. An unusual aspect of the work, and a major objective, was the effort to increase hydrogen yields by stripping hydrogen from the digester liquid phase by sparging with nitrogen gas or biogas.

\subsection{Experimental Concept}

Bench-scale, semi-continuously fed, stirred, anaerobic digesters were fed glycerol or food waste as a substrate. Hydrogen production was optimized for individual variables: culture $\mathrm{pH}$, hydraulic residence time (HRT), organic loading rate $(\mathrm{OLR})$, or gas sparging rates. Hydrogen production was expressed as either molar or volumetric hydrogen production.

Digester $\mathrm{pH}$ levels were controlled by phosphate buffer solutions mixed into the digester feedstock and by automatic $\mathrm{pH}$-stat pumping of a base solution into the digesters. The HRT (Equation 2-1) was controlled by pumps, and OLRs (Equation 2-2) were set by the substrate concentration selected, for the given HRT.

Hydraulic Residence Time $=\frac{\text { Working Volume of the Digester }(L)}{\text { Volumetric flowrate in/out of digester }(L / t)}$

Organic Loading Rate $=\frac{\text { Concentration of Substrate in the Feedstock }(\mathrm{g} / \mathrm{L})}{\text { Hydraulic Residence Time }(t)}$ 
Each variable was tested over a range of values in separate experiments. For example, when the optimum $\mathrm{pH}$ was being determined, all other variables were held constant. When the optimum $\mathrm{pH}$ was found, it was then adopted and held constant while the next variable was tested. Optimal conditions were those that produced the highest molar hydrogen yield or volumetric hydrogen production. Lastly, a range of sparging rates was tested to find the optimal sparging rates for hydrogen production with glycerol or food waste substrate (Table 1). A problem with this stepwise approach was that the operational variables were dependent, meaning that the optimal pH might be different for different HRT and OLR values. The benefit to this one-at-a-time optimization method was that it was straightforward and clearly revealed the impacts of each operational variable on hydrogen yields and production.

Table 1. Operational variables, either treatment variables or constant variables, for each experiment. The stepwise optimization experiments were conducted in the order listed.

\begin{tabular}{|c|c|}
\hline Treatment Variable & Operational Variables \\
\hline $\mathrm{pH}$ & $\begin{array}{l}\text { Constants: Hydraulic Residence Time, Organic Loading Rate, No } \\
\text { Sparging }\end{array}$ \\
\hline $\begin{array}{l}\text { Organic Loading } \\
\quad \text { Rate }\end{array}$ & Constants: Hydraulic Residence Time, Optimal pH, No Sparging \\
\hline Hydraulic Residence & Constants: Optimal Organic Loading Rate, Optimal pH, No Sparging \\
\hline Sparging Rate & $\begin{array}{l}\text { Constants: Optimal Organic Loading Rate, Optimal pH, Optimal } \\
\text { Hydraulic Residence Time }\end{array}$ \\
\hline
\end{tabular}

In experiments with glycerol as feed, pure glycerol was used to avoid the potentially inhibitory compounds in crude glycerol from biodiesel production. For food waste feeding experiments, $\sim 91$ kilograms of post-consumer food waste was collected from The Avenue, a campus dining hall at California Polytechnic State University, San Luis Obispo. 


\subsection{Bench-Scale Anaerobic Digesters Design}

Six hydrogen fermentation digesters were constructed and operated in duplicate, so three levels of each operational variable were tested simultaneously during each experiment. Each digester vessel was a 2-L bottle with 1.3-mm thick walls of fluorinated high-density polyethylene (FLPE) (Nalgene, ThermoFisher Scientific, Waltham, Massachusetts). FLPE was selected because of its low permeability to hydrogen gas.

Holes were drilled in each vessel for a temperature probe, $\mathrm{pH}$ probe, inlet and outlet ports, gas sparging port, gas exit port, and base addition port (Figure 1 \& 2). Holes were fitted with 6.4-mm inner diameter (ID) barbed bulkhead fittings (Nalgene, ThermoFisher Scientific) and sealed with Lexel adhesive caulk (Sashco, Brighton, Colorado). Tubing, 6.4-mm ID, (Masterflex Tygon E, ColeParmer, Vernon Hills, Illinois) was connected to the bulkhead fittings inside the digester for the inlet, outlet, and sparging ports to a depth of half of the liquid volume. Connected to the sparging tubing was a $20-\mathrm{cm}$ diameter, oval air stone (Uxcell, Hong Kong) for use in sparging experiments.

The temperature port was constructed with a 12.7-mm ID Nalgene barbed bulkhead fitting the inside of the digester vessel, sealed at the bottom using zip

ties and Lexel adhesive caulking. Sealing the end of this tube provided for a dead end inside the digester, allowing it to be filled with deionized water from outside the digester for more accurate temperature readings and control. A 6.4-mm compression fitting with a 12.7-mm female threaded adapter (Parker Hannifin, 
Cleveland, Ohio) was screwed onto a 12.7-mm male threaded nipple (ColeParmer) for the airtight enclosure of the $\mathrm{pH}$ probe. All digesters were equipped with a MC122 pH controller, a MP810 dosing pump (both from Milwaukee Instruments, Rocky Mount, North Carolina), and an Extra-Long 220- x 6-mm pH electrode (Cole-Parmer) calibrated at the start of each experiment.

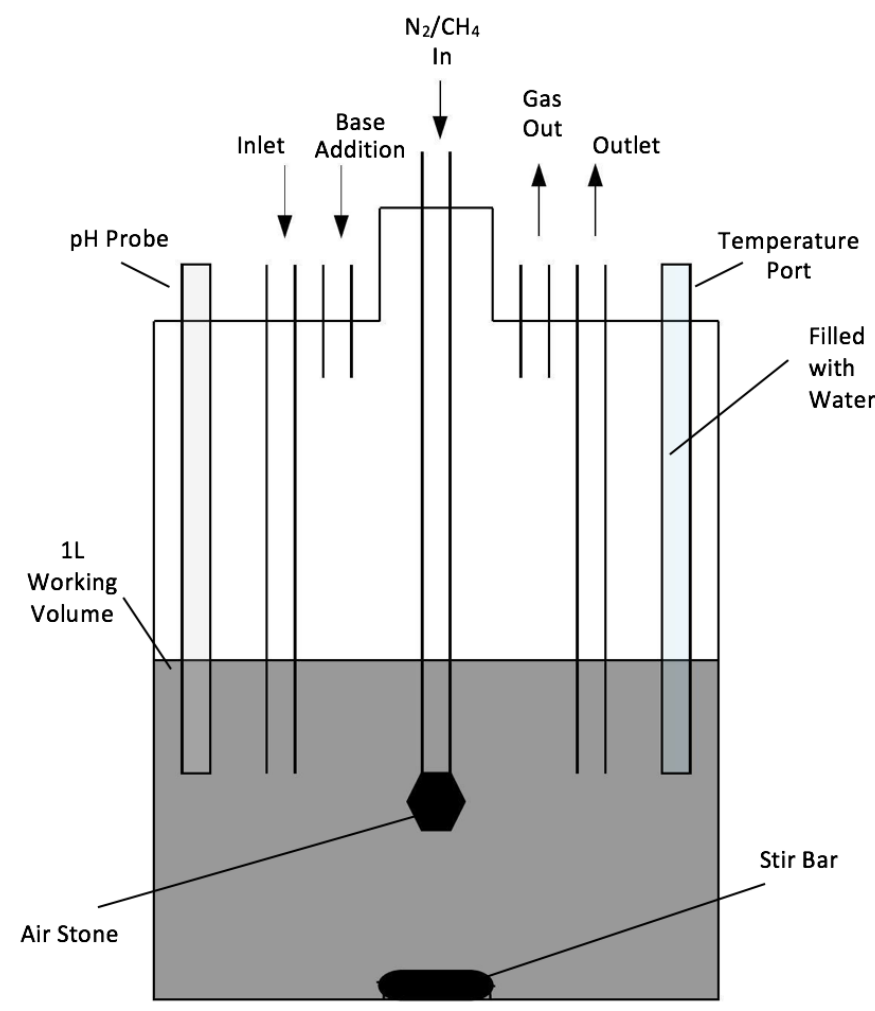

Figure 1. Schematic cross section of a typical digester used in the hydrogen optimization experiments. The lower end of the temperature port tube was sealed and filled with water. $A$ temperature probe was sealed in this tube. 


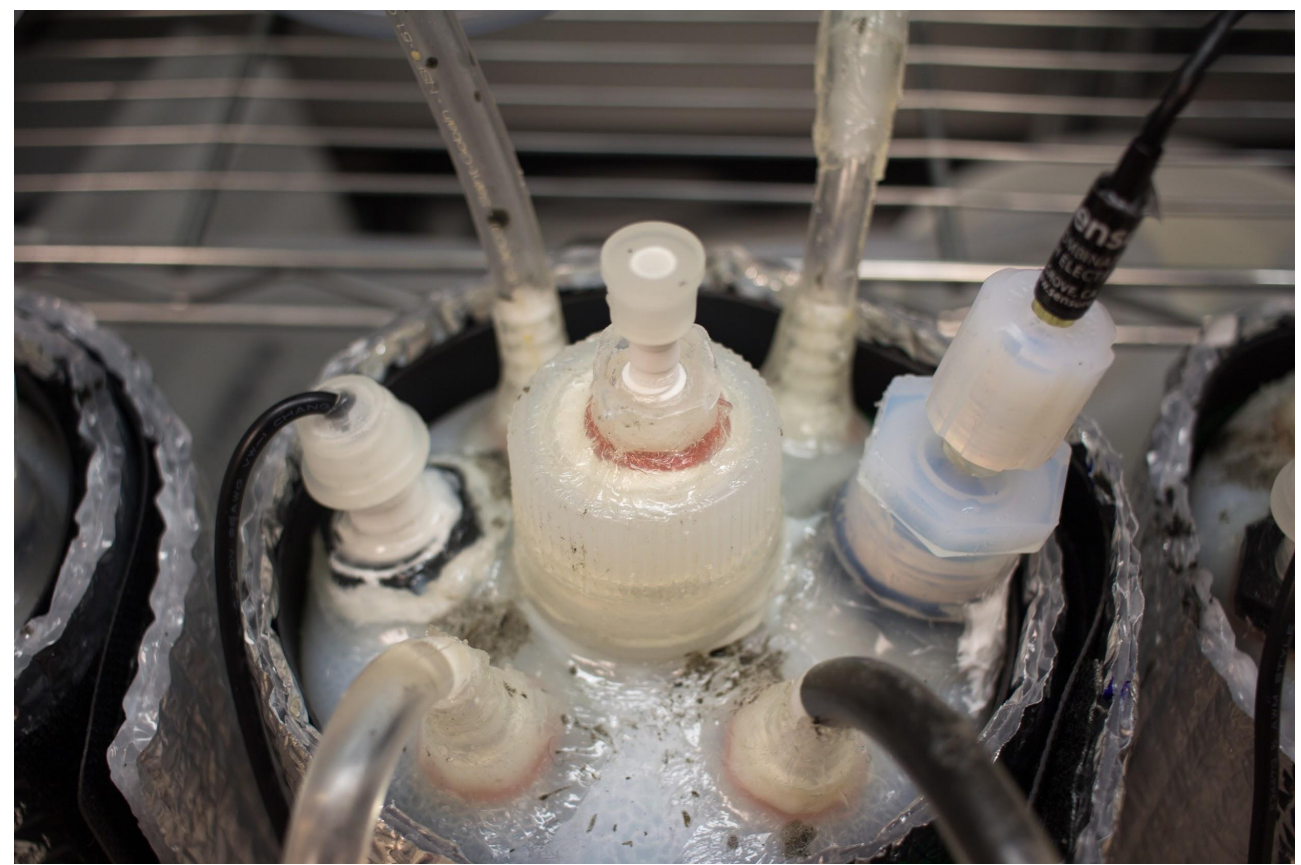

Figure 2. Digester inlets and outlets. Pictured at 1 o'clock is the gas outlet, 3 o'clock is the compression fitting and $\mathrm{pH}$ probe, 5 o'clock is the digestate outlet, 7 o'clock is the feed inlet, 9 o'clock is the sealed temperature probe, and 11 o'clock is the base addition line. Pictured in the center is the sealed lid and sparging gas inlet fitting. Also shown is the reflective heat mat wrapped around the digester.

Jumpstart Seedling Heat Mats (Hydrofarm, Petaluma, California) were affixed to duct insulation, wrapped around the digesters, and fastened with Velcro (Carlstadt, New Jersey). Heat mats were connected to Jumpstart Digital Temperature Controllers (Hydrofarm), and temperature probes were inserted into the temperature port and filled with deionized water. Temperature ports were capped with a rubber fitting and periodically filled with deionized water when low. The digesters were held at a constant $35 \pm 2.0^{\circ} \mathrm{C}$.

Gas generated in the headspace of each digester passed through the gas outlet fitting, which was connected to 6.4-mm ID Masterflex Tygon E-Lab tubing. The outlet tubing included a T-fitting with a compression fitting (Cole-Parmer) holding a septa for gas sampling (Thermo Fisher Scientific), another T-fitting leading to a 
0.5-L tedlar bag (Zefon, Ocala, Florida) to buffer gas flow, and a 6.4-mm one-way check valve (Cole-Parmer). The gas outlet tubing terminated at a tipping gas meter (Figure 3).

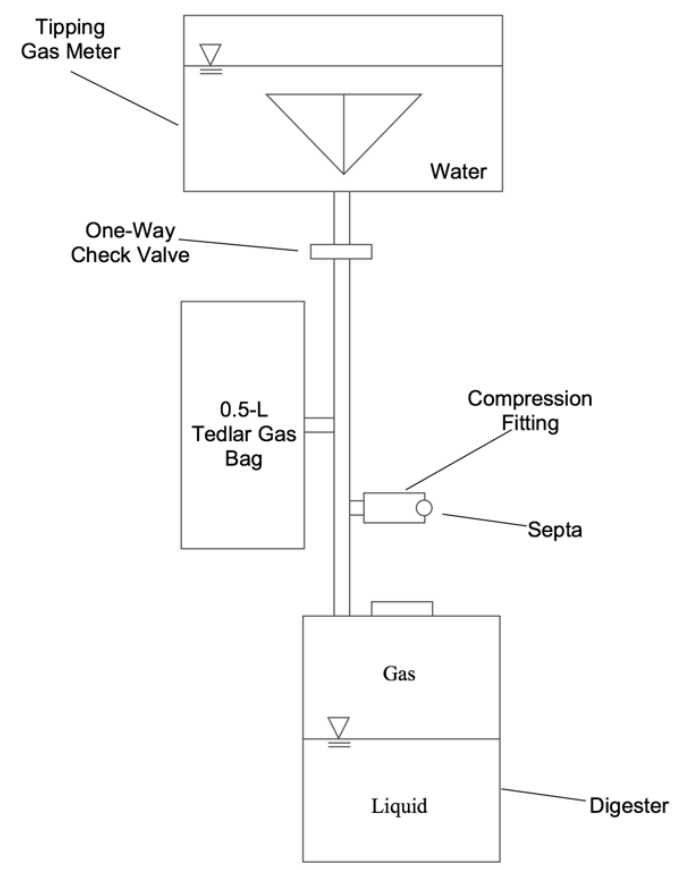

Figure 3. Outlet gas appurtenances

The gas meters contained two triangular-prism chambers in a tipping device, and were submerged in $13 \mathrm{~cm}$ of water. When one chamber would fill with enough gas to cause a tip, magnets attached to the tipping mechanism would trigger a reed switch (Standex-Meder Electronics, Cincinnati, Ohio) to open or close (Figure 4). The signal from the reed switch, as well as a timestamp, was recorded on a HOBO 4-Channel Pulse Data Logger (Onset, Bourne, Massachusetts). The meters were calibrated by injecting air through a dry gas flow meter. The average tip volume determined during calibration was $100 \pm 9.0$ $\mathrm{mL}$. Gas production was calculated as follows: 
Daily Gas Production =

Number of Tips per Day $\times$

(Eq 2-3)

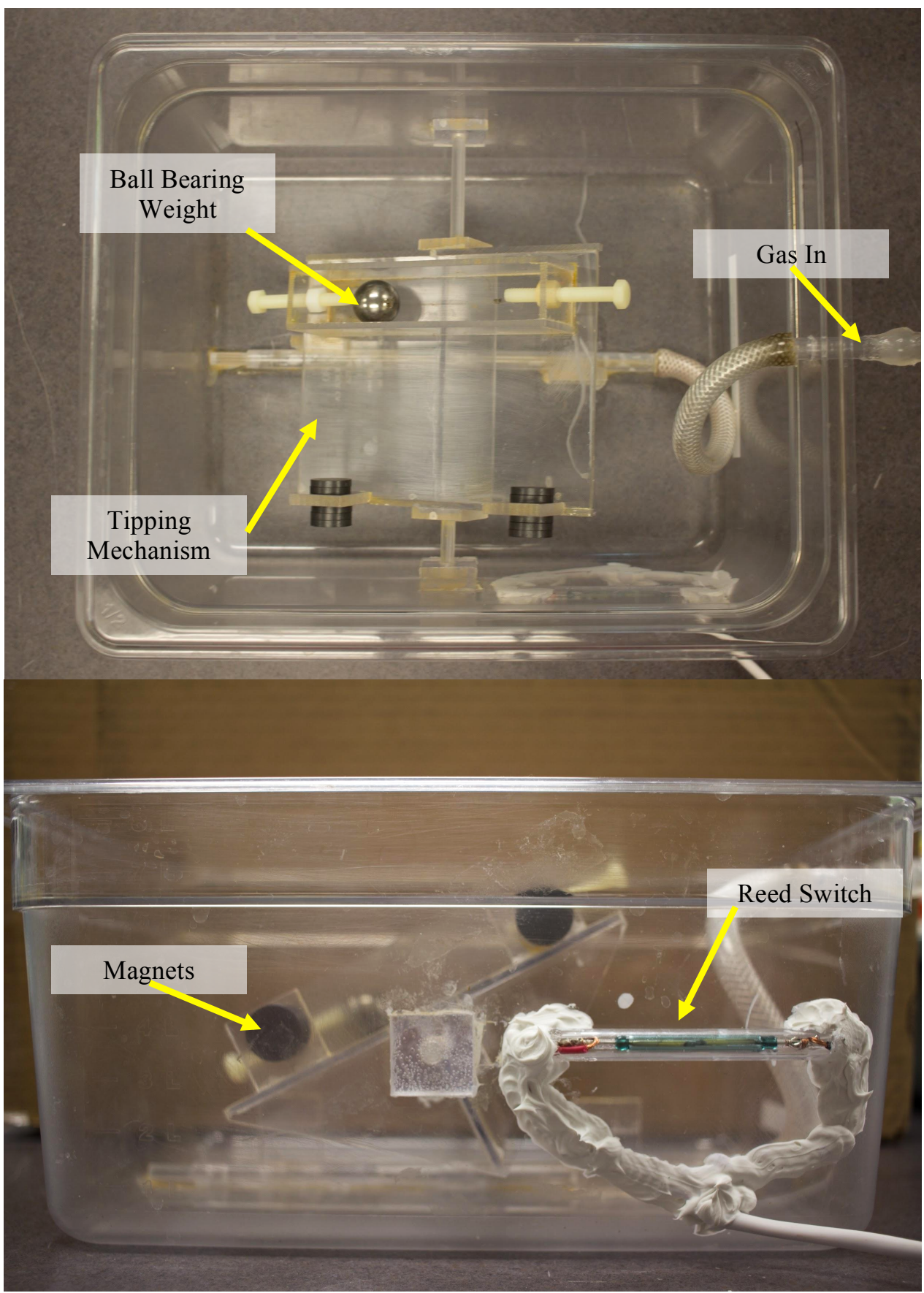

Figure 4. One of the tipping gas meters (not filled with water). Top: plan view. Bottom: side view. 
Two peristaltic pumps (Masterflex L/S, HV-07522-20, Cole-Parmer) delivered feedstock to the six digesters, and two additional pumps removed digestate from the digesters. The pumps' internal program allowed flow rates of 0.001 to 3400 $\mathrm{mL} / \mathrm{min}$ and multiple start-stop times per day. Masterflex L/S peristaltic pumps were also used to deliver gas into the digesters during the sparging experiments.

During the sparging experiments, sparging gas for each digester was held in a 25-L Tedlar gas bag. The sparging gas was either high purity nitrogen or biogas consisting primarily of methane and carbon dioxide. Masterflex Tygon E-Lab tubing was connected to each of the four bags, routed through the peristaltic pump, and attached to the $\mathrm{N}_{2} / \mathrm{CH}_{4}$ inlet port of four of the six digesters. When the volume of gas inside of the bags was low, bags were flushed with their respective sparging gas three times, and refilled.

\subsubsection{Leak Testing of Digesters}

Gas leak testing was performed on each digester before the start of each experiment. First, the digester ports were closed, and the digesters were pressurized with nitrogen gas to $41 \mathrm{kPa}(6 \mathrm{psi})$ and submerged into a sink filled with water. If, after one minute, no bubbles were observed, the digester was deemed ready for a 12-hour leak test. The 12-hour leak test involved filling the digester with one liter of water, closing all digester openings, and connecting a $60-\mathrm{cm}$ tall column of water to the digester inlet port. The digester headspace was pressurized by the $60-\mathrm{cm}$ tall column of water, and the level on the water column 
was noted. If the water level in the column did not change over the 12-hour period, the reactor was deemed leak-proof and used in experiments.

On a few occasions, leaks were suspected during experiments. Leaks were identified by increasing concentrations of nitrogen in the biogas, and a decrease in biogas production. The decrease in biogas production lowered the pressure inside of the digester and allowed ambient air to infiltrate the digester. When a leak was suspected, all ports were re-sealed with Lexel adhesive caulking. If the leak could not be stopped, the digester liquid contents were collected in a container, sparged with nitrogen to produce anaerobic conditions, and stored in a $35^{\circ} \mathrm{C}$ incubator until the digester was repaired and leak tested.

\subsubsection{Feedstock Reservoir Design}

Each duplicate pair of digesters was fed from one feedstock reservoir (10-L FLPE carboys, Nalgene, Thermo Fisher Scientific). Two holes were drilled at the bottom of each carboy and fitted with 6.4-mm Nalgene barbed bulkhead fittings. MasterFlex Tygon E-Lab tubing (ID 6.4-mm) was connected to the fittings and directed through peristaltic pumps into the inlet port on the digesters. Holes were drilled into the lids of the feed reservoirs and fitted with in-line HEPA disk filters (Whatman, GE Healthcare, Chicago, Illinois) to help prevent contamination of the feedstock with airborne microbes. The feedstock reservoirs were placed in a refrigerator at $4^{\circ} \mathrm{C}$ and mixed with 108-mm cylindrical polytetrafluoroethylene magnetic stir bars (Big Science Inc., Huntersville, North Carolina) and magnetic 
stir plates (Figure 5) (MegaMag Genie, Scientific Industries, Bohemia, New York).

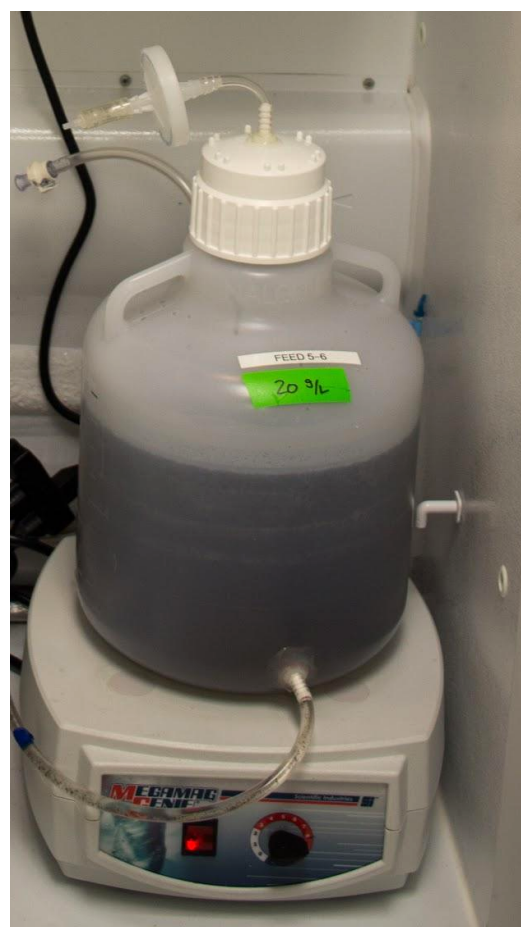

Figure 5. One of three filled digester feedstock reservoir atop a stir plate and located in a refrigerator.

\subsection{Operations and Maintenance}

The following section explains in further detail the setup and loading of the digesters and the methods used to start the operation.

\subsubsection{Experimental Startup}

Prior to starting a new experiment, digesters and feed reservoirs were disinfected overnight with a bleach solution and then rinsed. Tubing was also bleached, but rinsed immediately.

The inoculum was anaerobically-digested municipal wastewater sludge obtained from the City of San Luis Obispo Water Resource Recovery Facility (WRRF), 
which uses trickling filters and nitrifying activated sludge processes. Primary and secondary sludges are thickened and dosed with ferric chloride before digestion in three anaerobic tanks in series. The first two digesters were mixed and operated at $35^{\circ} \mathrm{C}$ and a 60 -day HRT. The third digester was unheated and unmixed with a 16 day HRT, and Digestate from this third digester (1.7\% volatile solids content) was the source of inoculum for all the hydrogen optimization experiments.

To start each experiment, fresh inoculum from the WRRF was obtained and filtered through a 4-mm screen to remove particles that might have clogged the tubing. Once filtered, one liter of the inoculum was pumped into each clean, leaktested lab digester. The digesters were placed onto the stir plates and fitted with the heat mats.

The inoculum was added to the digesters undiluted rather than diluted with substrate, because it allowed the microbes to acclimate to the conditions inside the digester over a longer period of time ( 3 HRTs). Anaerobic wastewater sludge was used as the inoculum, rather than a pure hydrogen-producing culture, because of the many disadvantages pure culture systems are faced with on a larger scale.

Digester feedstock was made by mixing substrate, buffer chemicals, $100 \mathrm{~mL}$ of nutrient solution and tap water to a final volume of $10 \mathrm{~L}$ (Table 2 ) and placing the mixture in the carboys on magnetic stir plates in a refrigerator at $4^{\circ} \mathrm{C}$. The nutrient solution was added to the feedstock reservoirs as sources of vitamins, 
minerals, and metals to support microbial growth. Glycerol is not a balanced substrate, so a nutrient solution was added to support the growth of the microbes inside the digesters. Though food waste is more of a balanced substrate, nutrient solution was added for consistency.

Table 2. Constituents added to the 10-L feedstock reservoirs

\begin{tabular}{cc}
\hline Constituent & Amount Added \\
\hline Substrate & Varied \\
Nutrient Solution & $100-\mathrm{mL}$ \\
$\mathrm{Na}_{2} \mathrm{HPO}_{4}$ & Varied \\
$\mathrm{KH}_{2} \mathrm{PO}_{4}$ & Varied \\
Tap Water & Varied \\
\hline
\end{tabular}

Nutrient solution was prepared by obtaining $20 \mathrm{~L}$ of wastewater sludge, filtering it through a 4-mm screen, and then autoclaving it at $121^{\circ} \mathrm{C}$ and $138 \mathrm{kPa}$ gauge (20 psig) for 2 hours. Once cooled, the autoclaved sludge was divided into 100-mL aliquots and stored at $-12^{\circ} \mathrm{C}$ in Ziploc freezer bags. When used, the sludge was thawed and poured into each feedstock reservoir.

The $\mathrm{pH}$ probes were calibrated using $\mathrm{pH} 4$ and $\mathrm{pH} 7$ buffers. Air was removed from inlet tubes and the digester headspaces purged with $\mathrm{N}_{2}$ gas for 3 minutes. For digesters to be sparged, the $\mathrm{N}_{2} \mathrm{CH}_{4}$ inlet ports were connected to their respective gas line, otherwise these ports were capped. After the digesters were sealed and anaerobic, the pre-calibrated and programmed peristaltic pumps were started to initiate operation. 


\subsubsection{Daily Maintenance}

Each day, the feed and effluent tubes were checked for clogging and gas traps and the digesters and feedstock reservoirs were checked to ensure mixing. The liquid volume of each digester was recorded and adjusted by adding feedstock if not at $1 \mathrm{~L}$. Temperature ports were filled with water if low. Potassium hydroxide containers for $\mathrm{pH}$ correction were filled. Gas meters were also filled with water if below the calibration level. When the feedstock was low, feedstock reservoirs were removed from the refrigerator, cleaned with bleach, rinsed with water, and refilled with the feedstock constituents.

\subsubsection{Sample Collection}

Samples were collected daily from the effluent port of each digester and from the feedstock reservoirs. The effluent port was crimped with a catheter clamp (Graham Field, Atlanta, Georgia) and a 140-mL syringe (Monoject, Kendall, Mansfield, Massachusetts) was connected to the port. Once connected, the catheter clamp was opened, and digestate was withdrawn and pushed back into the digester four times to ensure a representative sample was taken. The effluent port was crimped again, and the syringe with sample was removed and discharged into a $60-\mathrm{mL}$ bottle, with the remainder discharged in a larger $100-\mathrm{mL}$ bottle. The bottles were capped until analyzed, as described below. $\mathrm{pH}$ and alkalinity analysis was performed immediately after all samples were taken. Extra feedstock was added to the digesters, as needed, to bring the volume back to one liter. 
Preservation of the chemical oxygen demand samples included adding less than 0.25-mL concentrated sulfuric acid to a $50-\mathrm{mL}$ sample until the $\mathrm{pH}$ was below 2.0. Samples were then stored at $4^{\circ} \mathrm{C}$.

\subsubsection{Definition of Steady State Digester Performance}

The performance of the digesters while they were in steady-state was more relevant to potential future scale-up than performance during startup. Thus, sample and data analysis were more intensive during steady-state operation. This section describes the physical, chemical, and biological criteria used to identify steady-state periods. Experiments typically ended after at least 5 days of steady state performance.

For the physical criterion, if the digesters were perfect CSTRs, $95 \%$ of the inoculum would have washed-out after three hydraulic residence times had passed. In this study, steady-state was defined as possible only after steady operation of four HRTs.

For the chemical criteria, $\mathrm{pH}$ and alkalinity values could not be more than $20 \%$ different on consecutive days. A difference of $20 \%$ was used because it allowed for very minor fluctuations of $\mathrm{pH}$ and alkalinity to occur while maintaining relatively consistent performance.

For the biological criterion, gas production (volume per day) could not demonstrate a clear trend. Biogas production was not subject to the $20 \%$ rule 
because for some conditions, biogas production was so low that the gas meters tipped at long intervals (less than one a day).

\subsection{Analytical Methods}

Prior to steady-state performance, daily $\mathrm{pH}$ and alkalinity were determined for each digestate and feed sample, and gas chromatography was performed for each digester to determine if hydrogen was being produced. Hydrogen production was also measured daily prior to steady state because the data loggers were constantly recording data from the tipping gas meters. However, hydrogen production data prior to the steady state period was not used in calculating molar hydrogen yields or volumetric hydrogen production.

After steady state performance was achieved, $\mathrm{pH}$ and alkalinity was measured, gas chromatography was analyzed, and total and volatile suspended solids was measured. Feed and digestate sub-samples were preserved for chemical oxygen demand determination.

The $\mathrm{pH}$ and alkalinity were determined according to standard methods (American Public Health Association [APHA], 2005). The pH was measured with a gel type electrode (WD-35801-71, Oakton, Vernon Hills, Illinois) after a 3-point calibration with standard solutions at a pH values of 4,7 , and 10 . Alkalinity was measured following Method 2320B by titrating $15 \mathrm{~mL}$ of sample with $0.20-\mathrm{N} \mathrm{H}_{2} \mathrm{SO}_{4}$ to a $\mathrm{pH}$ of 4.5. The $\mathrm{pH}$ electrode included a temperature probe that provided sample temperature over the course of $\mathrm{pH}$ and alkalinity analysis (typically 45 minutes). Any changes in temperature during analysis were noted. 
Chemical oxygen demand samples were taken on a daily basis during steady state periods and preserved as described earlier. The closed reflux colorimetric method (Method 5220D, 1997, APHA 2005) was performed with commercially prepared test tubes (CHEMetrics, Midland, Virginia), which were used with a Hach DR/890 Colorimeter (S/N 011090017823 Hach, Colorado) to measure the COD of the samples.

Total and volatile suspended solids were measured daily following standard methods (APHA, 2005). Samples were filtered through 4.7-cm glass fiber filters dried to a constant weight at $105^{\circ} \mathrm{C}$, and then ashed at $550^{\circ} \mathrm{C}$.

Biogas composition was determined by gas chromatography (Model $8610, \mathrm{SRI}$ Instruments, Torrance, California). The gas chromatograph (GC) used a thermal conductivity detector and a 1.8-m concentric packed column (Alltech CTR I, Deerfield, Illinois) at $55^{\circ} \mathrm{C}$. High purity argon gas was the carrier $(310 \mathrm{kPa}, 45$ psi). Samples of $1 \mathrm{~mL}$ were withdrawn from each digester and immediately injected into the GC. Each sample was run for 22 minutes allowing hydrogen, methane, nitrogen, carbon dioxide, and oxygen peaks to be read.

To ensure accuracy of all analytical tests, quality control procedures were used. Splits were performed for each test, while matrix spikes were performed in addition to splits for COD analysis. If the splits were within $10 \%$ of each other, they were considered passing. If matrix spikes were used, the recovery was considered passing if within $85 \%$ to $115 \%$ of the expected concentration. 
Samples that did not pass quality control procedures were rerun until passed, or discarded

\subsection{Experimental Plan Details}

This section provides, in greater detail, the background and methods used to vary the different operational conditions for each experiment performed. Table 3 illustrates the main operational conditions for each experiment.

Table 3. The various operational conditions and values tested for food waste and glycerol substrates

\begin{tabular}{|c|c|c|c|c|c|}
\hline Experiment Name & Substrate & $\begin{array}{c}\text { Organic Load } \\
\text { (g COD/L-day) }\end{array}$ & $\begin{array}{l}\text { HRT } \\
\text { (hrs) }\end{array}$ & $\mathrm{pH}$ & $\begin{array}{c}\text { Sparging } \\
\text { Gas }\end{array}$ \\
\hline $\mathrm{pH} 1$ & Glycerol & 24.32 & 12 & $6.2,6.5,6.8$ & None \\
\hline $\mathrm{pH} 2$ & Glycerol & 24.32 & 12 & $6.2,6.5,6.8$ & None \\
\hline $\begin{array}{l}\text { Organic Loading } \\
\text { Rate } 1\end{array}$ & Glycerol & $18,24,30$ & 12 & 6.5 & None \\
\hline $\begin{array}{l}\text { Organic Loading } \\
\text { Rate } 2\end{array}$ & Glycerol & $12,18,24$ & 12 & 6.5 & None \\
\hline $\begin{array}{l}\text { Food waste Organic } \\
\text { Loading Rate }\end{array}$ & Food waste & $\begin{array}{c}12.79,19.18 \\
25.58\end{array}$ & 12 & 6.5 & None \\
\hline HRT 1 & Glycerol & 18 & $6,12,18$ & 6.5 & None \\
\hline HRT 2 & Glycerol & 18 & $3,6,9$ & 6.5 & None \\
\hline HRT 3 & Glycerol & 18 & $6,12,18$ & 6.5 & None \\
\hline Glycerol Sparging & Glycerol & 18 & 12 & 6.5 & $\begin{array}{l}\text { Biogas / } \\
\text { Nitrogen }\end{array}$ \\
\hline $\begin{array}{l}\text { Food waste } \\
\text { Sparging }\end{array}$ & Food waste & 25.58 & 12 & 6.5 & Nitrogen \\
\hline
\end{tabular}

Three different $\mathrm{pH}$ values were tested for optimal hydrogen production: 6.2, 6.5, and 6.8. These $\mathrm{pH}$ values were achieved in the digesters using phosphate 
buffers in the feedstock. The buffer formulations were based on the HendersonHasselbach equation.

Feedstocks for the $\mathrm{pH}$ experiments (12 hours, $24.32 \mathrm{~g} \mathrm{COD/L-day)} \mathrm{differed} \mathrm{only}$ in feed buffer concentrations. $\mathrm{pH}$ levels in the digesters were also maintained by the $\mathrm{pH}$ monitors which were set to dose in 0.2-M potassium hydroxide $(\mathrm{KOH})$ when the digesters were $0.1 \mathrm{pH}$ units below the set point.

Organic loading rate experiments $(6.5,12$ hours $)$ used glycerol or food waste as the substrate. For the glycerol experiments, different amounts of pure glycerol (anhydrous, Carolina Biological, Burlington, North Carolina) were added to the feedstock reservoirs to accomplish organic loading rates ranging from 12 to $30 \mathrm{~g}$ COD/L-day. The amount of glycerol to be added to the feedstocks was determined by dividing the desired OLR, in units of $\mathrm{g} C O D / L-d a y$, by the volume of feed added to the digesters in one day. From there, the concentration, in units of $\mathrm{g} \mathrm{COD/L}$, was converted to concentration of glycerol knowing that 3.5 moles of oxygen (COD) were required to convert one mole of glycerol (Equation 2-4). Pure glycerol was weighed on a balance and added to feedstock reservoirs.

$\mathrm{C}_{3} \mathrm{H}_{8} \mathrm{O}_{3}+3.5 \mathrm{O}_{2} \rightarrow 3 \mathrm{CO}_{2}+4 \mathrm{H}_{2} \mathrm{O}$

Post-consumer food waste used in organic loading rate experiments was collected from The Avenue, an on-campus cafeteria at California Polytechnic State University, San Luis Obispo. Food waste is collected at the dining hall by means of separate "composting" trash cans. Roughly $91 \mathrm{~kg}$ of fresh food waste 
was collected mid-day, and a representative sample of $9.1 \mathrm{~kg}(10 \%$ of the total) was removed and categorized (Figure 6). All $91 \mathrm{~kg}$ of food waste was homogenized in an industrial blender (Waring, Conair, East Windsor, New Jersey) in small batches. Each batch of blended food waste was mixed together in a clean 190 liter garbage can, and mixed for consistency. While mixing, portions of blended food waste were removed from the garbage can, poured into 3.75-L Ziploc Freezer bags (S.C. Johnson, Racine, Wisconsin), and stored at $20^{\circ} \mathrm{C}$.

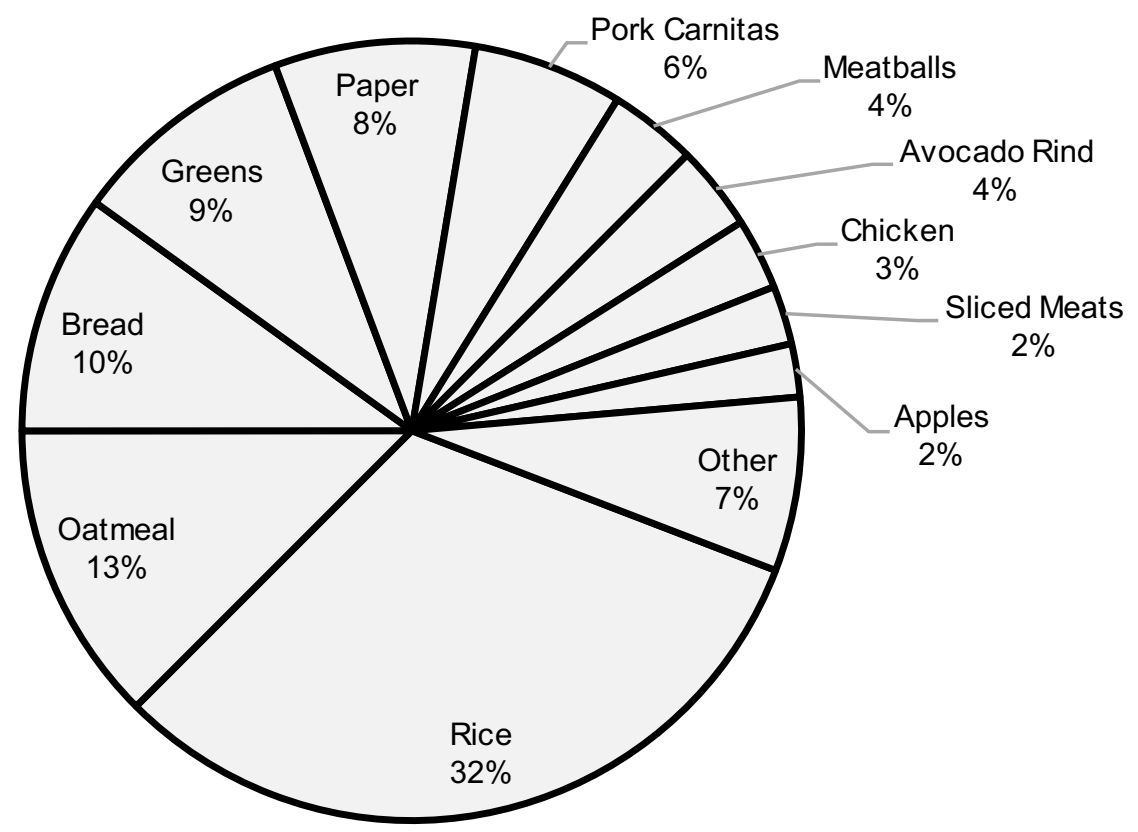

Figure 6. Components of food waste (in \% wet mass) obtained from a dining hall at California Polytechnic State University, San Luis Obispo, and used as digester feed.

Prior to the start of experiments using food waste as a substrate, food waste bags were thawed, mixed, and filtered through a 4-mm screen to prevent larger pieces from clogging tubing. Representative samples were taken from the filtered food waste and analyzed for total and volatile suspended solids. It was 
assumed that the volatile solids concentration was equal to glucose concentration because pure glucose is completely volatilized at $550^{\circ} \mathrm{C}$. The glucose concentration was then converted to COD concentration so that it could later be diluted to concentrations corresponding to organic loading rates that were to be tested. Food waste bags were placed back into the freezer until they were ready to be used in the feedstock reservoirs.

Different HRTs were achieved by changing the pumping rate of the influent and effluent peristaltic pumps. Glycerol was used as the substrate for HRT experiments, and the $\mathrm{pH}$ and OLR of all of the digesters were held constant. HRT is a factor in calculating OLR, so the concentration of glycerol in the feedstocks differed depending on HRT.

Once the optimal $\mathrm{pH}, \mathrm{HRT}$, and OLR were found for glycerol, a sparging experiment was performed on those conditions. Two digesters were sparged with high purity nitrogen gas, two digesters were sparged with biogas from methaneproducing anaerobic digesters in the lab, and the final two digesters were unsparged. Various sparging rates were accomplished by changing the flow rate on the peristaltic pump. Different sparging gasses were used to determine whether or not the type of gas had an effect on overall hydrogen production.

The sparging experiment using food waste as the substrate ran under the optimal OLR found in the food waste OLR experiment. $\mathrm{pH}$ and HRT experiments were not performed on food waste, so the digesters were run under the optimal conditions found in the glycerol experiments - a pH of 6.5 , and an HRT of 12 
hours. Four of the six digesters were sparged with high purity nitrogen gas, and two of the digesters were not sparged. Different flowrates were achieved by changing the pumping rate on the peristaltic pump carrying gas to the digesters. 


\section{CHAPTER 3: RESULTS}

The following section reports the results obtained from each of the individual $\mathrm{pH}$, OLR, HRT, and gas sparging experiments. Data from each experiment was used to produce a chemical oxygen demand balance, and calculate molar hydrogen yields and volumetric hydrogen production.

\section{1 pH Experimental Results}

The $\mathrm{pH}$ experiments were conducted to determine the $\mathrm{pH}$ that would maximize hydrogen production for given constant OLRs and HRTs. The optimal OLR and HRT were not yet determined for glycerol, so OLR and HRT values from similar experiments using glucose were used, specifically an OLR of $24.3 \mathrm{~g}$ COD/L-day and an HRT of 12 hours (Olivas, 2015).

Two $\mathrm{pH}$ experiments were performed and operated at the same conditions to see whether the data obtained was repeatable (Table 4). $\mathrm{pH}$ values of $6.2,6.5$, and 6.8 were tested. These $\mathrm{pH}$ values were maintained in the digesters for the majority of both experiments; however, fluctuations in $\mathrm{pH}$ did occur. $\mathrm{pH}$ monitors had an accuracy of \pm 0.2 , and the difference in target $\mathrm{pH}$ values was \pm 0.3 . Digesters occasionally stopped mixing, causing the $\mathrm{pH}$ probes to read $\mathrm{pH}$ values that were not representative of the mixed digester. The imprecision of the $\mathrm{pH}$ monitors and the occasionally unmixed digester sometimes caused the dosing pumps to activate, adding concentrated $\mathrm{KOH}$ when not necessary. When this occurred, the date and $\mathrm{pH}$ were recorded, and $100-\mathrm{mL}$ of effluent digestate from the duplicate digester was pumped into the affected digester to reduce the $\mathrm{pH}$. If 
the digesters were unable to return to normal operation, the experiment was terminated, and restarted.

Table 4. Target operational variables for $\mathrm{pH}$ Experiment 1 and $\mathrm{pH}$ Experiment 2

\begin{tabular}{cccc}
\hline Reactor & $\mathrm{pH}$ & OLR (g COD/L-Day) & HRT (hours) \\
\hline $\begin{array}{l}\text { Digester 1 } \\
\text { Digester 2 }\end{array}$ & 6.20 & 24.32 & 12 \\
\hline $\begin{array}{l}\text { Digester 3 } \\
\text { Digester 4 }\end{array}$ & 6.50 & 24.32 & 12 \\
\hline $\begin{array}{l}\text { Digester 5 } \\
\text { Digester 6 }\end{array}$ & 6.80 & 24.32 & 12 \\
\hline
\end{tabular}

$\mathrm{pH}$ Experiment 1 had a steady state period of Days 12-16, for all digesters.

Digester 1 (D1) and Digester 2 (D2) operated at an average pH of 6.08 (Figure 7) and an average alkalinity of $2600 \mathrm{mg} \mathrm{CaCO}, / \mathrm{L}$. D3 and D4 had an average $\mathrm{pH}$ of 6.47 and an average alkalinity of $4500 \mathrm{mg} \mathrm{CaCO} / \mathrm{L}$. D5 and D6 had an average $\mathrm{pH}$ of 6.83 and an average alkalinity of $6500 \mathrm{mg} \mathrm{CaCO}_{3} / \mathrm{L}$ (Figure 8) 


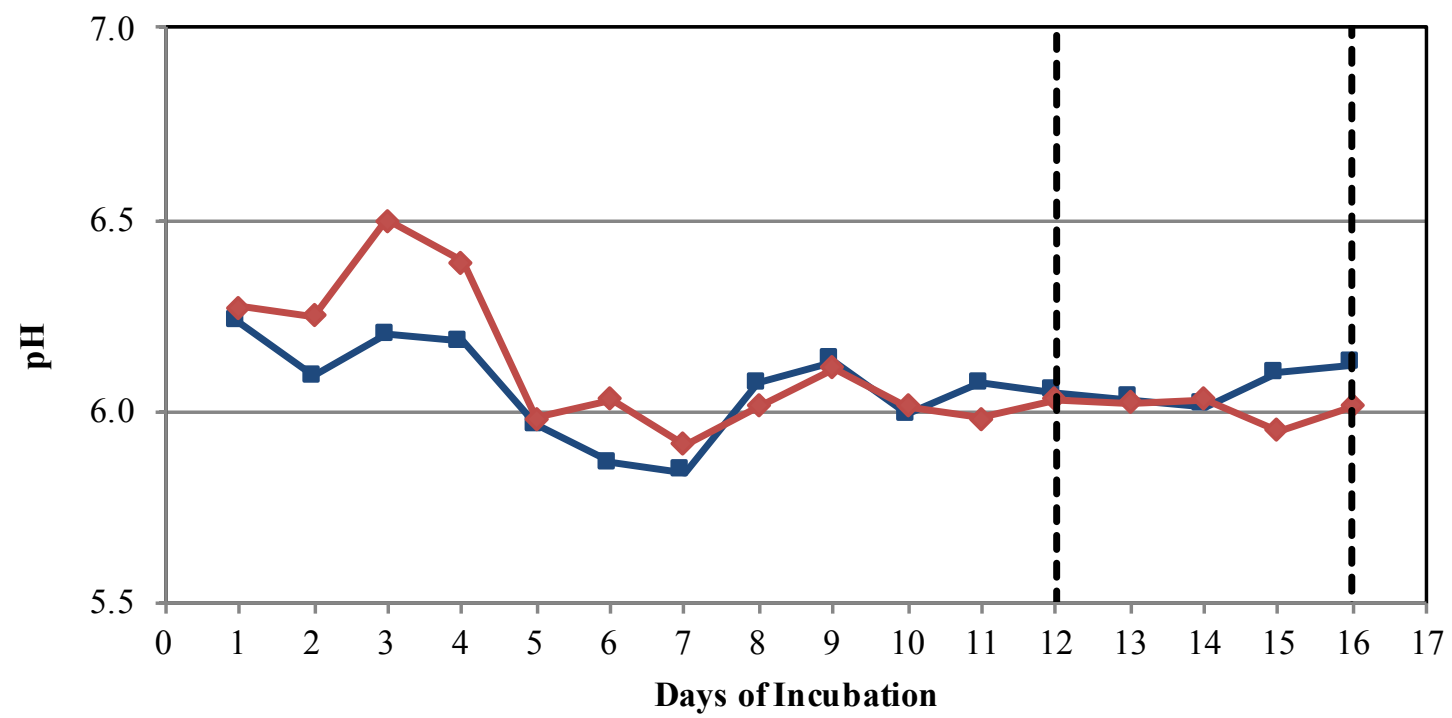

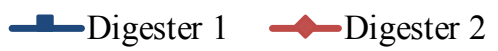

Figure 7. Time-series $\mathrm{pH}$ readings for replicate digesters $\mathrm{D} 1$ and $\mathrm{D} 2$ (target $\mathrm{pH}$ 6.2). The mean $\mathrm{pH}$ of the duplicate digesters was 6.08 during the steady-state period (within the vertical lines). On Day 3, D2 stopped mixing and was dosed with $\mathrm{KOH}$, raising the $\mathrm{pH}$ to 6.50. HRT was 12 hours.

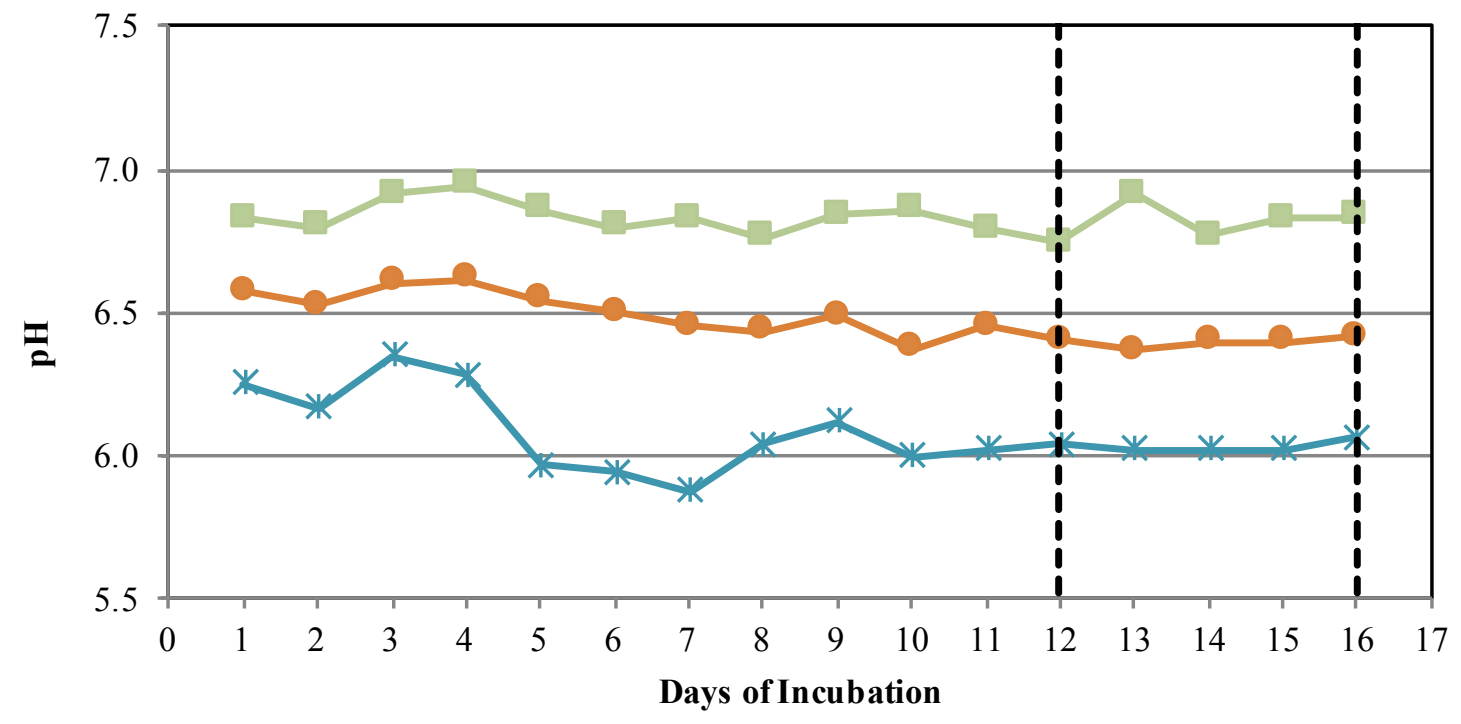

* Mean (D1-D2) $\longrightarrow$ Mean (D3-D4) - -Mean (D5-D6)

Figure 8. Mean of duplicates $\mathrm{pH}$ readings during $\mathrm{pH}$ Experiment 1. The steady state period is depicted as the days between the vertical lines. 
The HRT was maintained for the entirety of the $\mathrm{pH}$ Experiment 1, and the OLR for each set of digesters was within one standard deviation of the target OLR of $24.3 \mathrm{~g} \mathrm{COD/L-day.} \mathrm{D1} \mathrm{and} \mathrm{D2} \mathrm{had} \mathrm{an} \mathrm{average} \mathrm{OLR} \mathrm{of} 25.3 \pm 1.00 \mathrm{~g}$ COD/L-day (mean \pm SD), D3 and D4 had an average OLR of $25.3 \pm 1.16 \mathrm{~g} \mathrm{COD/L-day,} \mathrm{and}$ D5 and D6 had an average OLR of $26.1 \pm 1.76 \mathrm{~g} \mathrm{COD/L-day.} \mathrm{The} \mathrm{OLR} \mathrm{for} \mathrm{each}$ digester set was calculated using data obtained from COD analysis of feedstock samples.

$\mathrm{pH}$ Experiment 2 was run to ensure the results of $\mathrm{pH}$ Experiment 1 were repeatable, and had average $\mathrm{pH}$ values of $6.21,6.47$, and 6.83 . The steady state period for this experiment occurred on Day 5-9 for D1 and D2, and Day 9-13 for D3-6. $\mathrm{pH}$ values during the second experiment ranged from 5.85 to 7.06 . The alkalinity increased with $\mathrm{pH}$ and averaged $3500 \mathrm{mg} \mathrm{CaCO}_{3} / \mathrm{L}, 5400 \mathrm{mg} \mathrm{CaCO}_{3} / \mathrm{L}$, and $6600 \mathrm{mg} \mathrm{CaCO} / \mathrm{L}$ for D1-2, D3-4, and D5-6, respectively.

The OLR values for $\mathrm{pH}$ Experiment 2 were lower than the target OLR of $24.3 \mathrm{~g}$ COD/L-day. D1 and D2 had an average OLR of $20.7 \pm 1.57 \mathrm{~g} \mathrm{COD/L-day} \mathrm{(mean}$ $\pm \mathrm{SD}$ ); D3 and D4 had an average OLR of $22.3 \pm 2.08 \mathrm{~g}$ COD/L-day; and D5 and D5 had an average OLR of $22.5 \pm 1.42 \mathrm{~g} \mathrm{COD/L-day.}$

\subsubsection{COD Balance}

A COD balance was performed for each $\mathrm{pH}$ experiment, including influent, effluent, and gaseous COD data during the steady state periods. For a perfectly balanced system, the influent COD mass would be equal to the sum of effluent 
and gaseous COD masses for a given period. Influent COD data were measured from feedstock samples, while effluent COD was measured from effluent digester samples. Gaseous COD data were obtained by converting the daily hydrogen and methane gas production data to units of COD. In order to convert hydrogen gas production to COD concentration, the ideal gas law was used to convert the volume of hydrogen gas to moles of hydrogen at room temperature and pressure. The molar amount of hydrogen was then converted to COD concentration by a molar conversion to oxygen (COD). This was repeated for methane gas. Each graph includes the mean influent, effluent, and gaseous COD for each duplicate digester.

During the steady state period of $\mathrm{pH}$ Experiment 1, recovery of influent COD in effluent and biogas COD ranged from 92-97\% (Figure 9). These high recoveries indicate that the digesters were not leaking biogas and lend credence to the results. The COD recoveries for each experiment are a major factor in judging the level of confidence in the hydrogen production results. 


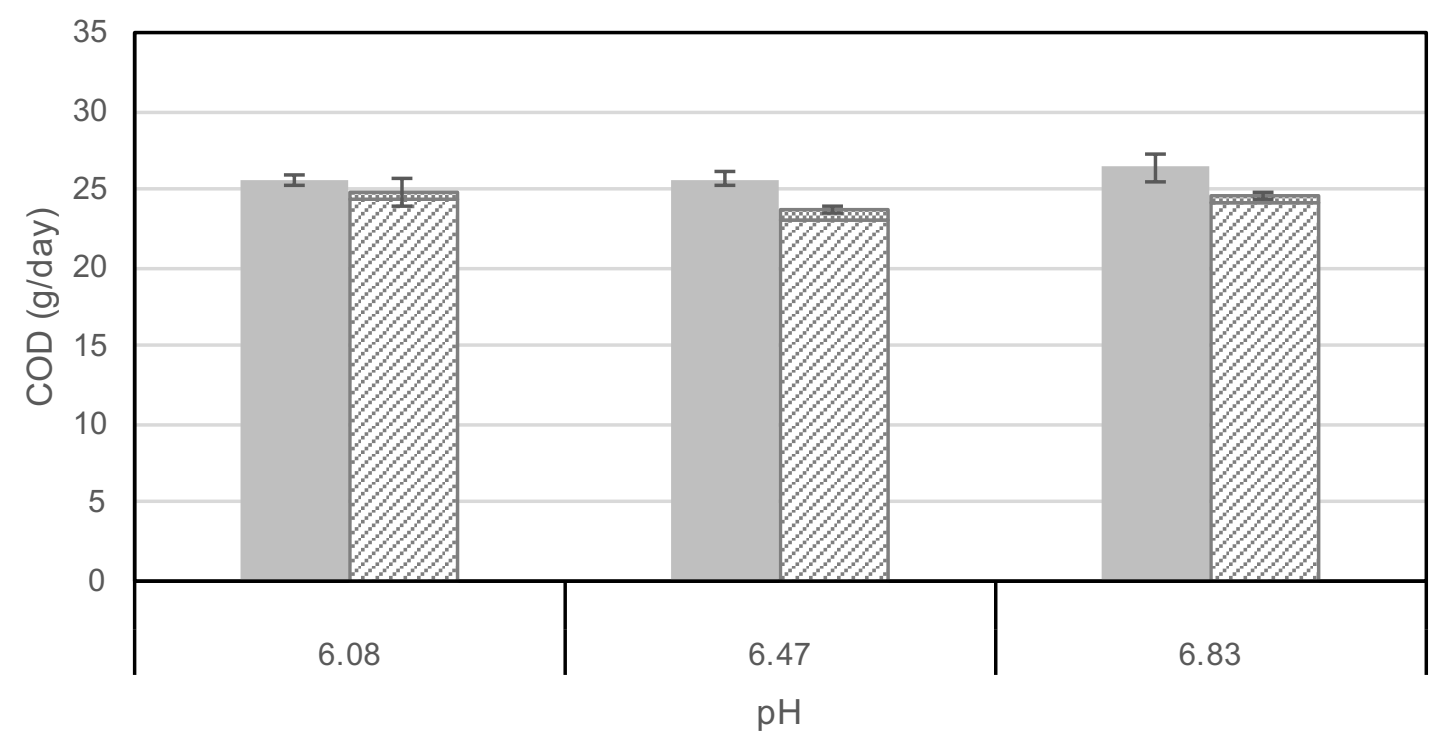

Figure 9. $C O D$ balance for $p H$ Experiment 1 where digesters were operated at $p H$ values of 6.08 , 6.47 , and 6.83, during the steady state performance period. The means of steady-state performance periods by duplicate digesters were used to calculate the standard errors $(\mathrm{n}=2)$ shown on the digester effluent and biogas bars. The influent standard errors were based on measurements during the steady state performance period $(n=5)$.

pH Experiment 2 was also well balanced (Figure 10). During the steady state period digesters operating a $\mathrm{pH}$ of 6.21 with recoveries of $95-99 \%$ of influent COD. Again, such high recoveries indicate accurate hydrogen yields. 


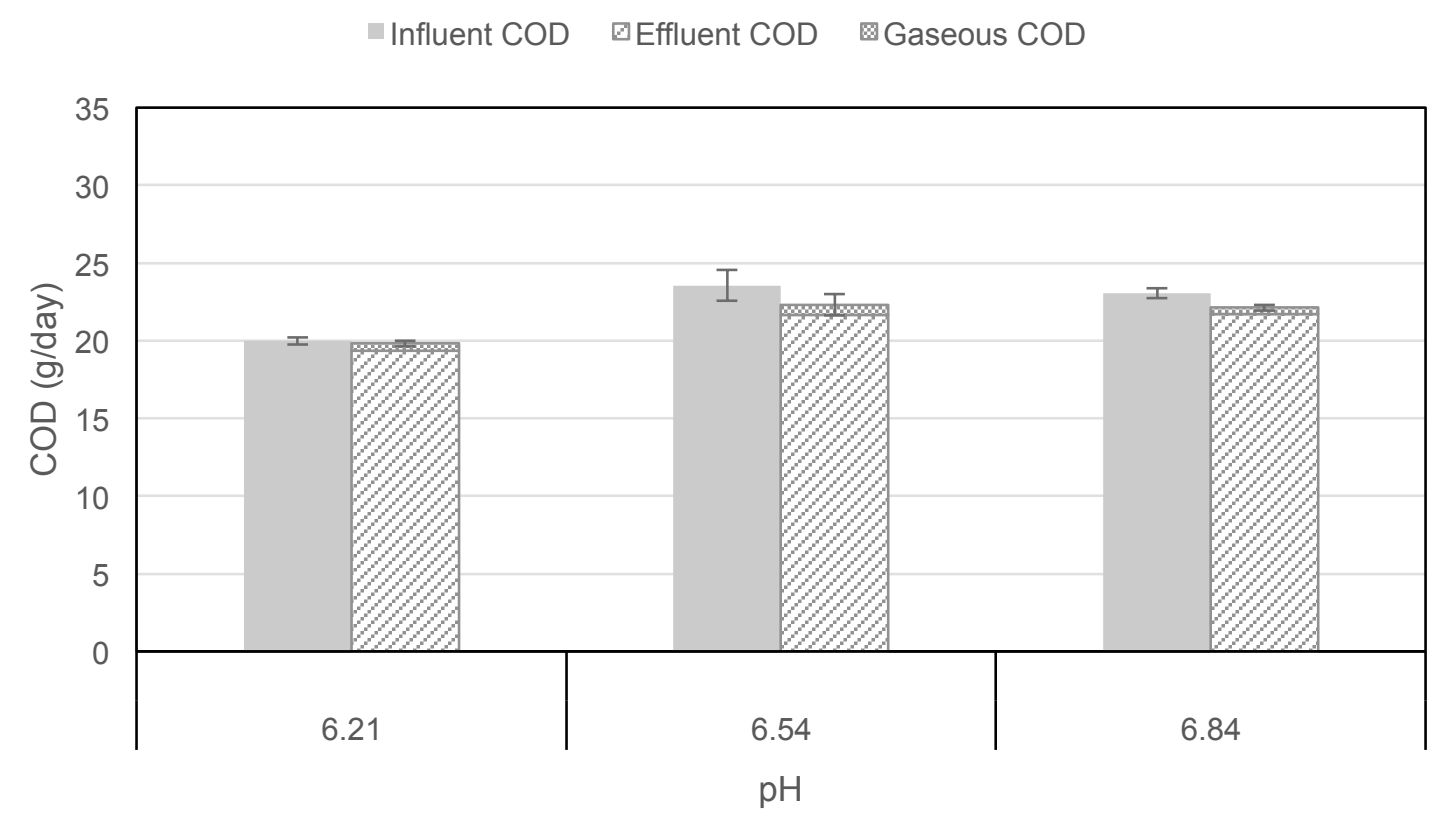

Figure 10. COD balance for $\mathrm{pH}$ Experiment 2 where digesters were operated at $\mathrm{pHs}$ of 6.21 , 6.54 , and 6.84 during the steady state performance period. The means of steady-state performance periods by duplicate digesters were used to calculate the standard errors $(n=2)$ shown on the digester effluent and biogas bars. The influent standard errors were based on measurements during the steady state performance period $(n=5)$.

\subsubsection{Molar Hydrogen Yields and Volumetric Hydrogen Production}

Data were combined from both $\mathrm{pH}$ experiments to calculate hydrogen yields and the standard error for digesters running under similar conditions. Molar hydrogen yields and volumetric hydrogen production were calculated over steady state periods. The molar yield was highest $\left(0.013 \pm 0.0029 \mathrm{~mol} \mathrm{H}_{2} / \mathrm{mol} \mathrm{COD}\right)$ for a mean $\mathrm{pH}$ of 6.51 for all four digesters (mean $\pm \mathrm{SE}$ ). At a mean $\mathrm{pH}$ of 6.15 , the molar yield was $0.006 \pm 0.0010 \mathrm{~mol} \mathrm{H}_{2} / \mathrm{mol} \mathrm{COD}$. The highest mean $\mathrm{pH}$ tested, 6.84, produced a molar yield of $0.004 \pm 0.0014 \mathrm{~mol} \mathrm{H}_{2} / \mathrm{mol} \mathrm{COD} \mathrm{(Figure} \mathrm{11).}$ Despite the high standard error between experiments, digesters operating at a mean $\mathrm{pH}$ of 6.51 converted the most moles of COD to hydrogen gas. 


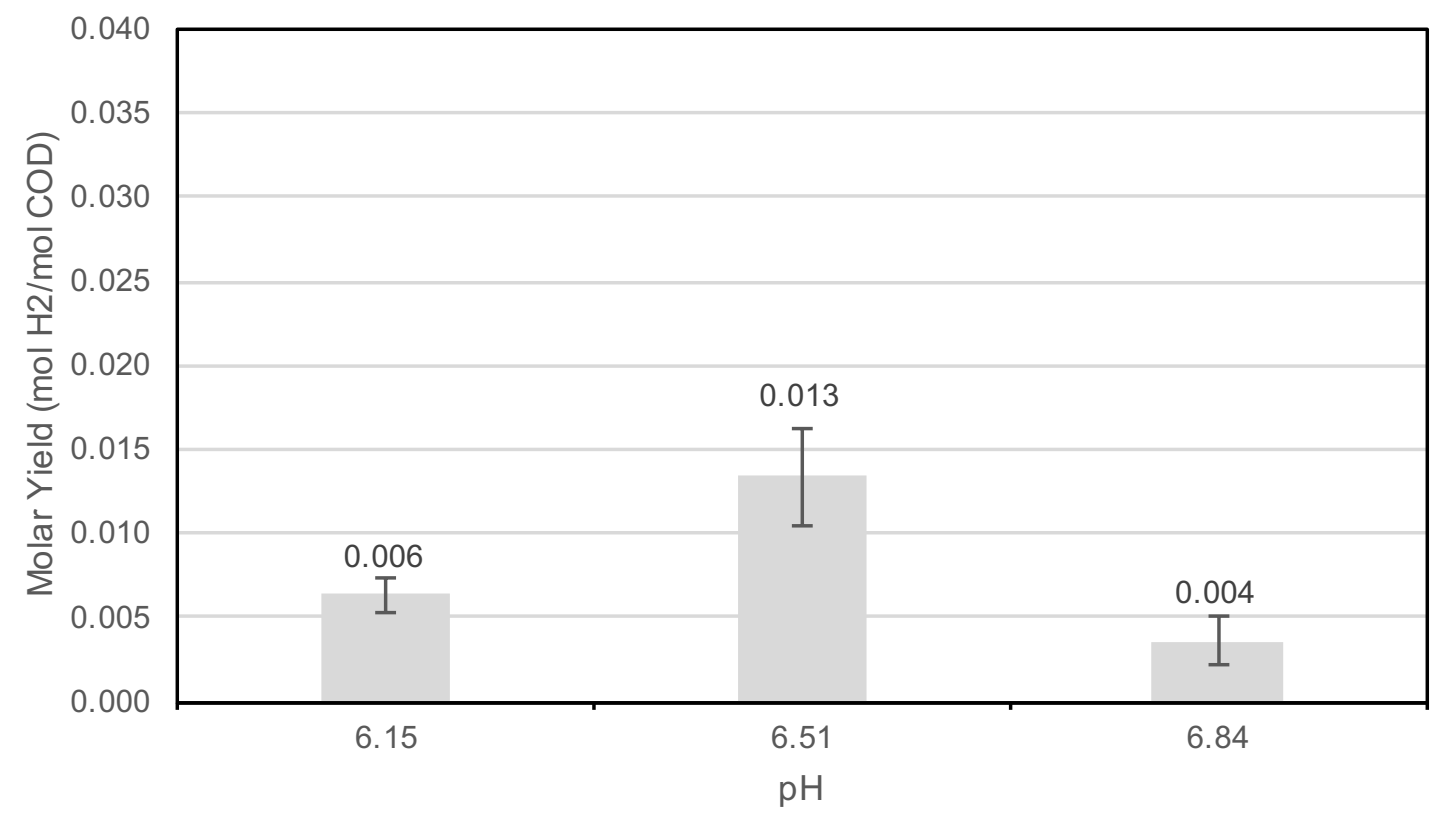

Figure 11. Molar hydrogen yields for mean $\mathrm{pH}$ values of 6.15, 6.51, and 6.84. The means of steady state performance periods by replicate experiments were used to calculate the standard errors shown on the molar yield bars $(\mathrm{n}=2)$. Molar hydrogen yields are based on influent COD.

Volumetric hydrogen production followed a similar pattern. At a pH of 6.51, D3 and D4 produced $0.244 \pm 0.0416 \mathrm{~L} \mathrm{H}_{2} / \mathrm{L}_{\text {Reactor-day }}$ (mean $\left.\pm \mathrm{SE}\right)$. D1 and D2 $(\mathrm{pH}$

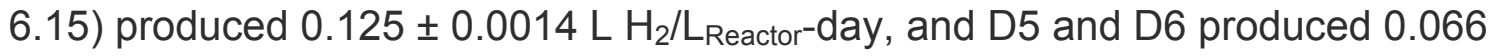
$\pm 0.0211 \mathrm{~L} \mathrm{H}_{2} / \mathrm{L}_{\text {Reactor-day }}$ (Figure 12). Volumetric hydrogen production for digesters operating at a mean $\mathrm{pH}$ of 6.15 produced repeatable results, with only 2.1\% difference between experiments. Digesters operating at $\mathrm{pH}$ values of 6.51 and 6.84 did not produce repeatable results with molar hydrogen yields between experiments $>20 \%$ different. A pH of 6.5 was used for the subsequent experiments because it produced hydrogen yields that were greater than the other two $\mathrm{pH}$ values tested, and its error was not within the bounds of the other sets of digesters. 


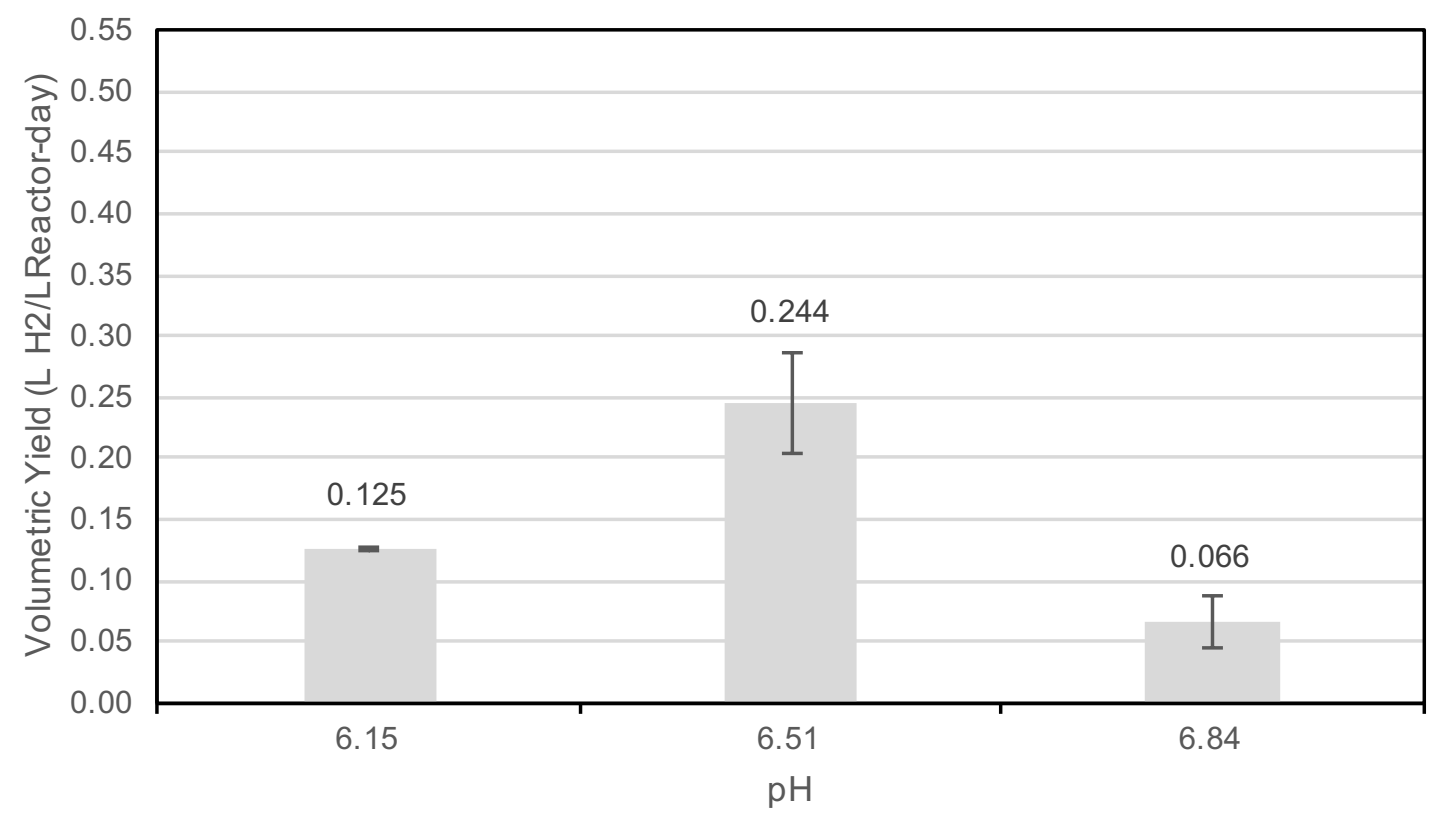

Figure 12. Volumetric hydrogen production for mean $\mathrm{pH}$ values of $6.15,6.51$, and 6.84 . The means of steady state performance periods by replicate experiments were used to calculate the standard errors shown on the volumetric hydrogen production bars $(\mathrm{n}=2)$.

\subsection{Organic Loading Rate Experiments}

The OLR experiments examined the effect of various concentrations of glycerol and food waste on hydrogen production. The previously found optimal $\mathrm{pH}$ of 6.5 was held constant in all digesters, as well as the 12-hour HRT. Organic loading rates of $12,18,24$, and $30 \mathrm{~g} \mathrm{COD/L-day} \mathrm{were} \mathrm{tested} \mathrm{over} \mathrm{two} \mathrm{experiments.}$

OLR Experiment 1 examined COD loadings of 18, 24, and $30 \mathrm{~g} \mathrm{COD/L-day.}$ Digester feedstocks contained $7.4 \mathrm{~g}$ glycerol/L for digesters operating at an OLR of $18 \mathrm{~g} \mathrm{COD/L-day,} 10 \mathrm{~g}$ glycerol/L for digesters operating at $24 \mathrm{~g} \mathrm{COD/L-day,}$ and $12.33 \mathrm{~g}$ glycerol/L for digesters operating at an OLR of $30 \mathrm{~g} \mathrm{COD/L-day.} \mathrm{D1}$ and D2 operated at an average OLR of $18.8 \pm 0.1843 \mathrm{~g}$ COD/L-day (mean \pm SD). D3 and D4 achieved an average OLR was $24.0 \pm 0.8474 \mathrm{~g} \mathrm{COD/L-day,} \mathrm{and}$ 
D5 and D6 had an average OLR of $28.8 \pm 1.307 \mathrm{~g} \mathrm{COD/L-day.} \mathrm{The} \mathrm{average} \mathrm{pH}$ and alkalinity in all digesters was 6.35 and $3500 \mathrm{mg} \mathrm{CaCO}_{3} / \mathrm{L}$ respectively. Steady state conditions were identified for Days 10-14 for D1 and D2, and Days 12-16 for D3-6.

OLR Experiment 2 used glycerol as a substrate and tested organic loadings of 12, 18, and $24 \mathrm{~g} \mathrm{COD/L-day.} \mathrm{Digester} \mathrm{feedstocks} \mathrm{contained} 4.9 \mathrm{~g}$ glycerol for digesters operating at an OLR of $12 \mathrm{~g} \mathrm{COD/L-day,} 7.4 \mathrm{~g}$ glycerol/L for digesters operating at $18 \mathrm{~g} \mathrm{COD/L-day,} \mathrm{and} 10 \mathrm{~g}$ glycerol/L for digesters operating at $24 \mathrm{~g}$ COD/L-day. D1 and D2 attained an average OLR of $12.7 \pm 0.7986 \mathrm{~g} \mathrm{COD/L-day}$ (mean $\pm \mathrm{SD}$ ). D3 and D4 achieved an average OLR of $17.6 \pm 0.3489 \mathrm{~g} \mathrm{COD/L-}$ day, and D5 and D6 had an average OLR of $23.1 \pm 1.054 \mathrm{~g} \mathrm{COD/L-day.} \mathrm{The}$ average $\mathrm{pH}$ for all digesters was 6.52 , while the average alkalinity was $4200 \mathrm{mg}$ $\mathrm{CaCO}_{3} / \mathrm{L}$. Steady state conditions were met for D1 and D2 on Day $7-11$, for D3 and D4 on Day 10-14, and Day 11-15 for D5 and D6.

The final OLR experiment examined the use of food waste as a substrate. Previous research found that the optimal OLR for anaerobic digesters utilizing glucose as a substrate was $18 \mathrm{~g}$ glucose/L-day (19.2 g COD/L-day) (Olivas, 2015). At a 12-hr HRT, this loading corresponded to a concentration of $9 \mathrm{~g}$ glucose/L. Food waste glucose concentrations were estimated by volatile solids content (see methods 2-6) so food waste was diluted to achieve a concentration of $9 \mathrm{~g}$ glucose/L, or an organic loading rate of $18 \mathrm{~g}$ glucose/L-day. OLRs of $12 \mathrm{~g}$ glucose/L-day and $24 \mathrm{~g}$ glucose/L-day were also tested (Table 5). 
Table 5. Target OLRs for food waste in concentration units of glucose and COD

\begin{tabular}{cc}
\hline \multicolumn{2}{c}{ Organic Loading Rate } \\
g glucose/L-day & g COD/L-day \\
\hline 12 & 12.8 \\
18 & 19.2 \\
24 & 25.6 \\
\hline
\end{tabular}

D1 and D2 were fed concentrations of food waste targeting an OLR of $12.8 \mathrm{~g}$ COD/L-day; however, the mean OLR was $25.8 \pm 3.97 \mathrm{~g}$ COD/L-day. D3 and D4 target OLR was $19.2 \mathrm{~g} \mathrm{COD/L-day,} \mathrm{and} \mathrm{a} \mathrm{mean} \mathrm{OLR} \mathrm{of} 31.2 \pm 4.231 \mathrm{~g} \mathrm{COD/L-}$ day was attained. D5 and D6 target OLR was $24 \mathrm{~g} \mathrm{COD/L-day,} \mathrm{and} \mathrm{a} \mathrm{mean} \mathrm{OLR}$ of $33.9 \pm 7.96 \mathrm{~g} \mathrm{COD} / \mathrm{L}$-day was attained. The average $\mathrm{pH}$ and alkalinity of the digesters was 6.51 and $4700 \mathrm{mg} \mathrm{CaCO}_{3} / \mathrm{L}$. D1 and D2 reached steady state on Day 4-8, while D3-6 experienced steady state conditions on Day 31-35. D1 and D2 experienced leaks that were unable to be fixed, despite shutting down D1 and D2 for repair and restarting them on Day 14.

\subsubsection{COD Balance}

During the steady state period of OLR Experiment 1, digesters running at an OLR of $18.8 \mathrm{~g} \mathrm{COD/L-day} \mathrm{recovered} 92 \%$ of the influent COD, while digesters running at $24.0 \mathrm{~g} \mathrm{COD/L-day} \mathrm{achieved} 98 \%$ recovery of the influent COD feed. At an OLR of $28.8 \mathrm{~g} \mathrm{COD/L-day,} \mathrm{gaseous} \mathrm{and} \mathrm{effluent} \mathrm{COD} \mathrm{was} \mathrm{slightly} \mathrm{greater}$ than the influent COD, recovering $101 \%$ of influent COD (Figure 13). 


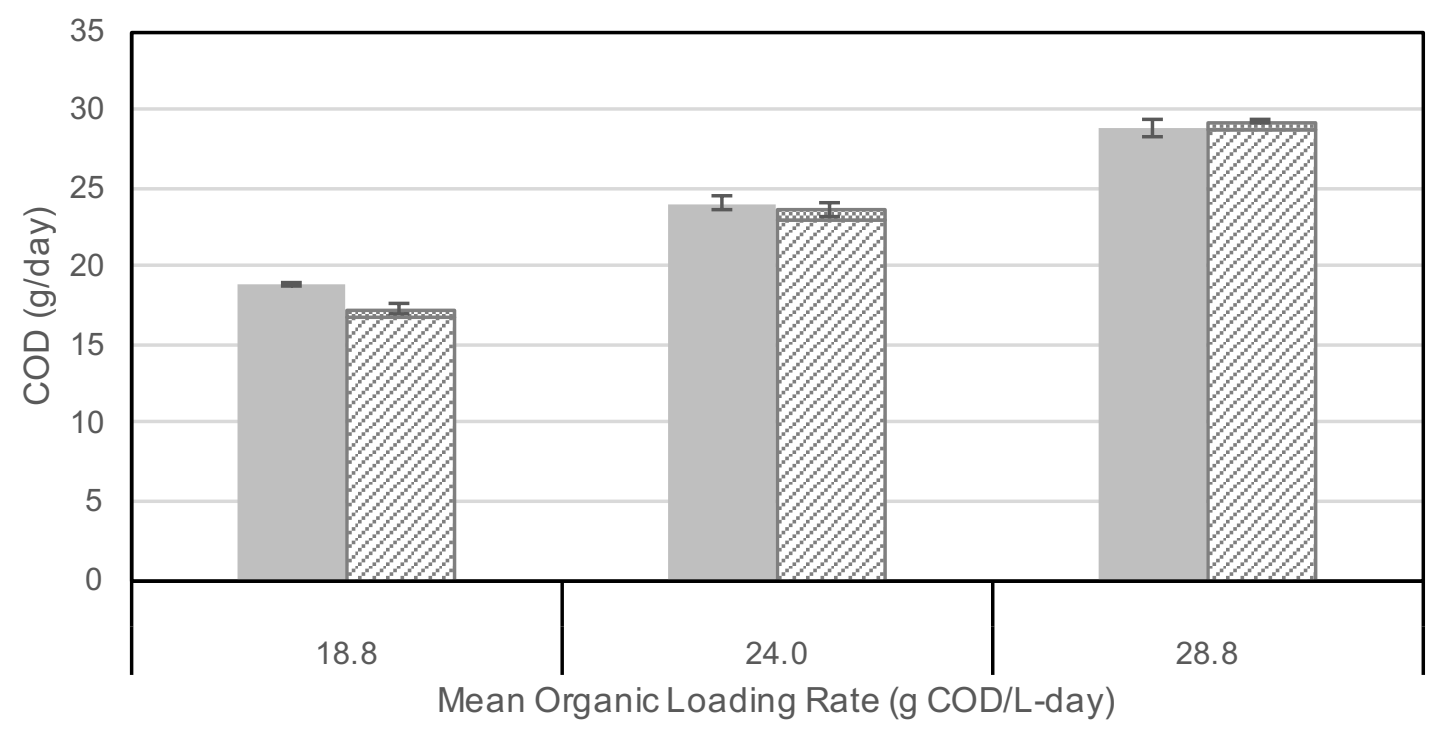

Figure 13. COD balance for digesters operated at mean OLRs of 18.8, 24.0, and $28.8 \mathrm{~g} C O D / \mathrm{L}$ day. OLR values were calculated as the mean over the course of the steady state period. The means of steady-state performance periods by duplicate digesters were used to calculate the standard errors $(\mathrm{n}=2)$ shown on the digester effluent and biogas bars. The influent standard errors were based on measurements during the steady state performance period $(\mathrm{n}=5)$.

During the steady state period of OLR Experiment 2, OLRs of 12.7 and $17.6 \mathrm{~g}$ COD/L-day recovery was $96 \%$ of influent COD (Figure 14). At an OLR of $23.1 \mathrm{~g}$ COD/L-day, $91 \%$ of influent COD was recovered. 


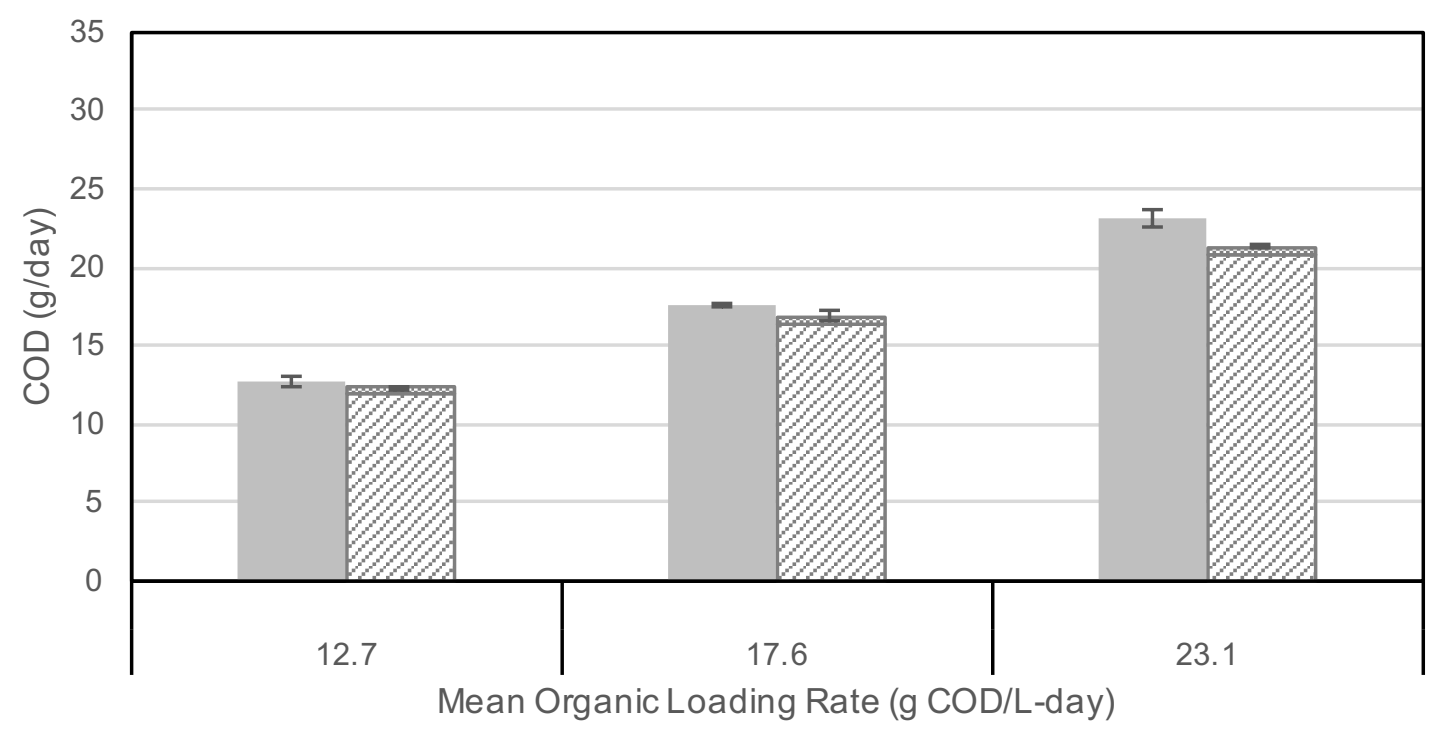

Figure 14. COD balance for digesters operated at mean OLRs of 12.7, 17.6, and $23.1 \mathrm{~g} C O D / L-$ day. OLR values were calculated as the mean over the course of the steady state period. The means of steady-state performance periods by duplicate digesters were used to calculate the standard errors ( $\mathrm{n}=2)$ shown on the digester effluent and biogas bars. The influent standard errors were based on measurements during the steady state performance period $(\mathrm{n}=5)$.

Food waste-fed digesters operating at an OLR of $25.8 \mathrm{~g}$ COD/L-day with food waste had a recovery of $87 \%$ of the influent COD (Figure 15). At organic loading rates of $31.2 \mathrm{~g} \mathrm{COD/L-day} \mathrm{and} 33.9 \mathrm{~g}$ COD/L-day, the recoveries were $90 \%$ and $95 \%$, respectively. 


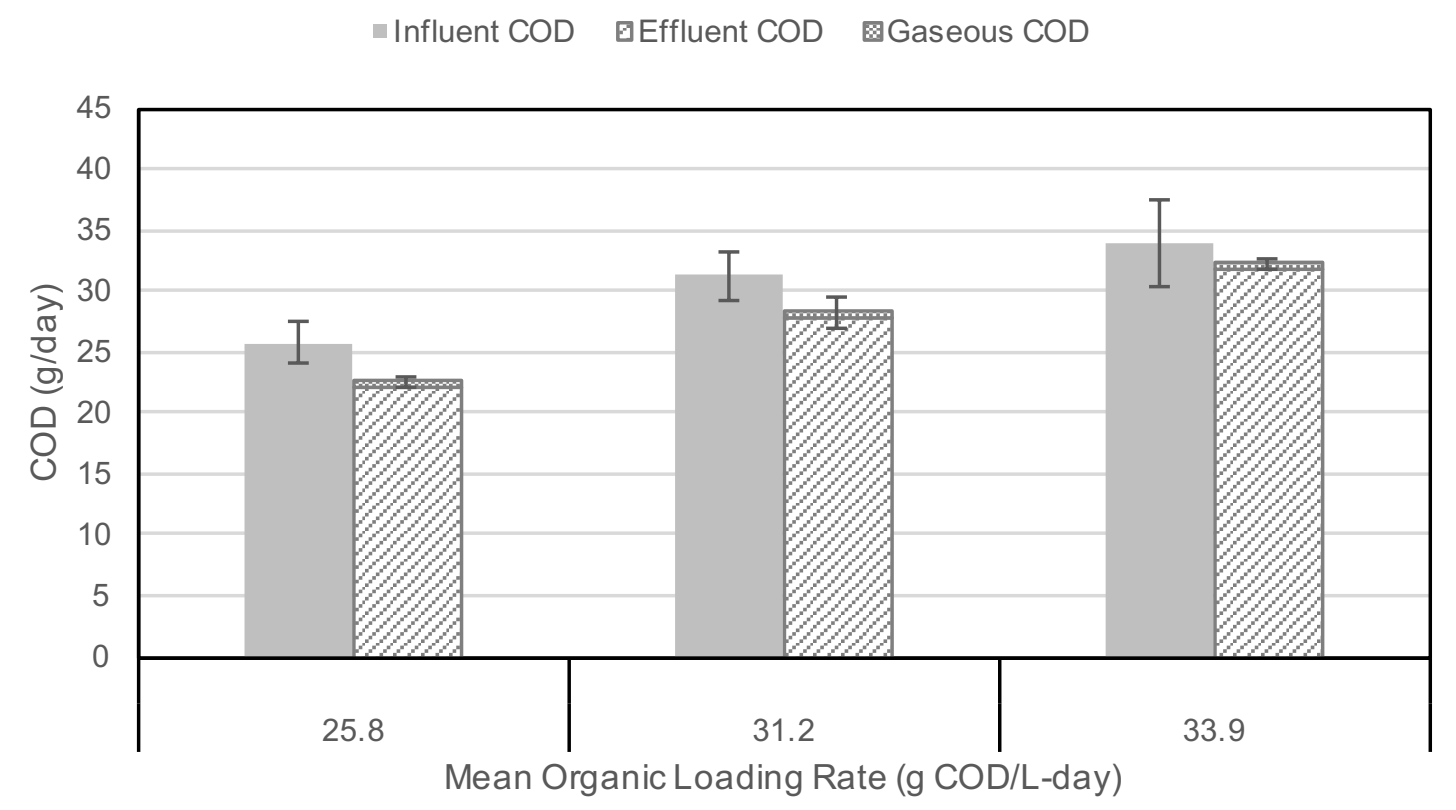

Figure 15. COD balance for food waste-fed digesters operated at mean OLRs of 25.8, 31.2, and $33.9 \mathrm{~g} \mathrm{COD/L-day.} \mathrm{OLR} \mathrm{values} \mathrm{were} \mathrm{calculated} \mathrm{as} \mathrm{the} \mathrm{mean} \mathrm{over} \mathrm{the} \mathrm{course} \mathrm{of} \mathrm{the} \mathrm{steady} \mathrm{state}$ period. The means of steady-state performance periods by duplicate digesters were used to calculate the standard errors $(\mathrm{n}=2)$ shown on the digester effluent and biogas bars. The influent standard errors were based on measurements during the steady state performance period ( $\mathrm{n}=$ $5)$.

\subsubsection{Molar Hydrogen Yields and Volumetric Hydrogen Production}

Molar hydrogen yields observed at 18 and $24 \mathrm{~g} \mathrm{COD/L-day} \mathrm{were} \mathrm{less} \mathrm{than} 10 \%$ different between replicate experiments, indicating reproducible results. Molar hydrogen production was highest at a mean OLR of $18.2 \mathrm{~g}$ COD/L-day, producing $0.015 \pm 0.0021 \mathrm{~mol} \mathrm{H} / \mathrm{mol}$ COD (mean $\pm \mathrm{SE}$ ). A yield of $0.010 \pm$ $0.0011 \mathrm{~mol} \mathrm{H}_{2} / \mathrm{mol} \mathrm{COD}$ was produced at an OLR of $12.7 \mathrm{~g} \mathrm{COD} / \mathrm{L}$-day, and a yield of $0.008 \pm 0.0002 \mathrm{~mol} \mathrm{H}_{2} / \mathrm{mol} \mathrm{COD}$ was produced at a mean OLR of $23.6 \mathrm{~g}$ COD/L-day. The highest OLR, at $28.8 \mathrm{~g} \mathrm{COD/L-day,} \mathrm{produced} \mathrm{the} \mathrm{lowest} \mathrm{molar}$ yield of $0.005 \pm 0.0002 \mathrm{~mol} \mathrm{H}_{2} / \mathrm{mol} \mathrm{COD} \mathrm{(Figure} \mathrm{16).}$ 


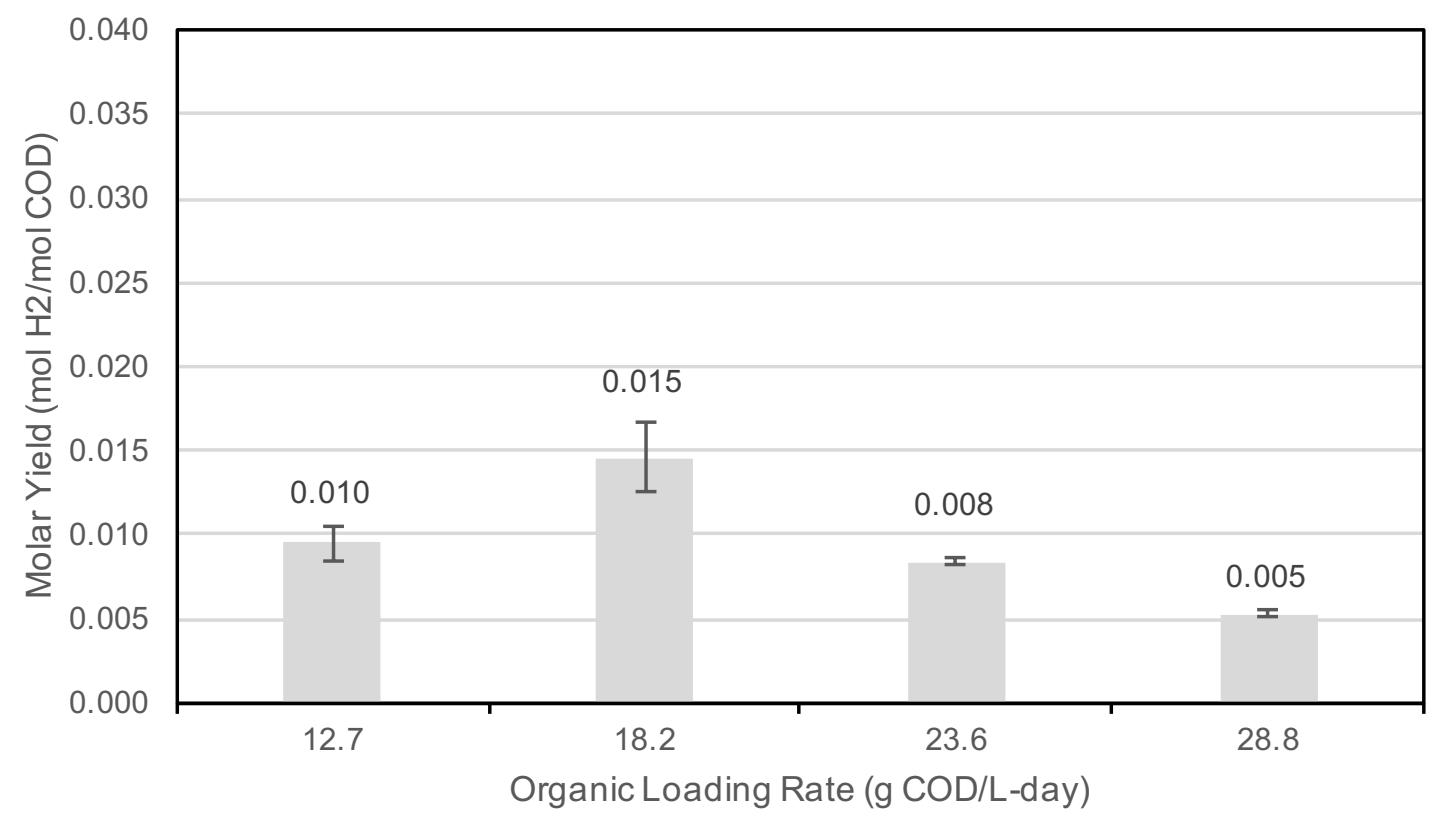

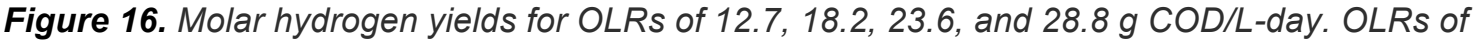
18.2 and $23.6 \mathrm{~g} \mathrm{COD/L-day} \mathrm{were} \mathrm{calculated} \mathrm{mean} \mathrm{OLRs} \mathrm{between} \mathrm{replicate} \mathrm{experiments.}$ Standard error bars for those OLRs represent the error between replicate experiments $(\mathrm{n}=2)$. OLRs of 12.7 and 28.8 were tested once, so standard error bars represent the error among duplicate digesters $(\mathrm{n}=2)$.

Volumetric hydrogen production for glycerol-fed digesters was highest at an OLR of $18.2 \mathrm{~g} \mathrm{COD/L-day} \mathrm{and} \mathrm{produced} 0.199 \pm 0.0218 \mathrm{LH}_{2} / \mathrm{L}_{\text {Reactor-day }}$ (mean $\pm \mathrm{SE}$ ). Digesters operating at an OLR of $23.55 \mathrm{~g} \mathrm{COD/L-day} \mathrm{produced} \mathrm{the} \mathrm{second}$ highest volumetric hydrogen yield of $0.148 \pm 0.0003 \mathrm{LH}_{2} / \mathrm{L}_{\text {Reactor-day. At }} 28.8 \mathrm{~g}$

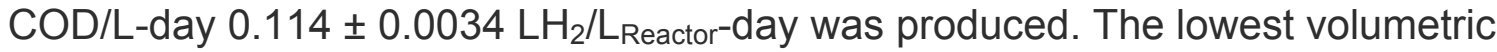
hydrogen production was observed at an OLR of $12.7 \mathrm{~g} \mathrm{COD/L-day} \mathrm{and} \mathrm{was}$ $0.091 \pm 0.0102 \mathrm{LH}_{2} / L_{\text {Reactor-day }}$ (Figure 17). Both molar hydrogen yields and volumetric hydrogen production for glycerol-fed digesters were highest at an OLR of $18.2 \mathrm{~g} \mathrm{COD/L-day.}$ 


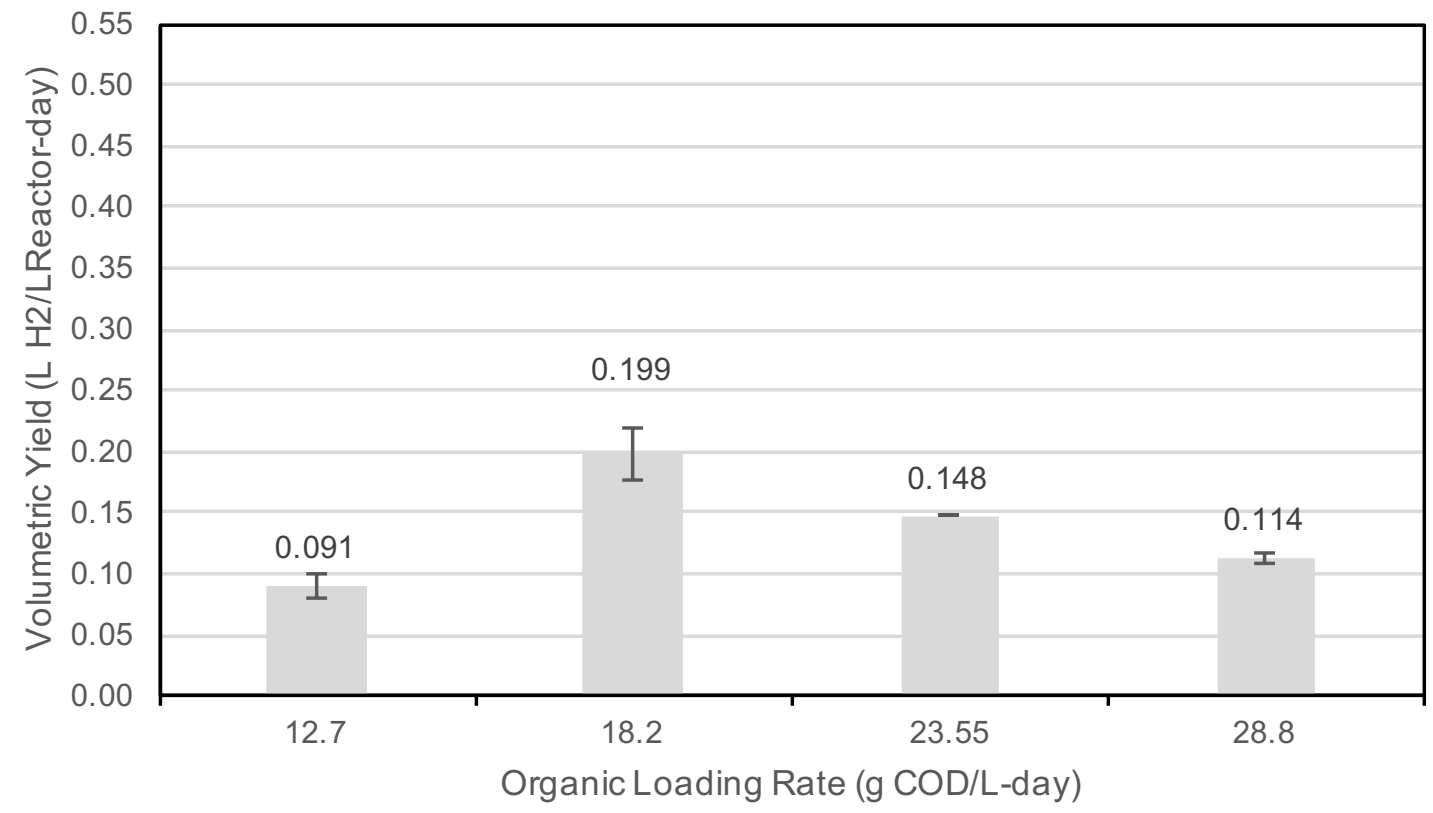

Figure 17. Volumetric hydrogen yields for OLRs of 12.7, 18.2, 23.6, and $28.8 \mathrm{~g} C O D / L$-day. OLRs of 18.2 and $23.6 \mathrm{~g} C O D / L-d a y$ were calculated mean OLRs between replicate experiments.

Standard error bars for those OLRs represent the error between replicate experiments $(\mathrm{n}=2)$. OLRs of 12.7 and 28.8 were tested once, so standard error bars represent the error among duplicate digesters $(\mathrm{n}=2)$.

The highest molar hydrogen yield for food waste-fed digesters occurred at an

OLR of $33.9 \mathrm{~g} \mathrm{COD/L-day} \mathrm{and} \mathrm{was} 0.007 \pm 0.0016 \mathrm{~mol} \mathrm{H}_{2} / \mathrm{mol} \mathrm{COD}$ (mean $\pm \mathrm{SE}$ )

(Figure 18). A molar hydrogen yield of $0.005 \pm 0.0016 \mathrm{~mol} \mathrm{H}_{2} / \mathrm{mol} \mathrm{COD}$ was produced at the second highest OLR of $31.2 \mathrm{~g} \mathrm{COD/L-day.} \mathrm{The} \mathrm{Lowest} \mathrm{OLR,}$ $25.8 \mathrm{~g} \mathrm{COD} / \mathrm{L}-$ day, produced $0.004 \pm 0.0012 \mathrm{~mol} \mathrm{H} / \mathrm{mol}$ COD. 


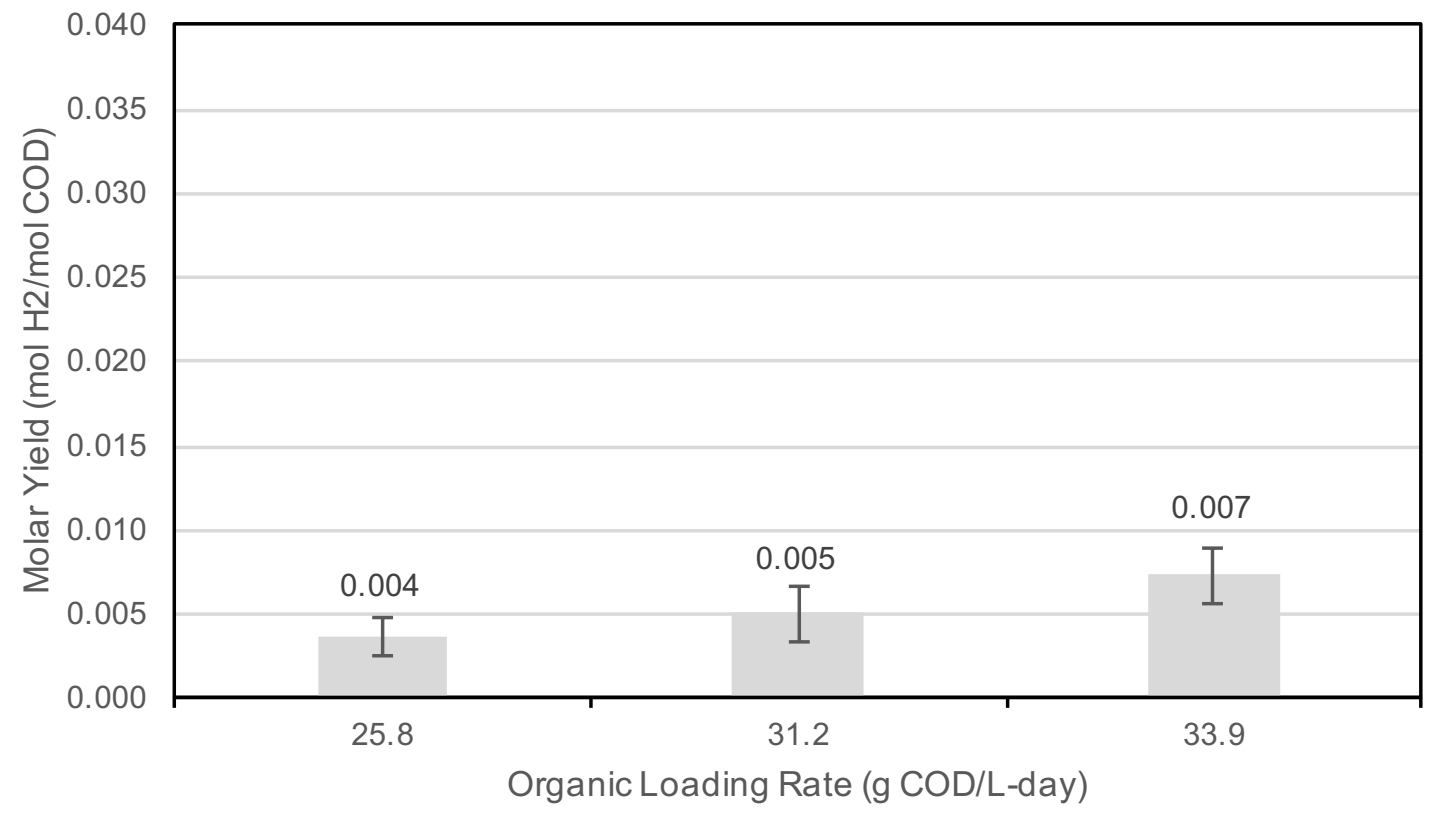

Figure 18. Molar hydrogen yields for food waste-fed digesters at OLRs of 25.8, 31.2, and $33.9 \mathrm{~g}$ $C O D / L$-day. OLR values represent the average OLR over the steady state period. The means of steady-state performance periods by duplicate digesters were used to calculate the standard errors shown $(\mathrm{n}=2)$.

The volumetric hydrogen production for food waste-fed digesters was highest at highest OLR of $33.9 \mathrm{~g} \mathrm{COD/L-day} \mathrm{and} \mathrm{was} 0.177 \pm 0.0373 \mathrm{LH}_{2} / \mathrm{L}_{\text {Reactor-day }}$ (mean $\pm \mathrm{SE}$ ). At an OLR of $31.2 \mathrm{~g} \mathrm{COD/L-day,} 0.117 \pm 0.0314 \mathrm{LH}_{2} / \mathrm{L}_{\text {Reactor-day }}$ was produced. The lowest volumetric hydrogen yield occurred at an OLR of 25.8

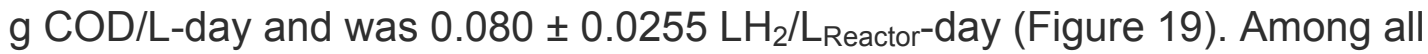
OLRs tested for food waste, the highest OLR, $33.9 \mathrm{~g}$ COD/L-day, produced the most hydrogen. It is likely that volumetric hydrogen production would increase at OLRs higher than $33.9 \mathrm{~g}$ COD/L-day. 


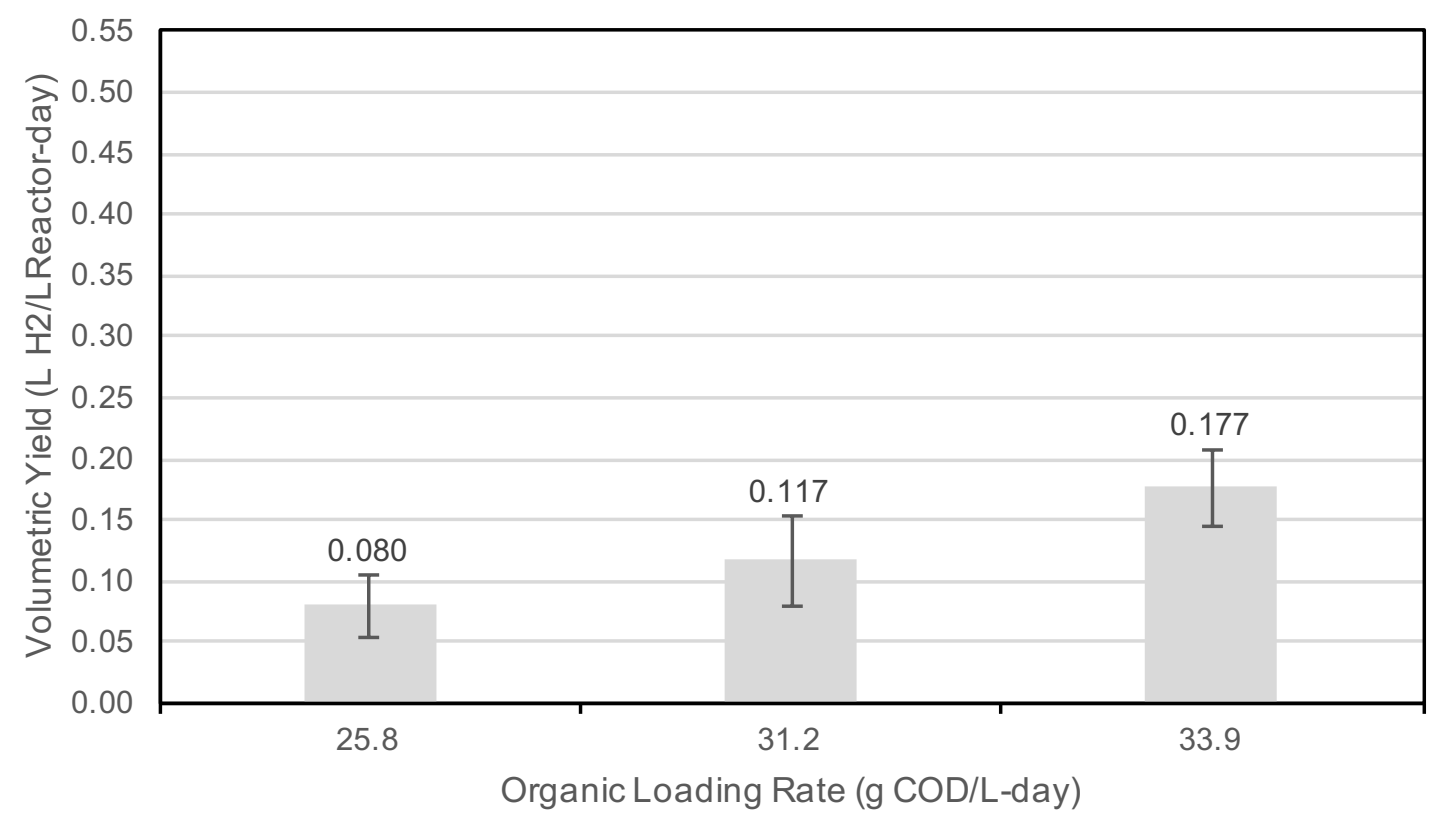

Figure 19. Volumetric hydrogen production for food waste-fed digesters at OLRs of 25.8, 31.2, and $33.9 \mathrm{~g} C O D / L$-day. OLR values represent the average OLR over the steady state period. The means of steady-state performance periods by duplicate digesters were used to calculate the standard errors shown $(\mathrm{n}=2)$.

\subsection{HRT Experiments}

Three HRT experiments were performed to test the effect of variable residence times on hydrogen production. The previously found optimal $\mathrm{pH}$ of 6.5 and OLR of $18 \mathrm{~g} \mathrm{COD/L-day} \mathrm{were} \mathrm{held} \mathrm{constant} \mathrm{amongst} \mathrm{all} \mathrm{glycerol-fed} \mathrm{digesters.} \mathrm{HRTs}$ of $3,6,9,12$, and 18 hours were tested.

HRT Experiment 1 tested HRTs of 6, 12, and 18 hours. The average pH was 6.53 amongst all digesters, while the average alkalinity was $3700 \mathrm{mg} \mathrm{CaCO} / \mathrm{L}$. The mean OLR was $19.7 \pm 1.88 \mathrm{~g}$ COD/L-day and was within one standard deviation of the target optimal OLR of $18 \mathrm{~g} \mathrm{COD/L-day} \mathrm{(mean} \pm$ SD). Steady state conditions were met on Day 6-10 for D1-2, Day 7-11 for D3-4, and Day 1519 for D5-6. Steady-state periods varied for each set of duplicate digesters due 
to the steady-state criteria that said that at least 4 HRTs are to have passed before digesters were considered in steady state.

HRT Experiment 2 examined the HRTs of 3, 6, and 9 hours. The mean pH amongst the digesters was 6.58 , while the mean alkalinity was $3800 \mathrm{mg}$ $\mathrm{CaCO}_{3} / \mathrm{L}$. The mean OLR was $19.6 \pm 1.67 \mathrm{~g} \mathrm{COD} / \mathrm{L}$-day and was within one standard deviation of the target OLR of $18 \mathrm{~g} \mathrm{COD/L-day} \mathrm{(mean} \pm \mathrm{SD}$ ). Steady state periods were met for D1-2 on Day 3-7, Day 4-8 for D3-4, and Days 8-12 for D5-6.

HRT Experiment 3 was a repeat of HRT Experiment 1 and examined HRTs of 6 , 12, and 18 hours. Experiment 3 was repeated to ensure the data was repeatable. The mean $\mathrm{pH}$ was 6.44 , while the mean alkalinity was $3600 \mathrm{mg} \mathrm{CaCO} / \mathrm{L}$. The OLR was within one standard deviation of the target OLR of $18 \mathrm{~g} \mathrm{COD/L-day} \mathrm{and}$ was $19.5 \pm 1.75 \mathrm{~g} \mathrm{COD/L-day} \mathrm{(mean} \pm \mathrm{SD})$.

\subsubsection{COD Balance}

HRT Experiment 1 achieved 104\%, 81\%, and 94\% recovery for digesters operating at HRTs of 6, 12, and 18 hours (Figure 20). At a 6-hour HRT, slightly more COD was recovered in the effluent and gaseous COD than was fed. Influent COD measurements were inaccurate. The effluent and gaseous COD standard error was contained within the error bounds of influent COD, adding to the credibility of the hydrogen yields. The low recovery observed at a 12-hour HRT was a result of a leaking digester that was noted during the experiment 


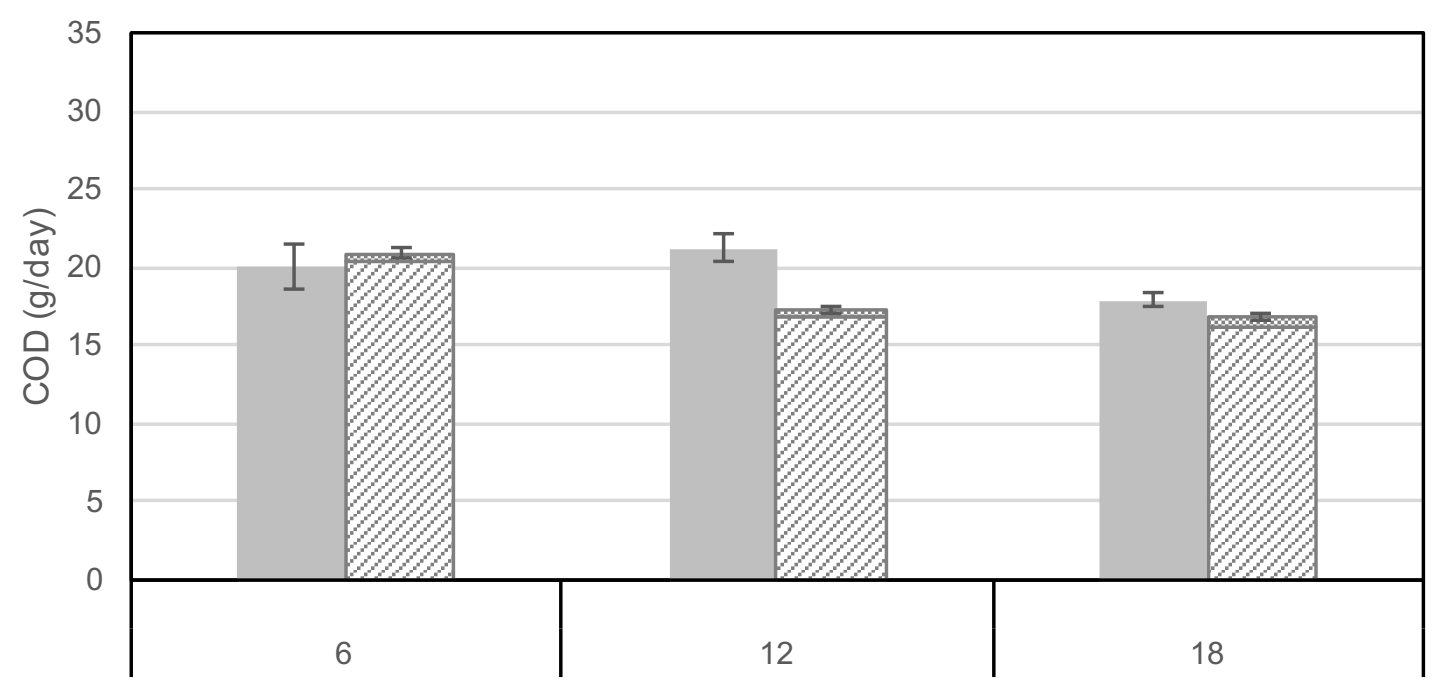

Hydraulic Residence Time (hr)

Figure 20. COD balance for HRT Experiment 1 with digesters operated at HRTs of 6, 12, and 18 hours. The means of steady-state performance periods by duplicate digesters were used to calculate the standard errors $(\mathrm{n}=2)$ shown on the digester effluent and biogas bars. The influent standard errors were based on measurements during the steady state performance period $(\mathrm{n}=$ 5).

HRT Experiment 2 recovered 97\%, 79\%, and $81 \%$ of influent feed COD (Figure 21). Hydrogen yields produced by digesters operating at a 3-hour HRT were accepted due to the high recovery; however, leaking digesters were noted at the 6- and 9-hour HRTs, confirmed by the lower COD recoveries and indicating lower confidence in their hydrogen yield values. 
-Influent COD $\quad$ Effluent COD $\quad$ Gaseous COD

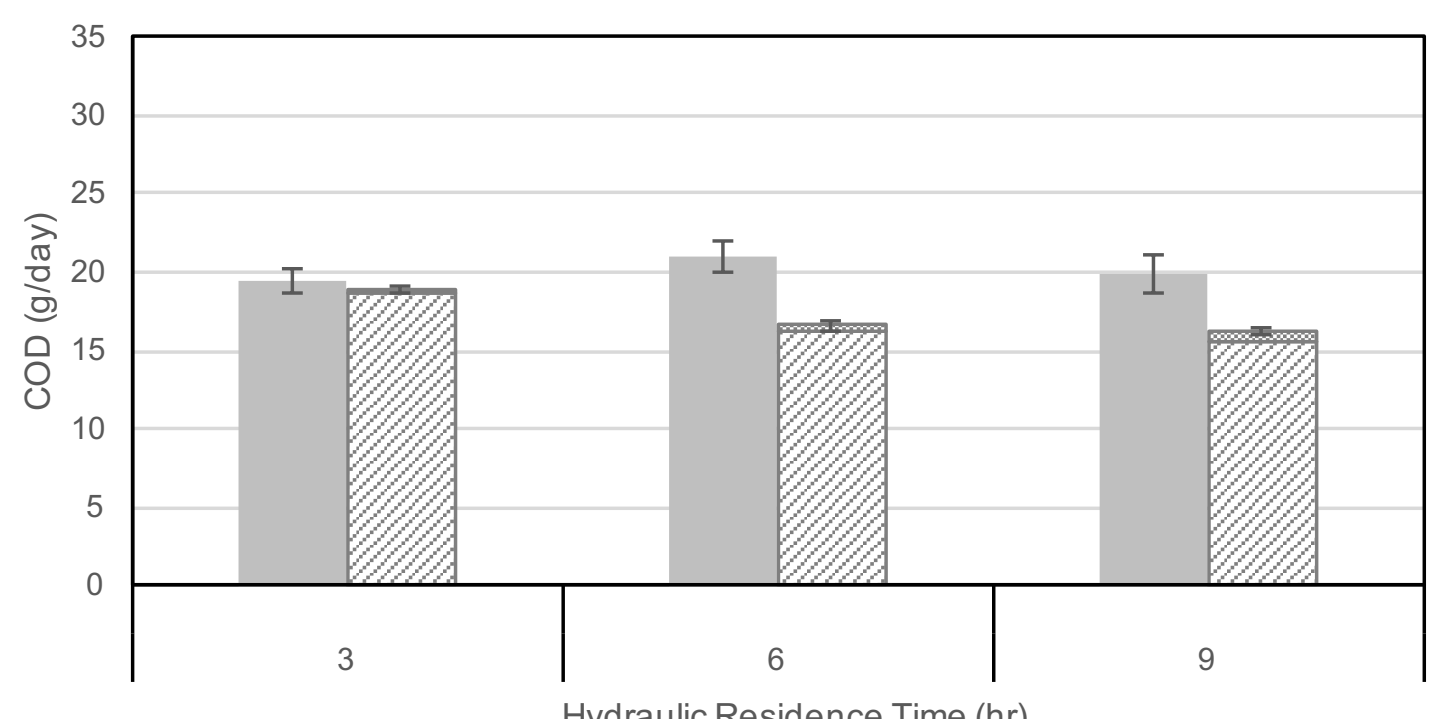

Hydraulic Residence Time (hr)

Figure 21. COD balance for digesters operated at HRTs of 3, 6, and 9 hours. The means of steady-state performance periods by duplicate digesters were used to calculate the standard errors $(\mathrm{n}=2)$ shown on the digester effluent and biogas bars. The influent standard errors were based on measurements during the steady state performance period $(\mathrm{n}=5)$.

Recoveries of $97 \%, 93 \%$, and $86 \%$ were achieved for digesters in the HRT

Experiment 3 operating at HRTs of 6, 12, and 18 hours (Figure 22). 


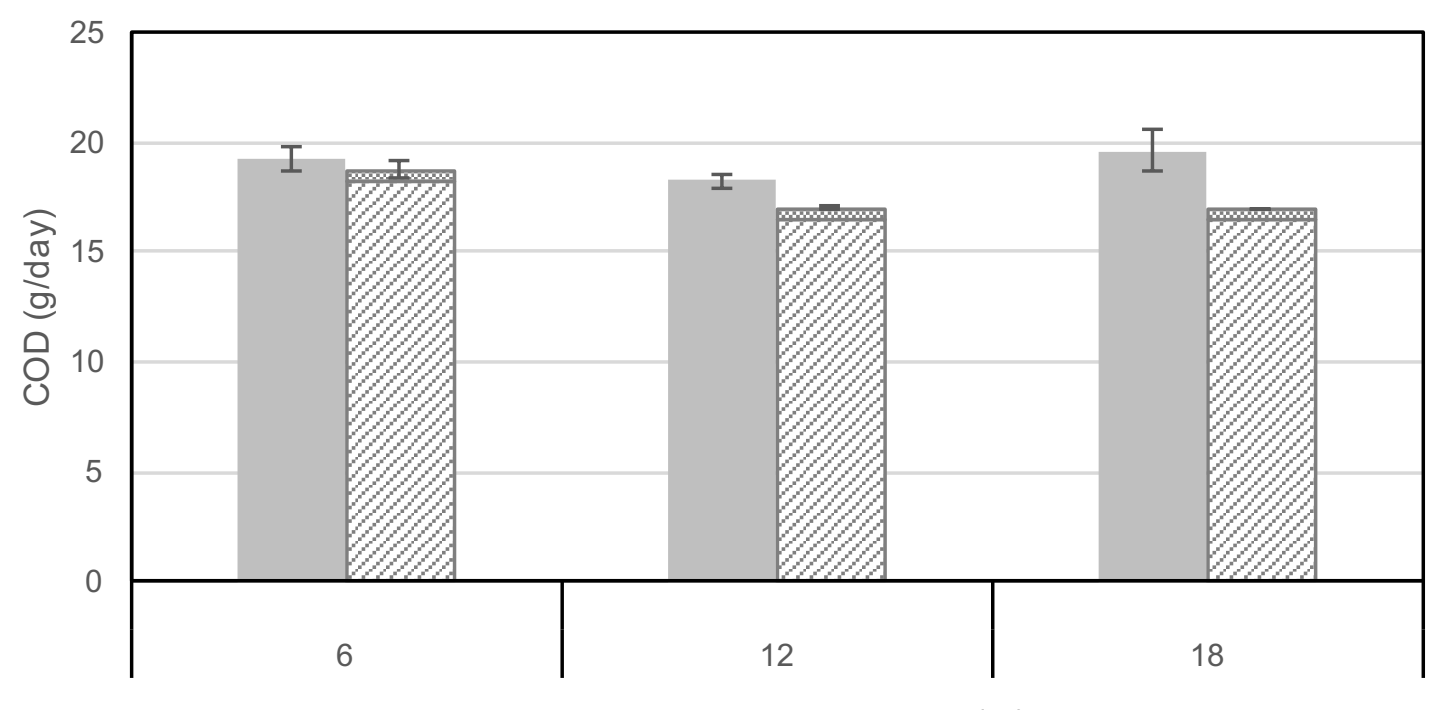

Hydraulic Residence Time (hr)

Figure 22. COD balance for digesters operated at HRTs of 6, 12, and 18 hours. The means of steady-state performance periods by duplicate digesters were used to calculate the standard errors $(\mathrm{n}=2)$ shown on the digester effluent and biogas bars. The influent standard errors were based on measurements during the steady state performance period $(\mathrm{n}=5)$.

\subsubsection{Molar Hydrogen Yields and Volumetric Hydrogen Production}

Among the three HRT experiments run, HRTs of 6,12 , and 18 hours were repeated. HRTs of 3 and 9 hours were tested once and represent the average molar hydrogen yield and volumetric hydrogen production between digester duplicates.

The highest molar yield was observed at HRTs of 6 and 12 hours. At an HRT of 6 hours, a molar hydrogen yield of $0.010 \pm 0.0032 \mathrm{~mol} \mathrm{H}_{2} / \mathrm{mol}$ COD was observed, while at an HRT of 12 hours, a molar yield of $0.010 \pm 0.0000 \mathrm{~mol} \mathrm{H}_{2} / \mathrm{mol} \mathrm{COD}$ was observed (mean $\pm \mathrm{SE}$ ) (Figure 23). A molar yield of $0.009 \pm 0.0004 \mathrm{~mol}$ $\mathrm{H}_{2} / \mathrm{mol}$ COD was obtained at an HRT of 12 hours, and $0.008 \pm 0.0014 \mathrm{~mol}$ 
$\mathrm{H}_{2} / \mathrm{mol} \mathrm{COD}$ at 18 hours. The lowest molar hydrogen yield was observed at the shortest HRT of 3 hours and was $0.002 \pm 0.0005 \mathrm{~mol} \mathrm{H}_{2} / \mathrm{mol}$ COD.

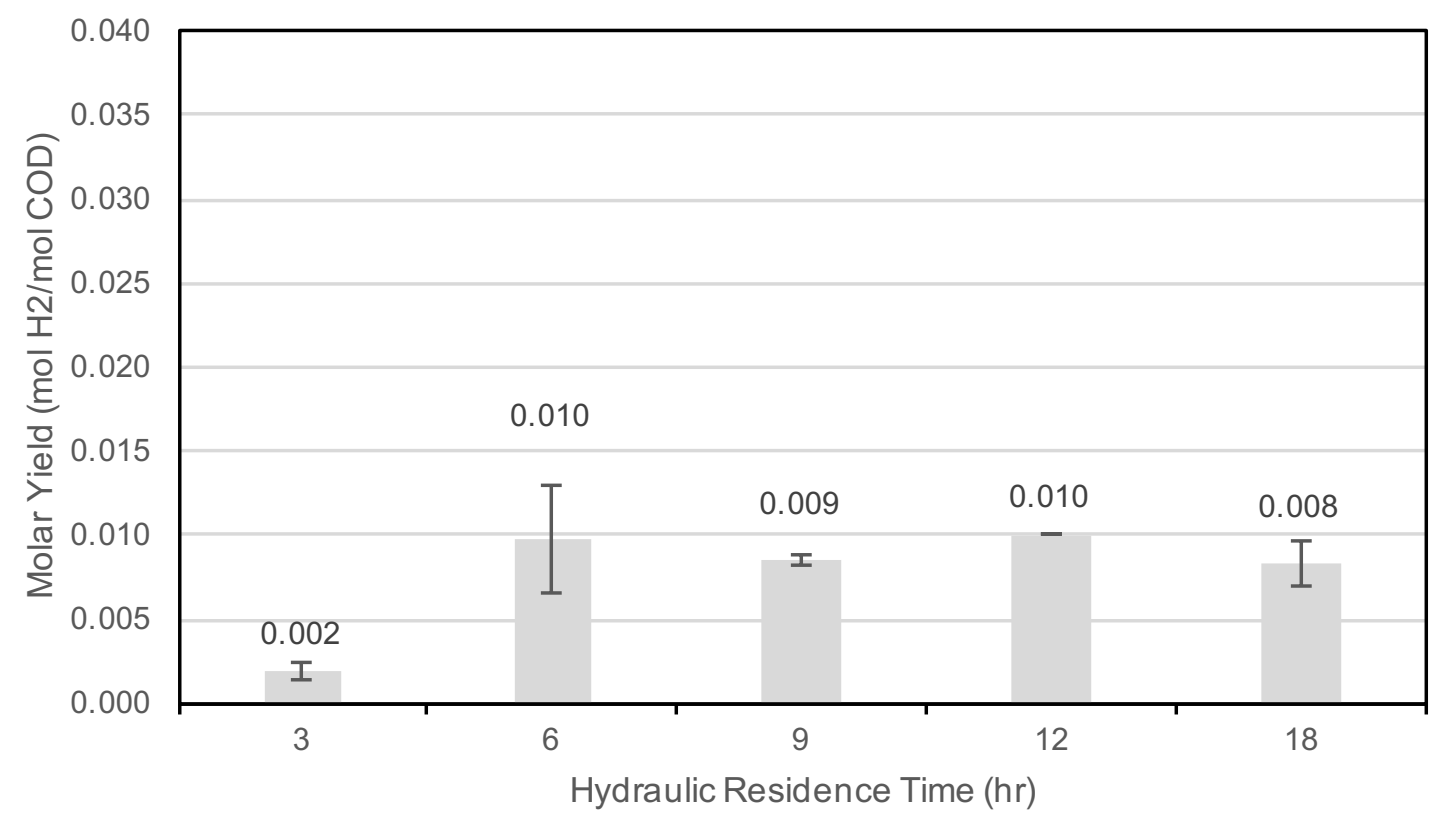

Figure 23. Molar yields for HRTs of 3, 6, 9, 12, and 18 hours. Standard error bars for HRTs of 6 , 12 , and 18 hours represent the standard error between replicate experiments $(\mathrm{n}=2)$. Standard error bars for 3- and 9-hour HRTs represent the error between duplicate digesters ( $\mathrm{n}=2)$.

The volumetric hydrogen production was highest at an HRT of 12 hours and was $0.148 \pm 0.0107 \mathrm{LH}_{2} / \mathrm{L}_{\text {Reactor-day }}$ (mean $\pm \mathrm{SE}$ ). A similar yield of $0.145 \pm 0.0465$

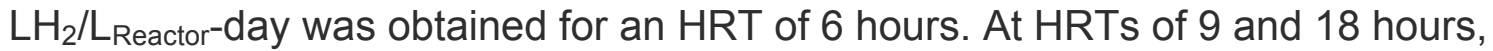
volumetric hydrogen production of $0.127 \pm 0.0041 \mathrm{LH}_{2} / \mathrm{L}_{\text {Reactor-day }}$ and $0.105 \pm$ $0.0012 \mathrm{LH}_{2} / \mathrm{L}_{\text {Reactor-day }}$ were observed. The shortest HRT, 3 hours, produced the lowest volumetric hydrogen production of $0.027 \pm 0.0072 \mathrm{LH}_{2} / \mathrm{L}_{\text {Reactor-day }}$ (Figure 24). Though HRTs of 6 and 12 hours produced similar molar hydrogen yields and volumetric hydrogen production, the standard error was considerably less at a 12 hour HRT. The lower standard error provided for a greater degree of confidence in an HRT of 12 hours, so it was used for subsequent experiments. 


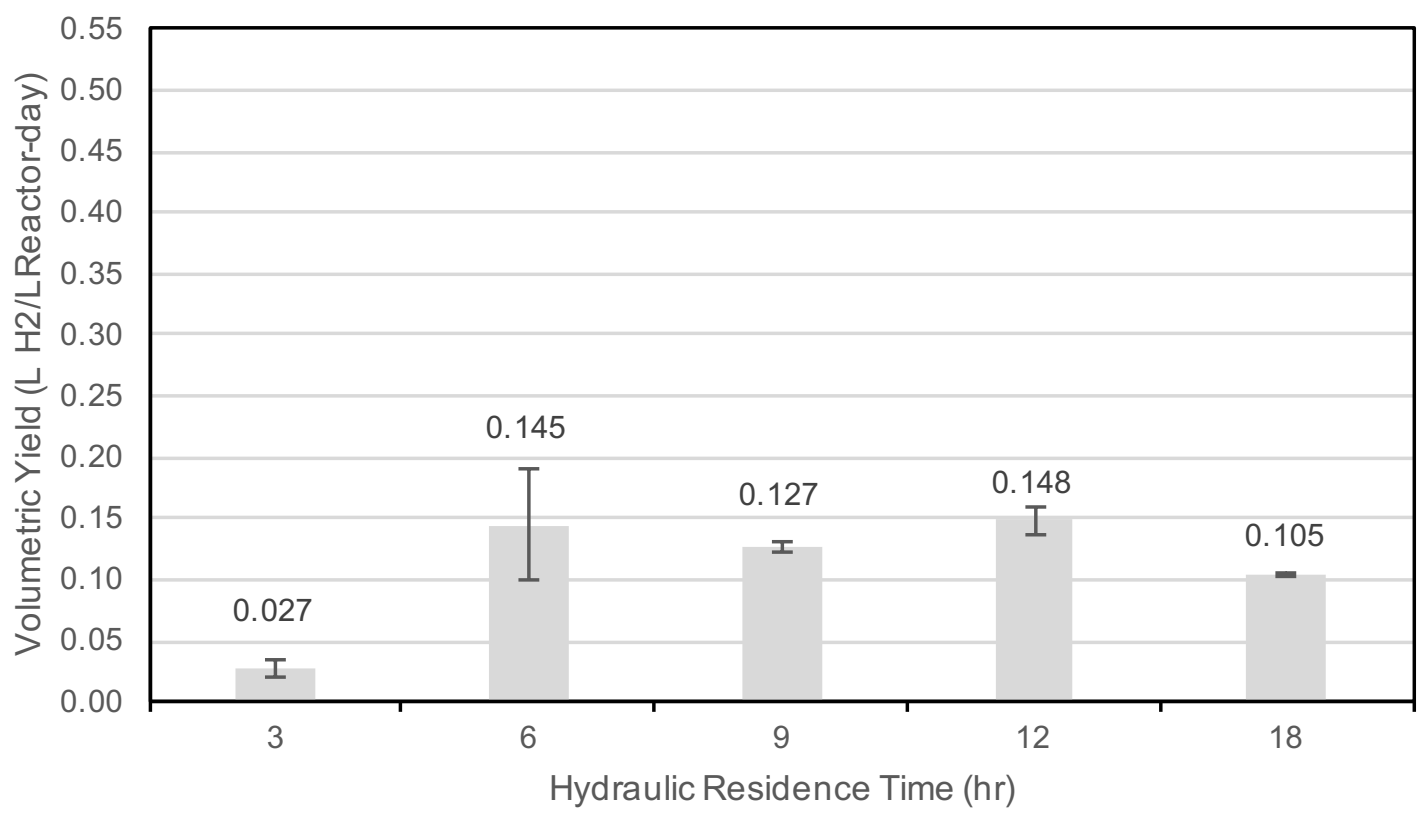

Figure 24. Volumetric hydrogen production for HRTs of 3, 6, 9, 12, and 18 hours. Standard error bars for HRTs of 6, 12, and 18 hours represent the standard error between replicate experiments $(n=2)$. Standard error bars for 3- and 9-hour HRTs represent the error between duplicate digesters $(n=2)$.

\subsection{Sparging Experiments}

Previous research found that sparging glucose-fed digesters with nitrogen gas nearly doubled the molar hydrogen yields and volumetric hydrogen production (Olivas, 2015). Sparging experiments were performed for both glycerol and food waste substrates at varying sparging rates to examine their effect on hydrogen production.

The glycerol sparging experiment was operated at a target $\mathrm{pH}$ of 6.51 , OLR of $18.2 \mathrm{~g} \mathrm{COD/L-day,} \mathrm{and} \mathrm{an} \mathrm{HRT} \mathrm{of} 12$ hours-conditions found to be optimal for hydrogen production in previous experiments. D1-2 were sparged with high purity nitrogen gas, D3-4 were unsparged and used as a control, and D5-6 were sparged with biogas $\left(70 \% \mathrm{CH}_{4}, 30 \% \mathrm{CO}_{2}\right)$ from four separate on-site anaerobic 
digesters. The sparging rates were dependent on the gas production rate from these digesters. However, sparging rates were low enough to ensure they could be sparged at a constant rate. Sparged digesters were always operated at the same sparging rate, regardless of gas type; however, the sparging rates were occasionally changed to observe any changes in hydrogen production. Sparging rates tested were $1.2,2,2.5,3$, and $3.2 \mathrm{~mL} / \mathrm{min}$.

The glycerol-fed digesters operated at a mean $\mathrm{pH}$ and alkalinity of 6.46 and 3500 $\mathrm{mg} \mathrm{CaCO} / \mathrm{L}$. The mean OLR during the experiment was $17.8 \pm 1.324 \mathrm{~g} \mathrm{COD} / \mathrm{L}-$ day (mean $\pm S D$ ) and was within one standard deviation of the target OLR of 18.2 g COD/L-day. Steady state conditions were achieved on Day 13-17 for D1-2 and D5-6, and Day 23-27 for D3-4. The steady state performance criteria were met much later for D3-4 because gas production was steadily increasing until Day 23.

The food waste sparging experiment was operated at the target OLR of $33.9 \mathrm{~g}$ COD/L-day. $\mathrm{pH}$ and HRT optimization experiments were not run for digesters fed food waste, so values from glycerol-fed digesters were used $(\mathrm{pH} 6.51$, HRT 12 hours). Digesters 1-2 and 5-6 were sparged with high purity nitrogen gas, while D3-4 were unsparged and used as a control. Sparging rates tested were 0.5 L/hr for D1-2, and 1.0 L/hr for D5-6. The mean $\mathrm{pH}$ and alkalinity was 6.40 and $4600 \mathrm{mg} \mathrm{CaCO} / \mathrm{L}$. The mean OLR was $32.9 \pm 3.4944 \mathrm{~g} \mathrm{COD/L-day} \mathrm{(mean} \pm$ SD). All digesters maintained steady state conditions for Days 7-11 of the experiment. 


\subsubsection{COD Balance}

Glycerol-fed digesters sparged with nitrogen gas achieved an influent COD recovery of $95 \%$, while the unsparged digesters achieved an influent COD recovery of $96 \%$. Biogas-sparged digesters achieved a $92 \%$ recovery. Recovery for biogas-sparged digesters was high because the digesters were being sparged with biogas consisting of $70 \%$ methane which contributes to the gaseous COD (Figure 25).

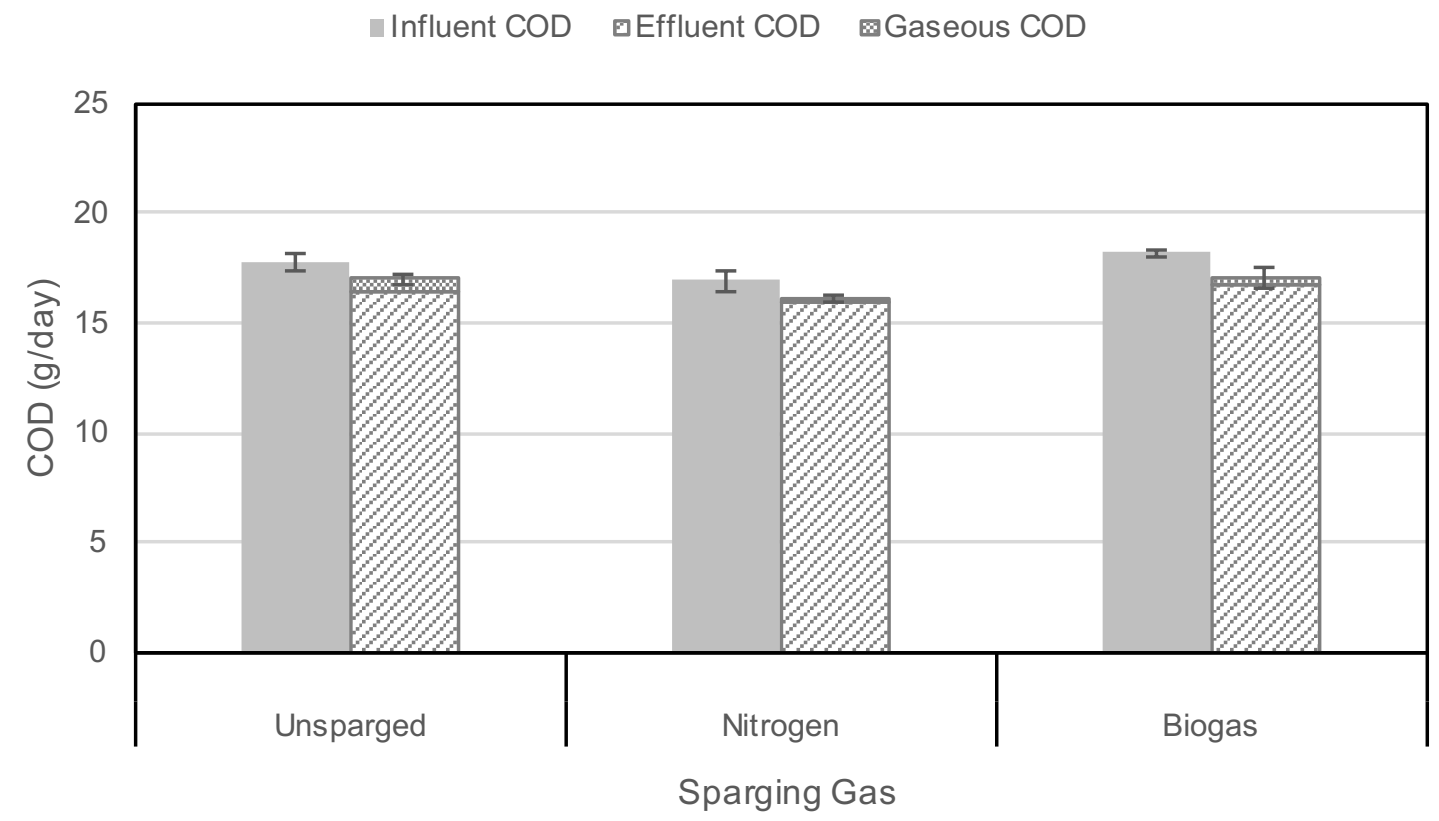

Figure 25. COD balance for sparged and unsparged digesters. Digesters were operated at a mean OLR of $17.8 \mathrm{~g} C O D / L$-day, pH of 6.46, and HRT of 12 hours. The means of steady-state performance periods by duplicate digesters were used to calculate the standard errors $(n=2)$ shown on the digester effluent and biogas bars. The influent standard errors were based on measurements during the steady state performance period $(n=5)$

Food waste-fed digesters sparged at a rate of $0.5 \mathrm{~L} \mathrm{~N} / \mathrm{hr}$ recovered $86 \%$ of the influent COD while digesters sparged at a rate of $1.0 \mathrm{~L} \mathrm{~N} / \mathrm{hr}$ recovered $102 \%$ of influent COD feed. The standard error in effluent and gaseous COD between digester duplicates at $1.0 \mathrm{~L} \mathrm{~N} / \mathrm{hr}$ was within the standard error of influent $\mathrm{COD}$ 
measurements, rather the inaccurate recovery is attributed to inaccurate influent COD measurements. The unsparged digesters recovered $93 \%$ of the influent COD feed. These recoveries indicate confidence in the hydrogen yields because it shows that the digesters were not leaking, and mass was not produced (Figure 26).

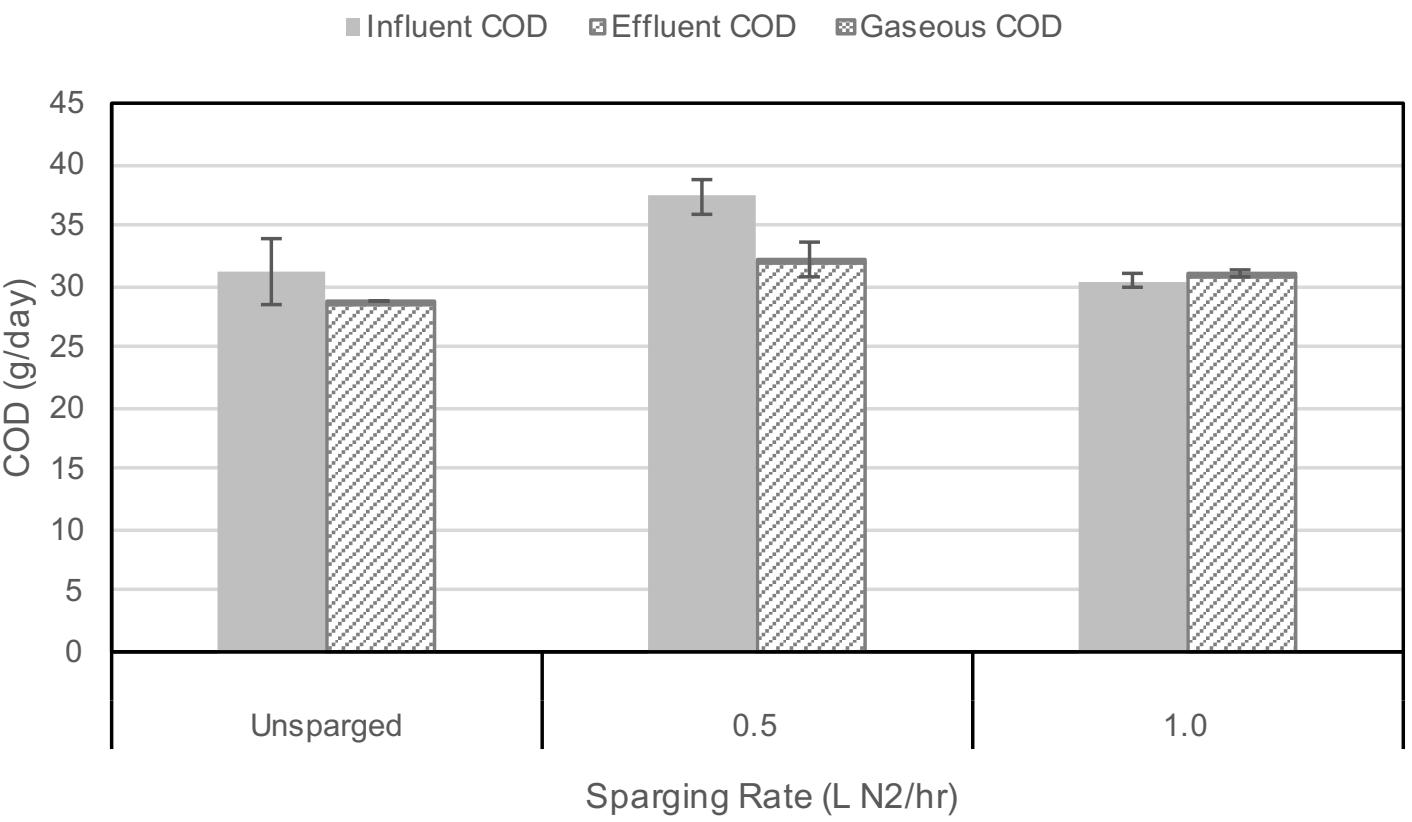

Figure 26. COD balance for food waste-fed digesters that were sparged or unsparged. Digesters were operated at a mean OLR of $32.9 \mathrm{~g} C O D / L$-day, $\mathrm{pH}$ of 6.40, and HRT of 12 hours. The means of steady-state performance periods by duplicate digesters were used to calculate the standard errors $(n=2)$ shown on the digester effluent and biogas bars. The influent standard errors were based on measurements during the steady state performance period $(n=5)$

\subsubsection{Molar Hydrogen Yields and Volumetric Hydrogen Production}

Molar hydrogen yields and volumetric hydrogen production were calculated for glycerol-fed digesters during their steady state period, and for each sparging rate tested (Figure 27). Nitrogen and biogas sparged digesters, sparged at a rate of $3.2 \mathrm{~mL} / \mathrm{min}$, produced nearly the same molar yield of hydrogen, with nitrogensparged digesters producing $0.020 \pm 0.0005 \mathrm{~mol} \mathrm{H}_{2} / \mathrm{mol} \mathrm{COD}$, and biogas- 
sparged digesters producing $0.020 \pm 0.0029 \mathrm{~mol} \mathrm{H}_{2} / \mathrm{mol} \mathrm{COD}$ (mean $\pm \mathrm{SE}$ ). The unsparged digesters produced $0.012 \pm 0.0016 \mathrm{~mol} \mathrm{H}_{2} / \mathrm{mol} \mathrm{COD}$. At steady state conditions, digesters that were sparged converted $40 \%$ more of the COD fed to them into hydrogen gas than the unsparged digesters. Similar molar hydrogen yields and volumetric hydrogen production for nitrogen gas and biogas was a surprising result.

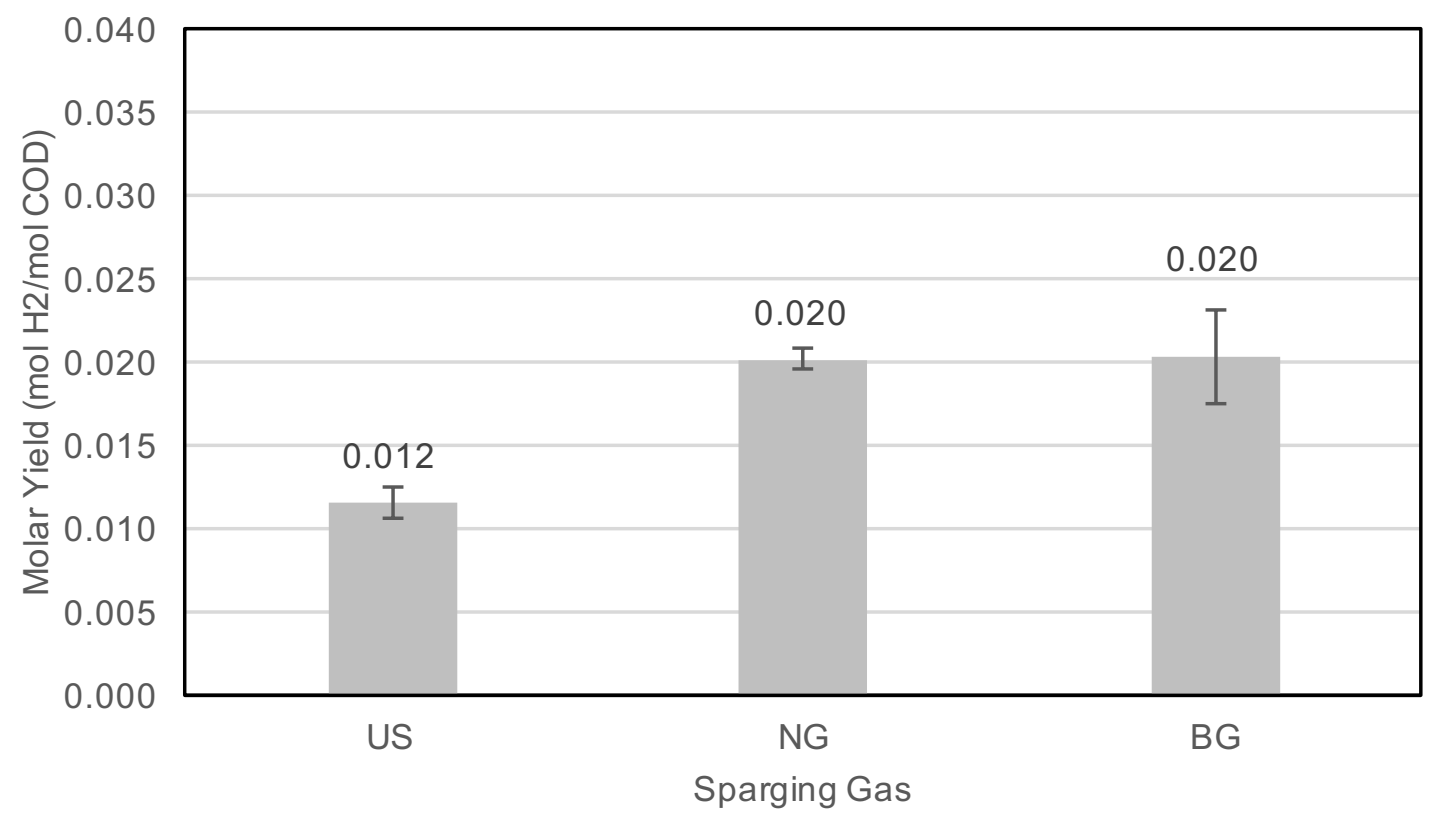

Figure 27. Molar yields for unsparged (US), nitrogen sparged (NG), and biogas sparged (BG) digesters during the steady state period. Digesters operated at a pH of 6.46, HRT of 12 hours, and an OLR of $17.8 \mathrm{~g} C O D / L$-day. The sparging rate for NG and BG was $3.2 \mathrm{~mL} / \mathrm{min}$. The means of steady-state performance periods by duplicate digesters were used to calculate the standard errors shown $(\mathrm{n}=2)$.

Volumetric hydrogen production for the glycerol-fed digesters at steady state were highest when sparged with biogas and nitrogen gas. Sparging rates for the steady state period were $3.2 \mathrm{~mL} / \mathrm{min}$. Biogas-sparged digesters produced 0.281

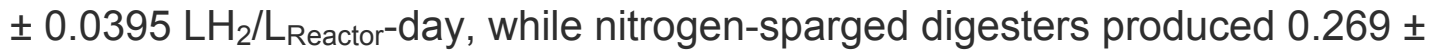
$0.0091 \mathrm{LH}_{2} / \mathrm{L}_{\text {Reactor-day }}$ (mean $\pm \mathrm{SE}$ ). Unsparged digesters produced $0.156 \pm$ 
$0.0210 \mathrm{LH}_{2} / \mathrm{L}_{\text {Reactor-day. }}$ On average, sparged digesters produced $44 \%$ more hydrogen gas than the unsparged digesters (Figure 28).

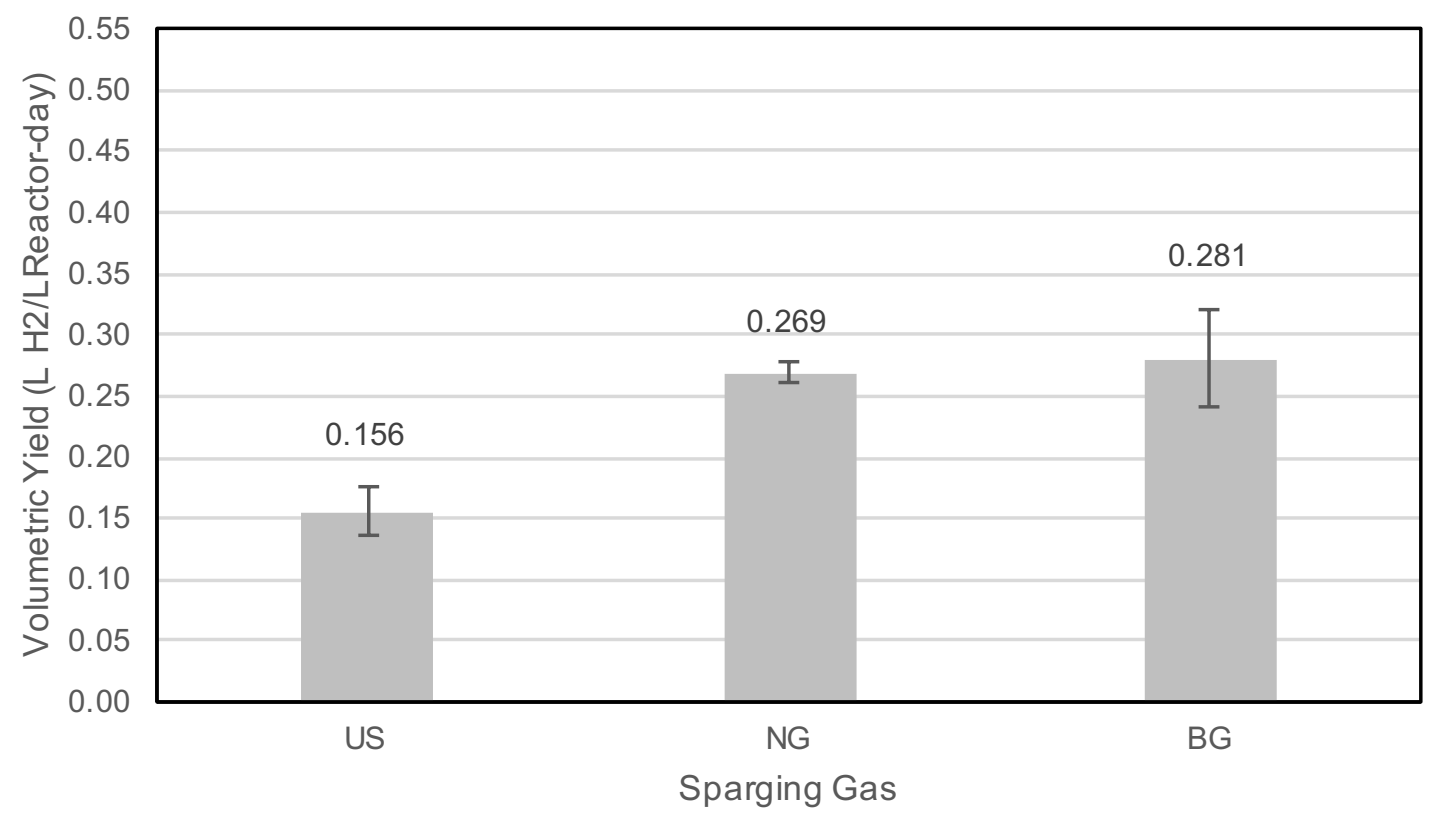

Figure 28. Volumetric hydrogen production for unsparged (US), nitrogen sparged (NG), and biogas sparged (BG) digesters during the steady state period. The sparging rate for NG and BG was $3.2 \mathrm{~mL} / \mathrm{min}$. Digesters operated at a pH of 6.46, HRT of 12 hours, and an OLR of $17.8 \mathrm{~g}$ $C O D / L$-day. The means of steady-state performance periods by duplicate digesters were used to calculate the standard errors shown $(\mathrm{n}=2)$.

Molar hydrogen yields for glycerol-fed digesters were calculated at each sparging rate and compared to the unsparged digester at steady state (Figure 29). The highest molar yield occurred when both nitrogen and biogas-sparged digesters were sparged at a rate of $3.2 \mathrm{~mL} / \mathrm{min}$. At this sparging rate, nitrogen-sparged digesters produced $0.020 \pm 0.0005 \mathrm{~mol} \mathrm{H}_{2} / \mathrm{mol} \mathrm{COD}$ (mean $\pm \mathrm{SE}$ ), and biogassparged digesters produced $0.020 \pm 0.0029 \mathrm{~mol} \mathrm{H}_{2} / \mathrm{mol} \mathrm{COD}$. The conversion of COD introduced to hydrogen gas increased with increasing sparging until reaching a sparging rate of $2.5 \mathrm{~mL} / \mathrm{min}$. At this sparging rate the molar yields began to stabilize, despite the increasing sparging rates. 


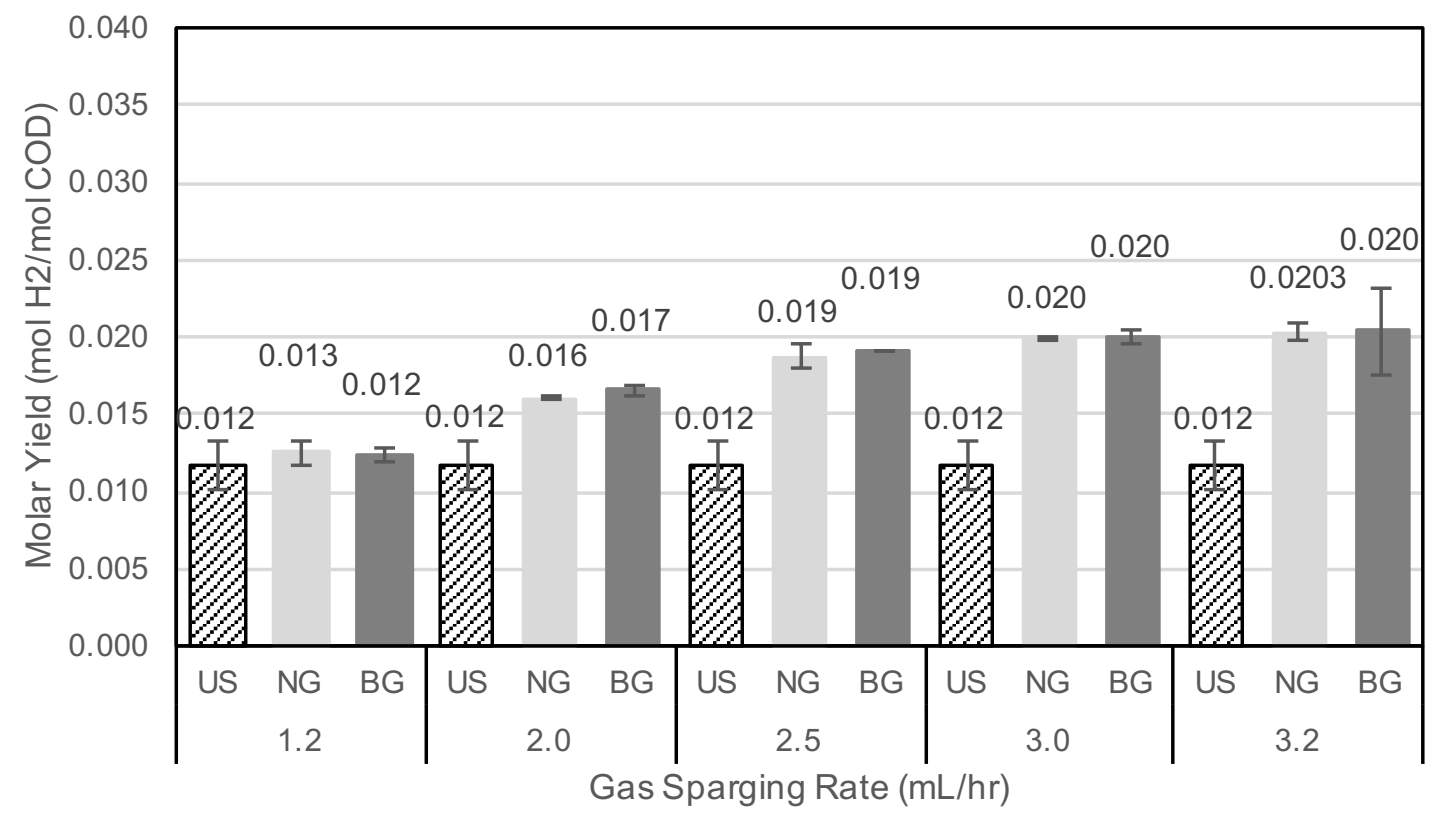

Figure 29. Molar hydrogen yields for unsparged (US), nitrogen sparged (NG), and biogas sparged (BG) digesters at various sparging rates. Digesters operated at a pH of 6.46, HRT of 12 hours, and an OLR of $17.8 \mathrm{~g}$ COD/L-day. The means of steady-state performance periods by duplicate digesters were used to calculate the standard errors shown $(\mathrm{n}=2)$. The leftmost bar in each set of sparging rates represents the steady state molar hydrogen yield of an unsparged digester running under the same conditions.

Figures 30 and 31 depict the mean molar hydrogen yields at each flow rate for the sparging gasses used. Molar hydrogen yield data for both nitrogen and biogas sparging were consistent with a linear fit. 


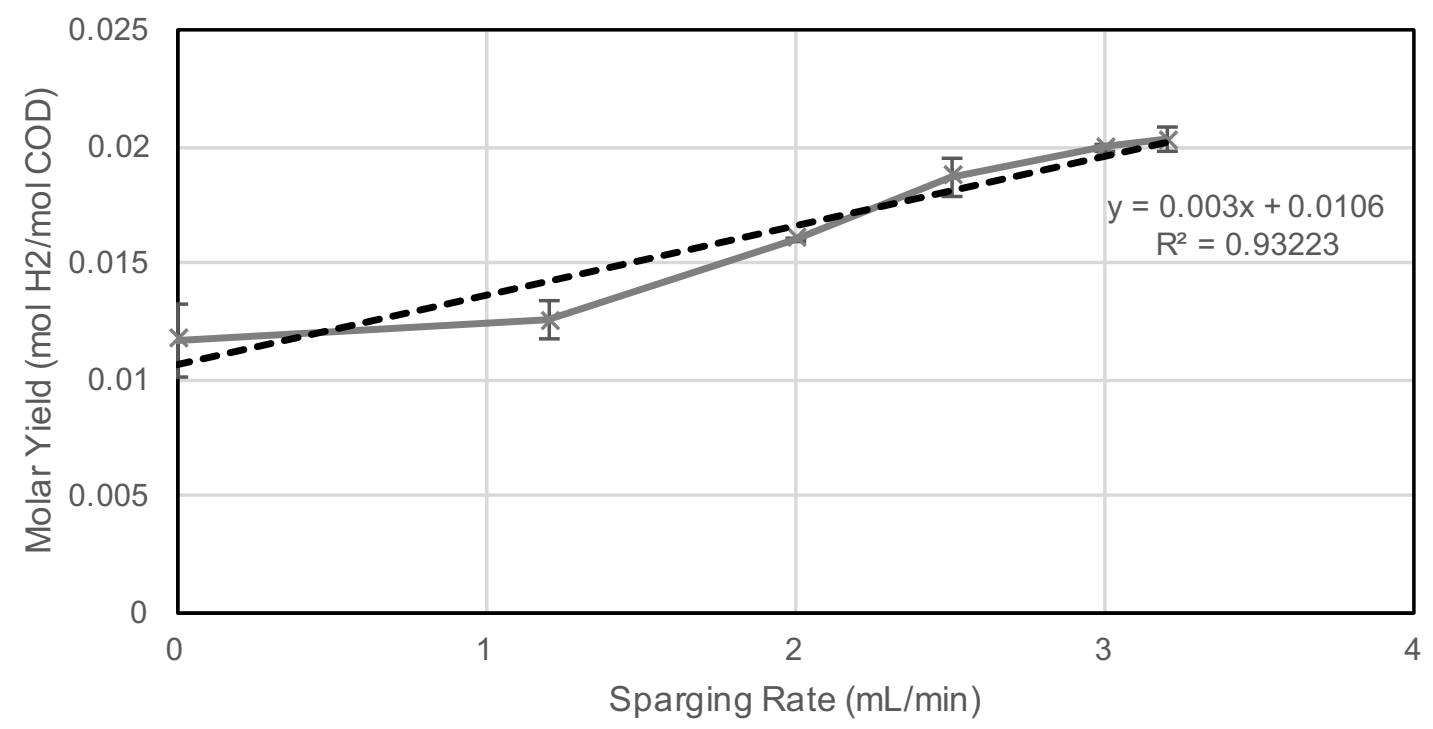

$\because \mathrm{NG}$

Figure 30. Molar hydrogen yields for digesters sparged with nitrogen gas (NG). The linear fit produced an $R^{2}$ value of 0.93 , and error bars depict the standard error produced between duplicate digesters $(n=2)$.

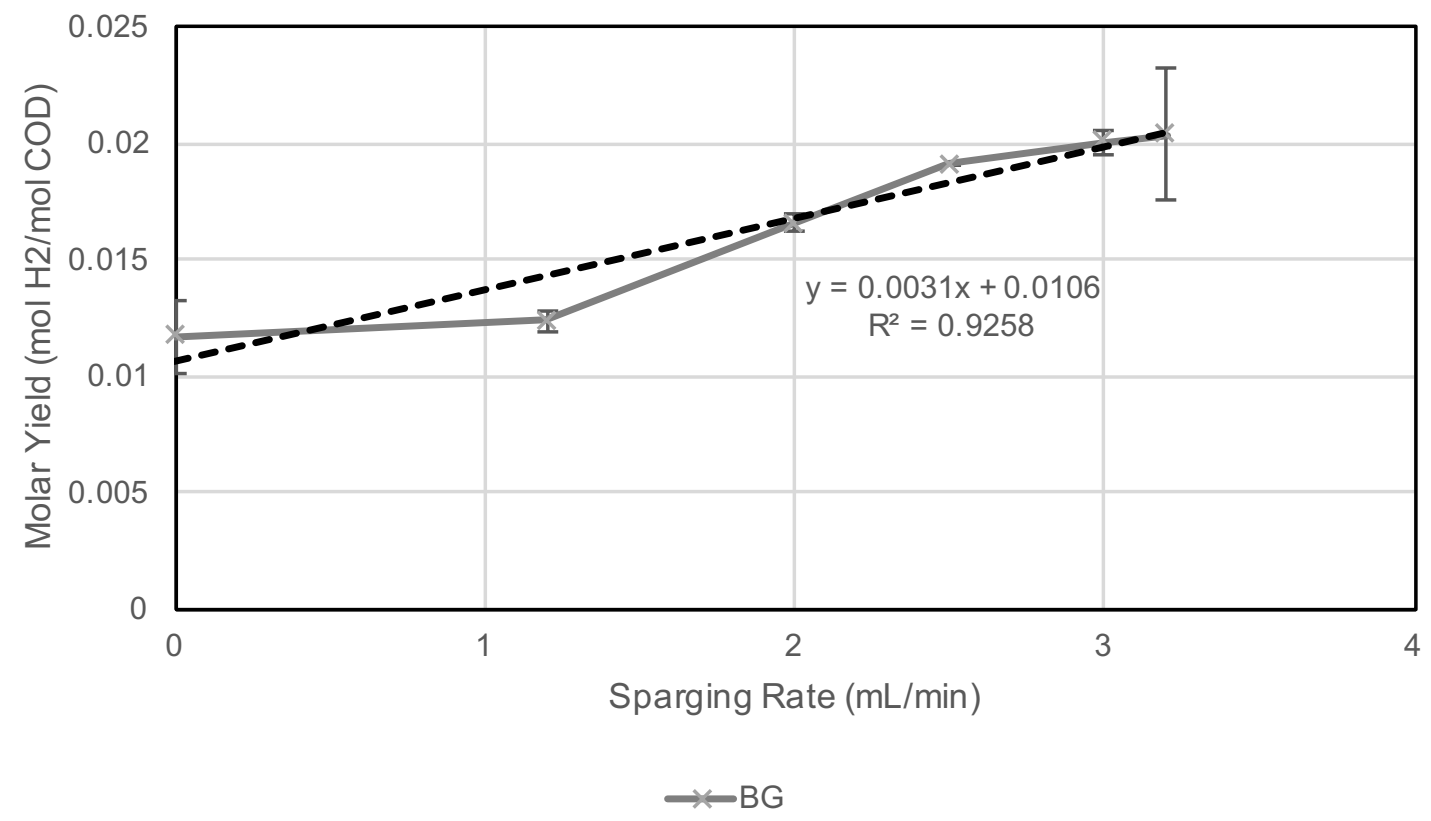

Figure 31. Molar hydrogen yields for digesters sparged with biogas (BG). The linear fit produced an $R^{2}$ value of 0.95 , and error bars depict the standard error produced between duplicate digesters $(n=2)$. 
Volumetric hydrogen production was highest at the flow rate of $3.2 \mathrm{~mL} / \mathrm{min}$.

Volumetric hydrogen production of $0.281 \pm 0.0395 \mathrm{LH}_{2} / \mathrm{L}_{\text {Reactor-day were }}$

observed for biogas-sparged digesters, and $0.269 \pm 0.0091 \mathrm{LH}_{2} / \mathrm{L}_{\text {Reactor-day was }}$

produced by nitrogen-sparged digesters (mean $\pm \mathrm{SE}$ ). Hydrogen production

increased with increasing sparging rates for both nitrogen and biogas-sparged

digesters. Unlike the trend seen for molar yields, the volumetric hydrogen

production does not stabilize above the sparging rate of $2.5 \mathrm{~mL} / \mathrm{min}$ (Figure 32).

Yields may increase at sparging rates higher than $3.2 \mathrm{~mL} / \mathrm{min}$.

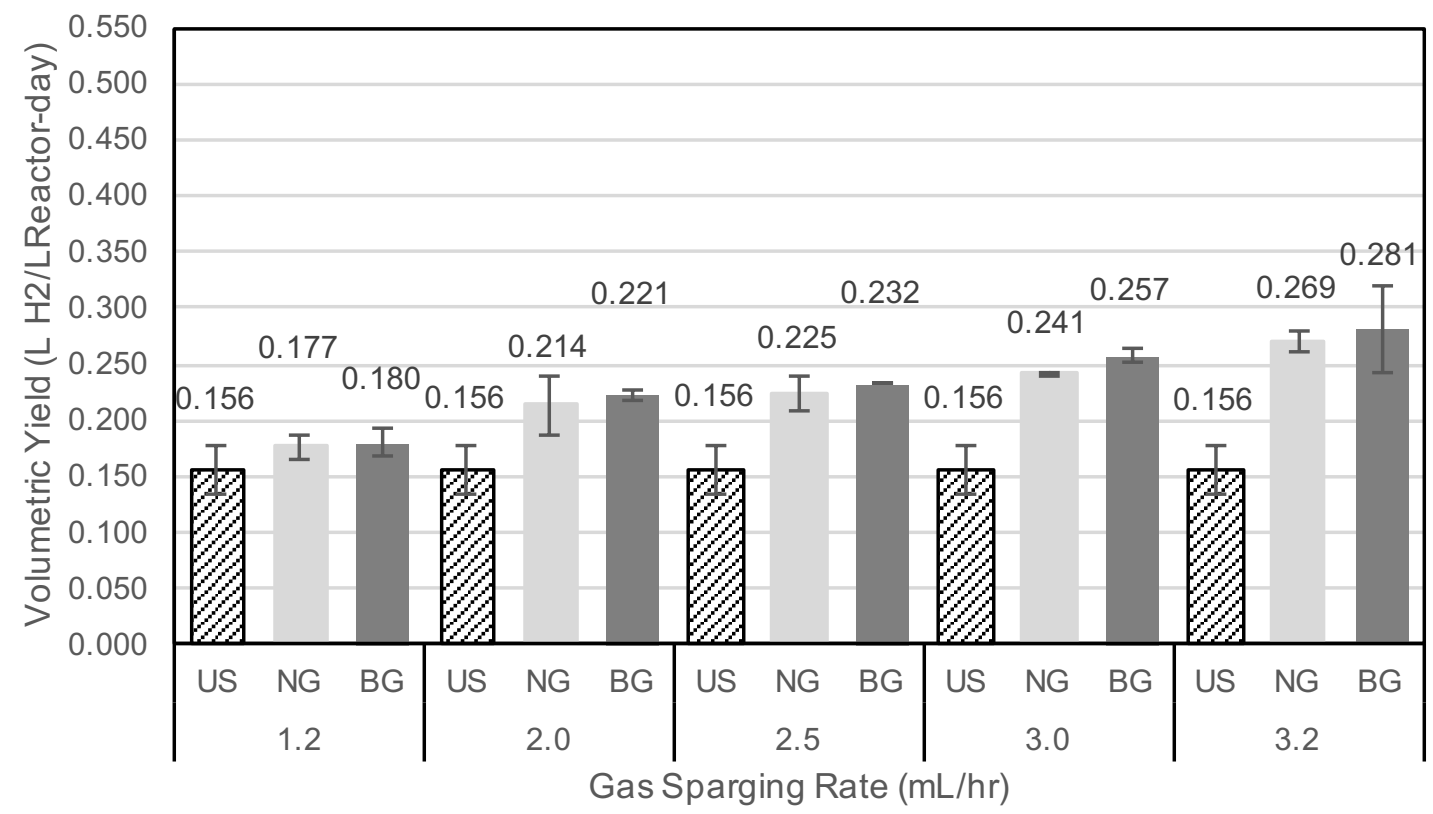

Figure 32. Volumetric hydrogen production for unsparged (US), nitrogen sparged (NG), and biogas sparged $(B G)$ digesters at varying sparging rates. Digesters operated at a $\mathrm{pH}$ of 6.46, HRT of 12 hours, and an OLR of $17.8 \mathrm{~g} C O D / L$-day. The means of steady-state performance periods by duplicate digesters were used to calculate the standard errors shown $(\mathrm{n}=2)$. The leftmost bar in each set of sparging rates represents the steady state volumetric hydrogen production of an unsparged digester running under the same conditions.

Figures 33 and 34 depict the mean volumetric hydrogen production at each flow rate and gas tested. Volumetric hydrogen production data for both nitrogen and 
biogas sparging were consistent with a linear fit, resulting in $R^{2}$ values of 0.94 and 0.96 respectively.

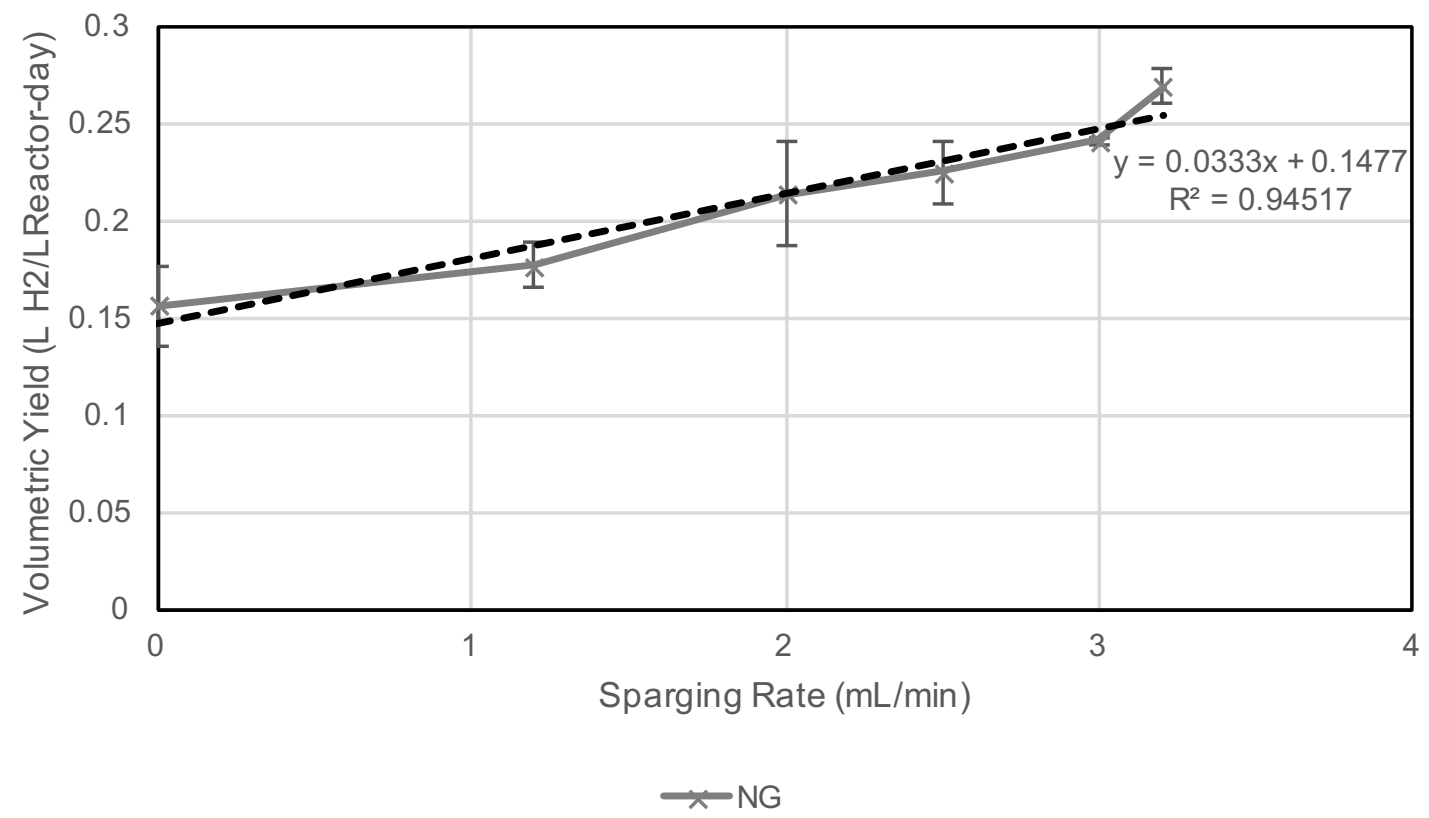

Figure 33. Volumetric hydrogen production for digesters sparged with nitrogen gas (NG). The linear fit produced an $R^{2}$ value of 0.94 , and the means of steady-state performance periods by duplicate digesters were used to calculate the standard errors shown $(n=2)$. 


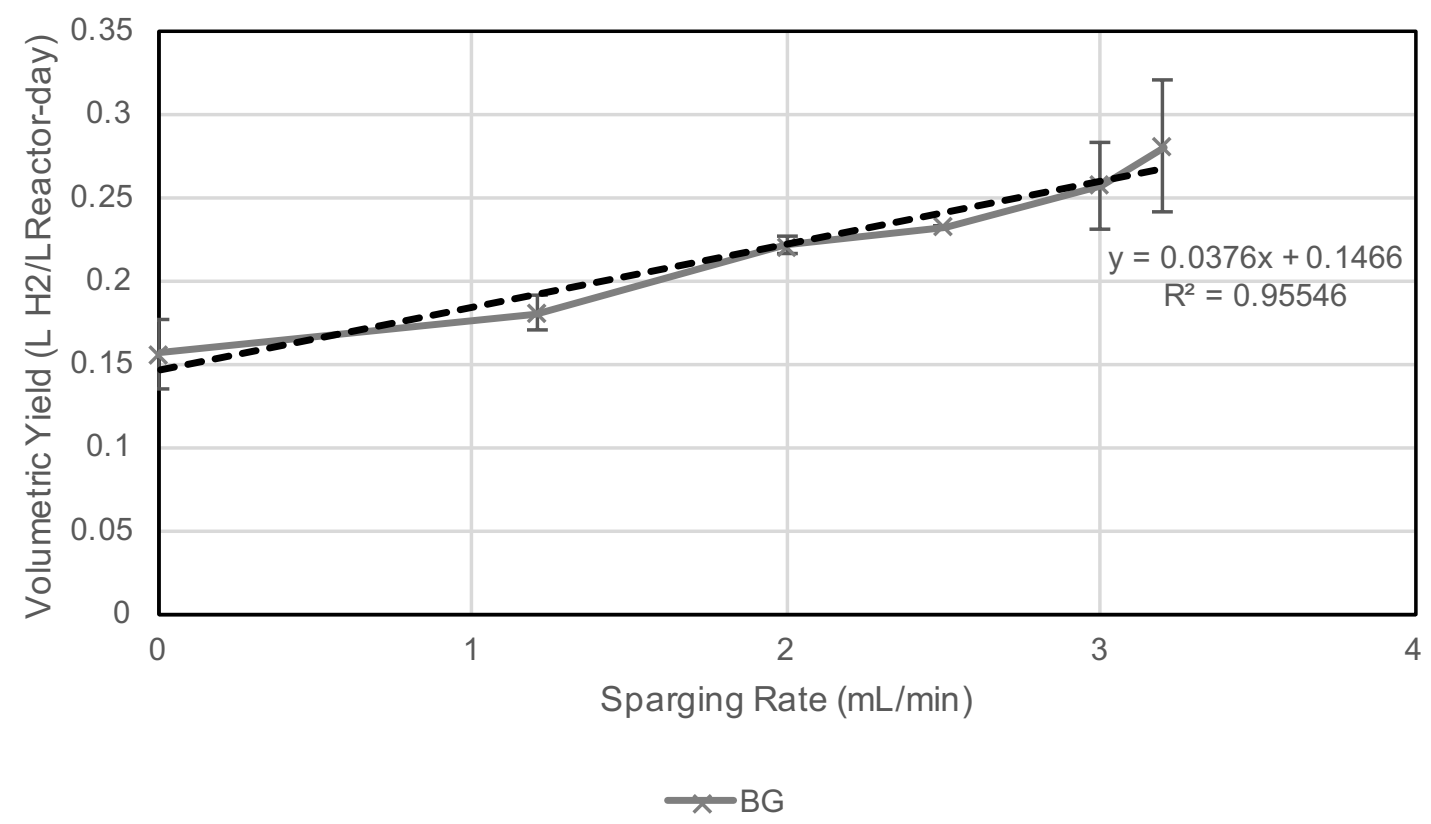

Figure 34. Volumetric hydrogen production for digesters sparged with biogas (BG). The linear fit produced an $R^{2}$ value of 0.95 , and the means of steady-state performance periods by duplicate digesters were used to calculate the standard errors shown $(n=2)$.

Molar yields for food waste-fed nitrogen-sparged digesters were highest for digesters sparged at $1 \mathrm{~L} \mathrm{~N} / \mathrm{hr}$. At this sparging rate, the molar hydrogen yield was $0.021 \pm 0.0013 \mathrm{~mol} \mathrm{H}_{2} / \mathrm{mol} \mathrm{COD}$ (mean $\pm \mathrm{SE}$ ) (Figure 35). At the lowest sparging rate tested, $0.5 \mathrm{~L} \mathrm{~N} / / \mathrm{hr}$, a molar yield of $0.014 \pm 0.0066 \mathrm{~mol} \mathrm{H}_{2} / \mathrm{mol}$ COD was observed. The unsparged digester produced $0.005 \pm 0.0006 \mathrm{~mol}$ $\mathrm{H}_{2} / \mathrm{mol}$ COD. The unsparged molar yield was low compared to the previously measure molar yield of $0.007 \pm 0.0016 \mathrm{~mol} \mathrm{H}_{2} / \mathrm{mol} \mathrm{COD}$ for food waste-fed digesters running under the same conditions. By sparging the digesters with $1 \mathrm{~L}$ $\mathrm{N}_{2} / \mathrm{hr}, 76 \%$ more of the influent COD was converted into hydrogen gas than the unsparged digester. A sparging rate of $0.5 \mathrm{~L} \mathrm{~N} / \mathrm{hr}$ produced $64 \%$ more hydrogen per mol of COD than the unsparged digester. Molar hydrogen yields increased linearly with sparging rate, resulting in an $\mathrm{R}^{2}$ value of 0.99 (Figure 36 ). 


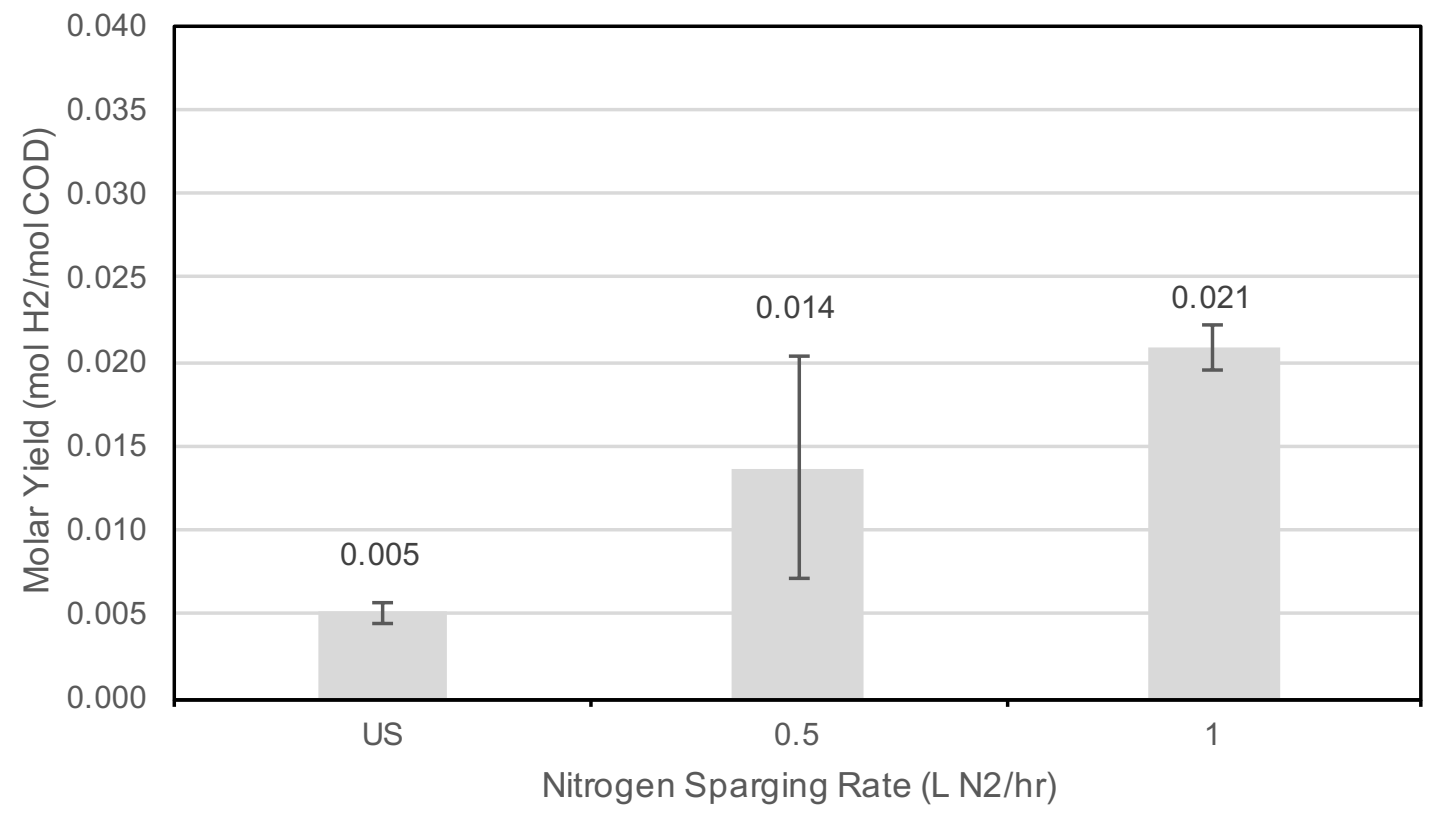

Figure 35. Molar hydrogen yields for food waste-fed digesters that were either unsparged (US) or sparged at flowrates of 0.5 and $1 \mathrm{~L} \mathrm{~N} / \mathrm{hr}$. All digesters operated at a mean OLR of $32.9 \mathrm{~g} \mathrm{COD/L-}$ day, $\mathrm{pH}$ of 6.40 , and HRT of 12 hours. The means of steady-state performance periods by duplicate digesters were used to calculate the standard errors shown ( $n=2)$.

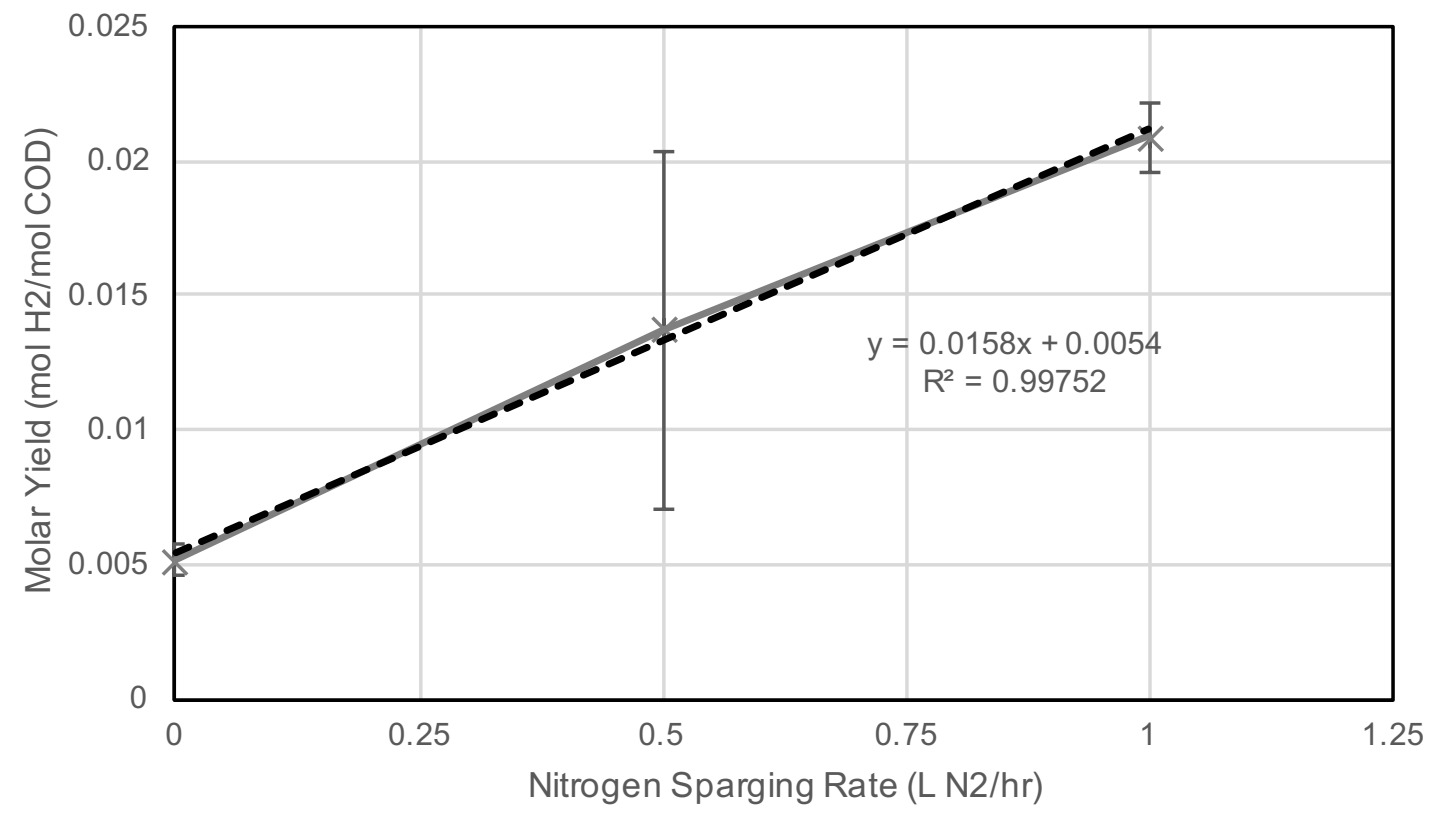

Figure 36. Molar hydrogen yields for food waste-fed digesters sparged with nitrogen gas. The linear fit produced an $R^{2}$ value of 0.99 , and the means of steady-state performance periods by duplicate digesters were used to calculate the standard errors shown $(\mathrm{n}=2)$. 
Volumetric hydrogen production for food waste-fed and nitrogen-sparged digesters were the highest of all substrates and conditions tested. Digesters sparged with $1 \mathrm{~L} \mathrm{~N} / \mathrm{hr}$ produced a volumetric hydrogen production of $0.478 \pm$ $0.0280 \mathrm{LH}_{2} / \mathrm{L}_{\text {Reactor-day }}$ (mean $\pm \mathrm{SE}$ ). At the lowest sparging rate tested, $0.5 \mathrm{~L}$ $\mathrm{N}_{2} / \mathrm{hr}$, a volumetric hydrogen production of $0.382 \pm 0.1049 \mathrm{LH}_{2} / \mathrm{L}_{\text {Reactor }}$-day was observed. The unsparged digester produced $0.123 \pm 0.0139 \mathrm{LH}_{2} / \mathrm{L}_{\text {Reactor-day }}$ (Figure 37). By sparging the digesters with $1 \mathrm{~L} \mathrm{~N} / \mathrm{hr}, 74 \%$ more hydrogen was produced than the unsparged digester. A sparging rate of $0.5 \mathrm{~L} \mathrm{~N} / \mathrm{hr}$ produced $64 \%$ more hydrogen per mol of COD than the unsparged digester. Volumetric hydrogen production increased linearly with sparging rate, resulting in an $\mathrm{R}^{2}$ value of 0.93 (Figure 38).

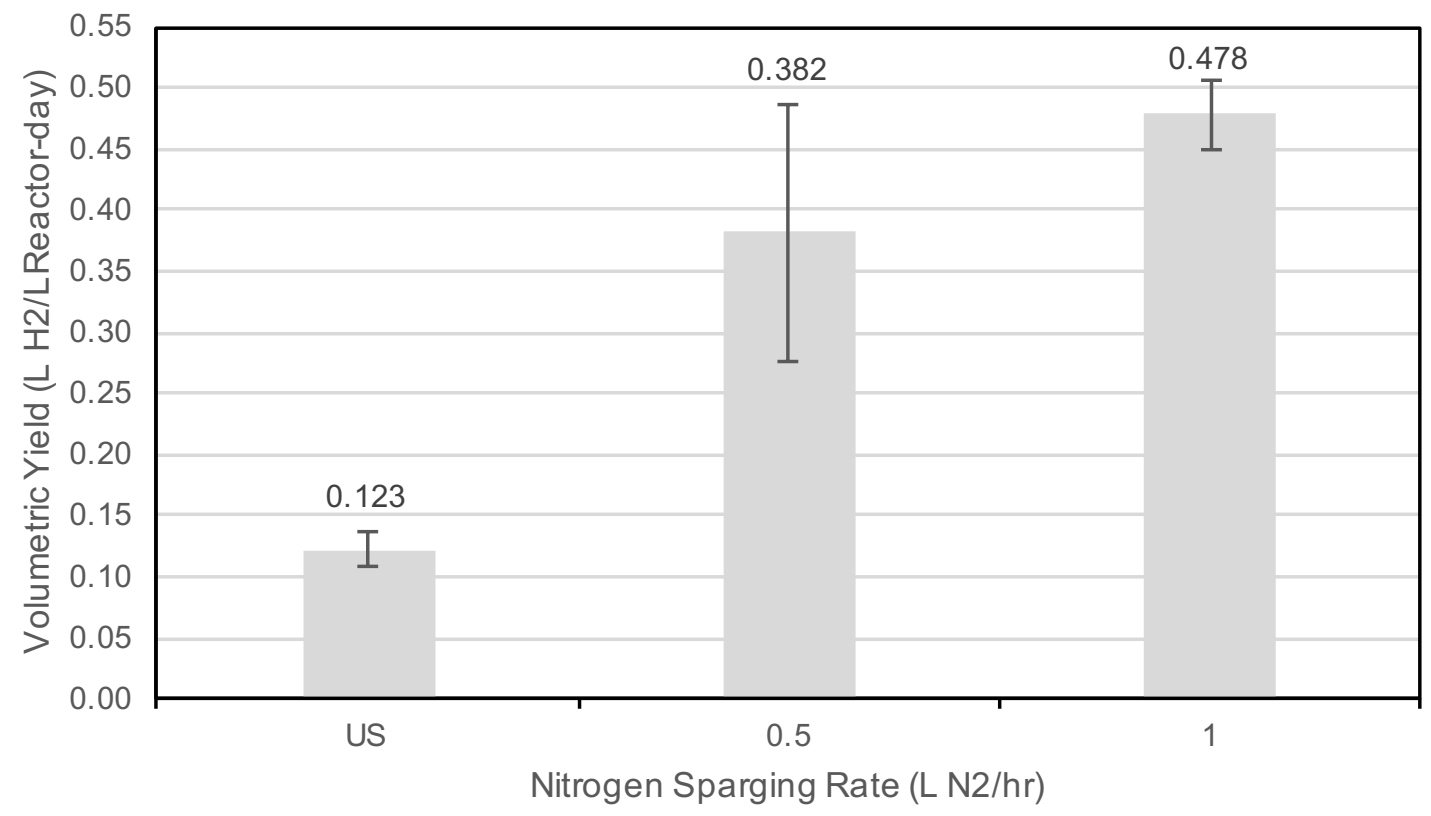

Figure 37. Volumetric hydrogen production for nitrogen-sparged and food waste-fed digesters operating at a mean OLR of $32.9 \mathrm{~g}$ COD/L-day, pH of 6.40, and HRT of 12 hours. The means of steady-state performance periods by duplicate digesters were used to calculate the standard errors shown $(\mathrm{n}=2)$. 


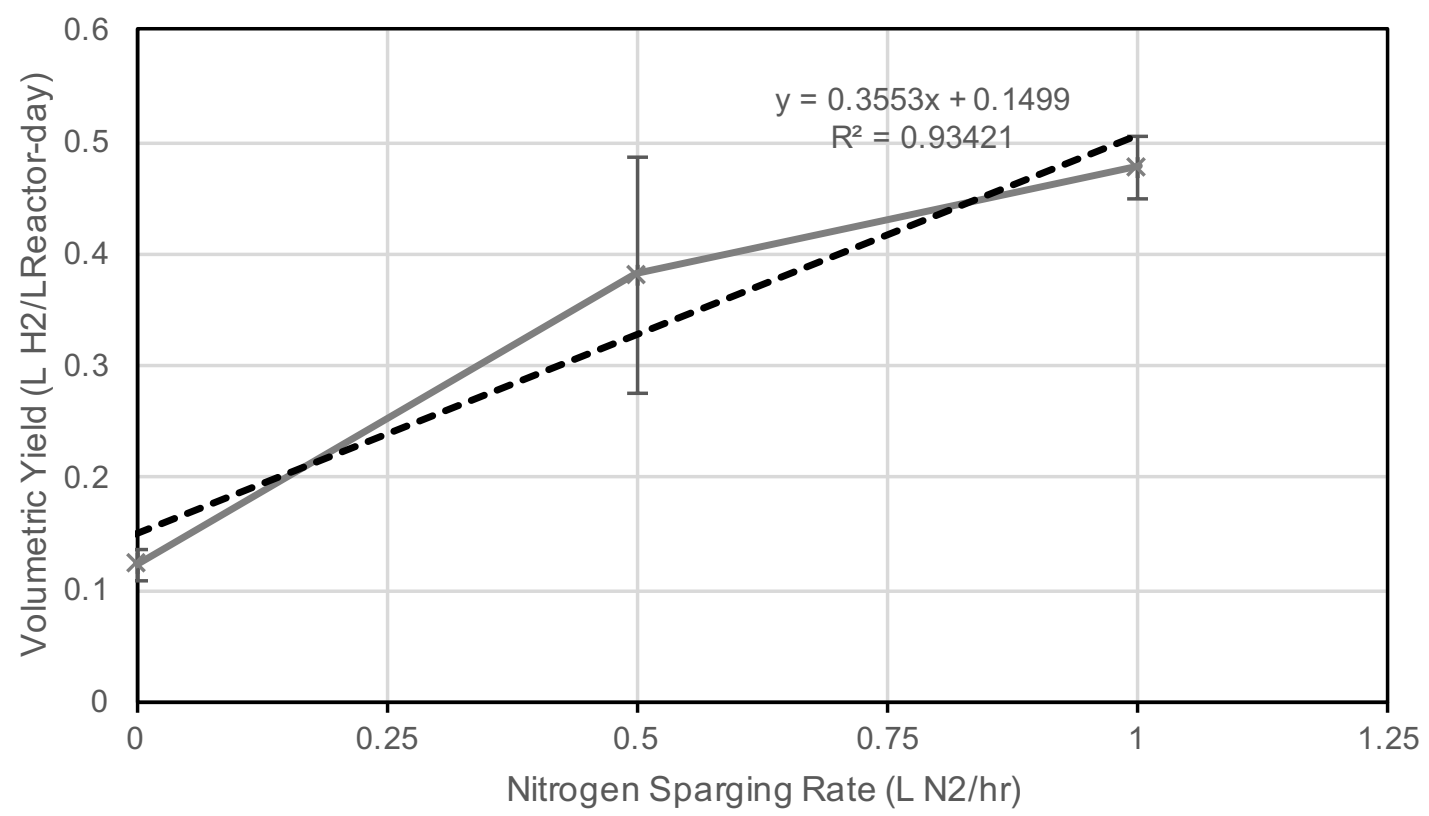

Figure 38. Volumetric hydrogen production for food waste-fed digesters sparged with nitrogen gas. The linear fit produced an $R^{2}$ value of 0.93 , and the means of steady-state performance periods by duplicate digesters were used to calculate the standard errors shown $(\mathrm{n}=2)$. 


\section{CHAPTER 4: DISCUSSION}

Results from each of the hydrogen optimization experiments show that $\mathrm{pH}, \mathrm{OLR}$, HRT, gas sparging, and substrate (glycerol or food waste) each individually affected hydrogen yields and production. Optimal conditions were defined as those producing the highest molar hydrogen yield or volumetric hydrogen production. The optimal operational conditions for glycerol substrate were a $\mathrm{pH}$ of 6.51, OLR of $18.8 \mathrm{~g} \mathrm{COD/L-day,} \mathrm{HRT} \mathrm{of} 12$ hours, and biogas or nitrogen sparging rate of $3.2 \mathrm{~mL} / \mathrm{min}(0.2 \mathrm{~L} / \mathrm{hr})$ Glycerol-fed digesters operating at these variable levels produced a molar yield of $0.020 \pm 0.0029 \mathrm{~mol} \mathrm{H}_{2} / \mathrm{mol} \mathrm{COD} \mathrm{and} \mathrm{a}$ volumetric hydrogen production of $0.281 \pm 0.0395 \mathrm{LH}_{2} / \mathrm{L}_{\text {Reactor-day }}$.

Three-dimensional surface plots of HRT, OLR, and hydrogen yield and production data were produced to graphically represent the data obtained in experiments fed glucose substrate. The surface plots depict the ways in which HRT and OLR affect hydrogen yield and production for unsparged digesters (Figures $39 \& 40$ ). These optimal conditions were determined before the sparging experiments to assess the effect of sparging on hydrogen production. The peak of each chart represents the highest molar hydrogen yield or volumetric hydrogen production. As values of HRT and OLR deviate from the conditions producing the peak (OLR $18.2 \mathrm{~g} \mathrm{COD/L-day,} \mathrm{HRT} 12$ hours) yields begin to decrease. 


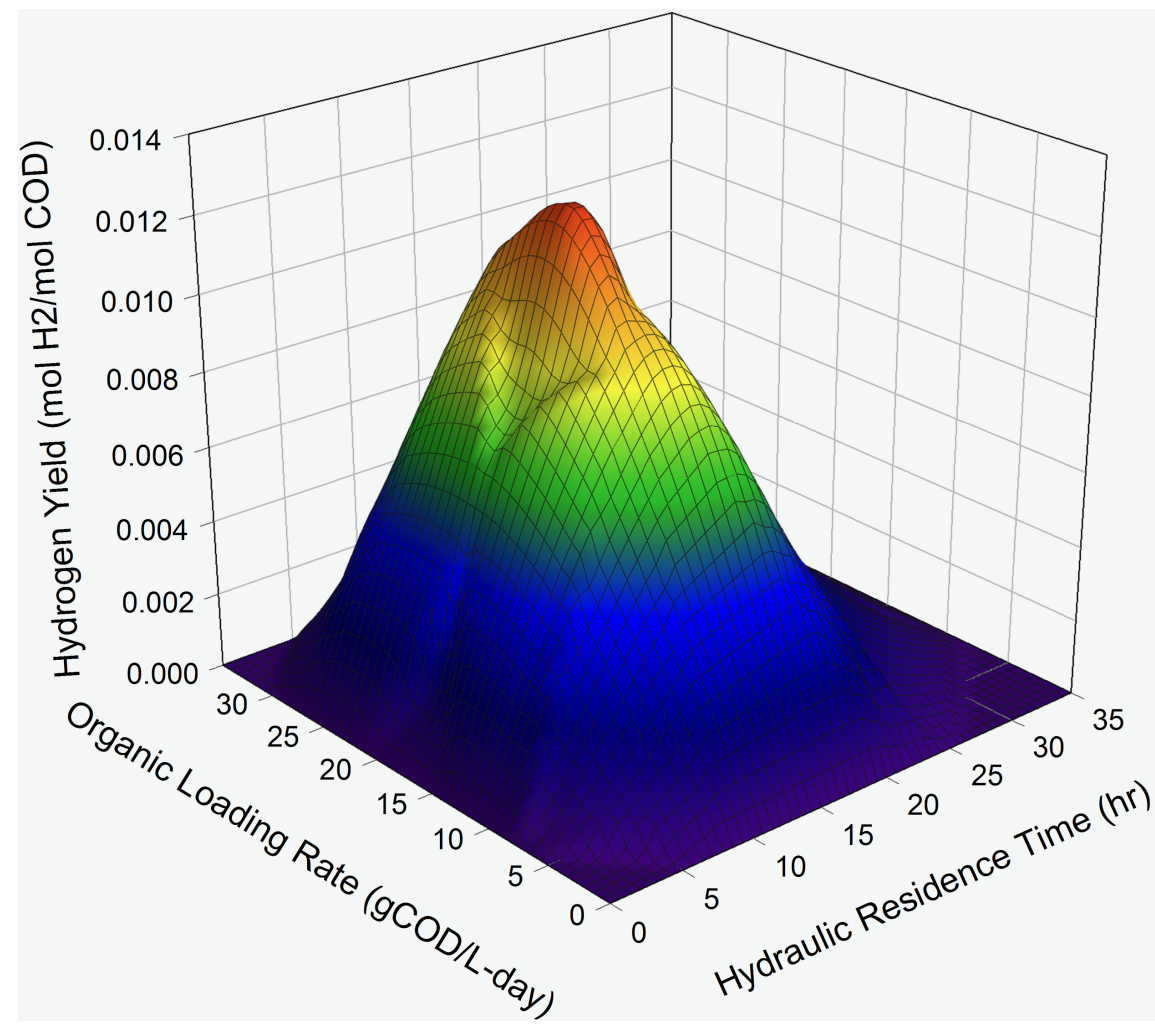

Figure 39. Molar hydrogen yields as a function of HRT and OLR within a pH range of 6.35 to 6.58. The optimal molar hydrogen yield is the peak of the surface plot $\left(0.012 \mathrm{~mol} \mathrm{H}_{2} / \mathrm{mol} C \mathrm{COD}\right)$ at an OLR value of $18.2 \mathrm{~g} C O D / L$-day and HRT of 12 hours. 


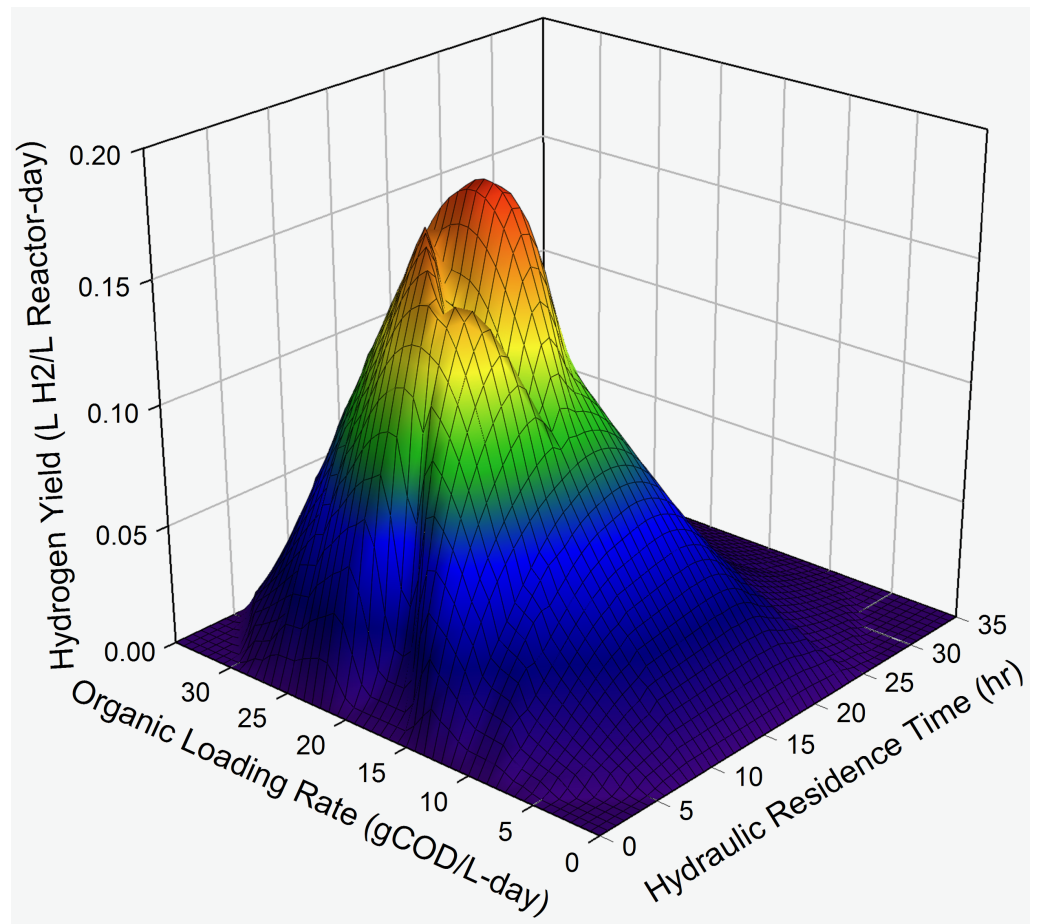

Figure 40. Volumetric hydrogen production as a function of HRT and OLR within a $p H$ range of 6.35 to 6.58. The optimal volumetric hydrogen production is the peak of the surface plot $(0.156 \mathrm{~L}$ $\mathrm{H}_{2} / \mathrm{L}_{\text {Reactor }}$-day) at an OLR value of $18.2 \mathrm{~g}$ COD/L-day and HRT of 12 hours.

Hydrogen optimization experiments for food waste substrate only focused on optimizing OLR and sparging rates because the optimal conditions for $\mathrm{pH}$ and HRT determined in glycerol experiments were used. Food waste-fed digesters operating at an OLR of $32.9 \mathrm{~g} \mathrm{COD/L-day,} \mathrm{pH}$ of 6.51 , HRT of 12 hours, and sparging rate of $1 \mathrm{~L} \mathrm{~N} / \mathrm{hr}$ produced a molar hydrogen yield of $0.021 \pm 0.0013 \mathrm{~mol}$ $\mathrm{H}_{2} / \mathrm{mol}$ COD and volumetric hydrogen production of $0.478 \pm 0.0280 \mathrm{~L} \mathrm{H}_{2} / \mathrm{L}_{\text {Reactor }}$ day.

The presence of methane indicates the presence of methanogenic bacteria which can consume hydrogen, potentially reducing hydrogen yields (Gunaseelan, 1997; Thompson, 2008). Based on gas chromatography that reported no methane gas, methanogenic bacteria did not have an effect on hydrogen yields 
for any of the hydrogen optimization experiments. Methane gas was not observed over the steady state periods in which hydrogen yields were calculated, except for the biogas ( $70 \%$ methane, $30 \%$ carbon dioxide) sparged digesters. Methane gas was not produced by the biogas sparged digesters, it was only present because the sparging gas, biogas, contained methane at the start of each experiment, methane production was observable prior to the complete washout of the methanogens in the inoculum; typically three residence times.

\subsection{Comparisons to Literature}

Results, specifically molar hydrogen yields, are compared to results from previous studies to understand the way in which reactor types, microorganisms, and operational conditions impact fermentative hydrogen production (Table 7). Molar yields were calculated on a COD-fed per day basis to allow comparisons among various substrates, including undefined ones such as food waste. The oxygen demand for one mole of glycerol, for example, is 3.5 moles of oxygen (Equation 4-1). Molar hydrogen yields were converted COD introduced to glycerol introduced (Equation 4-2, Table 6).

$$
\begin{aligned}
& \mathrm{C}_{3} \mathrm{H}_{8} \mathrm{O}_{3}+3.5 \mathrm{O}_{2} \rightarrow 3 \mathrm{CO}_{2}+4 \mathrm{H}_{2} \mathrm{O} \\
& \frac{0.013 \mathrm{~mol} \mathrm{H}}{\mathrm{mol} \mathrm{COD}} \times \frac{3.5 \mathrm{~mol} \mathrm{COD}}{\mathrm{mol} \mathrm{glycerol}}=\frac{0.047 \mathrm{~mol} \mathrm{H}_{2}}{\mathrm{~mol} \mathrm{glycerol}}
\end{aligned}
$$


Table 6. Molar yields observed at the optimal operational conditions with respect to COD and glycerol

\begin{tabular}{cccccc}
\cline { 4 - 5 } & & & \multicolumn{2}{c}{ Molar Hydrogen Yield } \\
\hline $\mathrm{pH}$ & $\begin{array}{c}\text { OLR } \\
(\mathrm{g} \text { COD/L- } \\
\text { day })\end{array}$ & HRT (hours) & $\begin{array}{c}\text { Sparging } \\
\text { Rate } \\
(\mathrm{mL} / \mathrm{min})\end{array}$ & $\mathrm{mol} \mathrm{H}_{2} / \mathrm{mol} \mathrm{COD}$ & $\begin{array}{c}\mathrm{mol} \mathrm{H} \mathrm{H}_{2} / \mathrm{mol} \\
\text { glycerol }\end{array}$ \\
\hline 6.51 & $23.8 \pm 1.502$ & 12 & 0 & $0.013 \pm 0.0029$ & $0.047 \pm 0.0102$ \\
6.40 & $18.2 \pm 0.6353$ & 12 & 0 & $0.015 \pm 0.0021$ & $0.051 \pm 0.0074$ \\
6.48 & $19.7 \pm 1.493$ & 12 & 0 & $0.010 \pm 0.0000$ & $0.035 \pm 0.0002$ \\
6.39 & $17.7 \pm 0.9010$ & 12 & 0 & $0.012 \pm 0.0016$ & $0.041 \pm 0.0055$ \\
6.49 & $18.7 \pm 2.046$ & 12 & 3.2 & $0.020 \pm 0.0029$ & $0.071 \pm 0.0100$ \\
\hline
\end{tabular}

The anaerobic digestion of glycerol yields numerous products including hydrogen, carbon dioxide propionic acid, succinic acid, butanol and ethanol (Yazdani \& Gonzalez, 2007). These products are formed through several fermentation pathways and are dependent on the environmental conditions and the type of microorganism involved in the fermentation process (Dharmadi, Muraka, \& Gonzales, 2006; Gonzales, Pelayo-Ortiz, Bories, Jauregui, \& Himmi, 2004; Yazdani \& Gonzalez, 2007). One potential fermentation pathway converts glycerol to ethanol, hydrogen, and carbon dioxide (Equation 4-3). Following this fermentation pathway, by stoichiometry and assuming no heat losses, one mole of hydrogen can theoretically be produced from one mole of glycerol. Biological yields are frequently significantly less than stoichiometric yields, possibly down to half (Hallenbeck \& Benemann, 2002).

$\mathrm{C}_{3} \mathrm{H}_{8} \mathrm{O}_{3} \rightarrow \mathrm{C}_{2} \mathrm{H}_{6} \mathrm{O}+\mathrm{H}_{2}+\mathrm{CO}_{2}$

One factor affecting fermentation pathways is the type of microorganism, or culture used to ferment the substrate. Many experiments have performed 
fermentative hydrogen production with pure cultures known to ferment glycerol to hydrogen. One study operating at an OLR of $24.3 \mathrm{~g} \mathrm{COD/L-day} \mathrm{and} \mathrm{an} \mathrm{HRT} \mathrm{of}$ 12 hours produced $0.38 \mathrm{~mol} \mathrm{H}_{2} / \mathrm{mol}$ glycerol when inoculated with Clostridium butyricum LMG 1212 t2 (Heyndrickx, Vos, \& Vancanneyt, 1991). This molar hydrogen yield is greater than what was found in this experiment. However, the use of pure cultures on a larger scale is not plausible because preventing contamination is challenging, especially with substrates that may already contain microorganisms (i.e. food waste). Energy intensive sterilization, or inactivation of microorganisms contained in the substrate may be required, and even then, contamination is still possible (Masset et. al. 2012).

The use of mixed cultures is of greater benefit to large scale systems because fluctuations in microbial communities have little impact on overall hydrogen production (Masset et al., 2012; Agler, Wrenn, Zinder, \& Angenent, 2011). The downfall to mixed cultures is that hydrogen yields are generally much lower than pure cultures (Masset et al., 2012). Anaerobic sludge used as an inoculum for a continuously stirred tank reactor produced $0.04 \mathrm{~mol} \mathrm{H}_{2} / \mathrm{mol}$ glycerol at $\mathrm{pH}$ of 6.5 , OLR of $24.3 \mathrm{~g}$ COD/L-day and an HRT of 12 hours (Silva-Illanes et al., 2015). This yield, was ten times lower than the observed yield of $0.38 \mathrm{~mol} \mathrm{H}_{2} / \mathrm{mol}$ glycerol obtained by Heyndrickx et al., whose reactors were run at the same OLR and HRT as Silva-Illanes et al., but were inoculated with a pure culture (1991, 2015). A nearly identical molar hydrogen yield to that found by Silva-Illanes et al. was observed in this experiment at the same OLR and HRT. Digesters in this experiment produced $0.047 \pm 0.0102 \mathrm{~mol} \mathrm{H}_{2} / \mathrm{mol}$ glycerol and were inoculated 
with a mixed culture, anaerobic sludge, and run at a pH of 6.5 , OLR of $23.8 \mathrm{~g}$ COD/L-day and HRT of 12 hours.

Table 7. Molar hydrogen yields obtained from various experiments using pure glycerol as a substrate. Each yield was generally higher than what was observed in this experiment.

\begin{tabular}{|c|c|c|c|c|c|c|}
\hline $\mathrm{pH}$ & Reactor & $\begin{array}{l}\text { Organic } \\
\text { Loading } \\
\text { Rate (g } \\
\text { COD/L-day) }\end{array}$ & $\begin{array}{c}\text { HRT } \\
\text { (hours } \\
\text { ) }\end{array}$ & $\begin{array}{c}\text { Yield } \\
\text { (mol } \\
\mathrm{H}_{2} / \mathrm{mol} \\
\text { glycerol) }\end{array}$ & Culture & Source \\
\hline 5.5 & CSTR & 24.3 & 12 & 0.41 & Anaerobic Sludge & $\begin{array}{l}\text { Silva-Illanes et } \\
\text { al. (2015) }\end{array}$ \\
\hline 6.5 & CSTR & 24.3 & 12 & 0.04 & Anaerobic Sludge & $\begin{array}{l}\text { Silva-Illanes et } \\
\text { al. (2015) }\end{array}$ \\
\hline 6.5 & CSTR & 36.5 & 8 & 0.17 & Anaerobic Sludge & $\begin{array}{l}\text { Silva-Illanes et } \\
\text { al. (2015) }\end{array}$ \\
\hline 5.5 & CSTR & 12.2 & 12 & 0.40 & Anaerobic Sludge & $\begin{array}{l}\text { Tapia-Venegas } \\
\text { et al. (2015) }\end{array}$ \\
\hline- & Batch & $\begin{array}{l}24.3(\mathrm{~g} \\
\text { COD/L) }\end{array}$ & - & 0.53 & $\begin{array}{c}\text { Klebsiella } \\
\text { pneumoniae }\end{array}$ & $\begin{array}{l}\text { Liu and Fang } \\
\qquad(2007)\end{array}$ \\
\hline- & CSTR & 24.3 & 12 & 0.38 & $\begin{array}{c}\text { Clostridium } \\
\text { butyricum LMG } \\
1212 \mathrm{t} 2\end{array}$ & $\begin{array}{l}\text { Heyndrickx et } \\
\text { al. (1991) }\end{array}$ \\
\hline- & CSTR & 24.3 & 12 & 1.05 & $\begin{array}{c}\text { Clostridium } \\
\text { pasteurianum LMG } \\
3285\end{array}$ & $\begin{array}{l}\text { Heyndrickx et } \\
\text { al. (1991) }\end{array}$ \\
\hline- & CSTR & 24.3 & 12 & 0.50 & $\begin{array}{c}\text { Clostridium } \\
\text { pasteurianum } \mathrm{CH} 4\end{array}$ & Lo et al. (2013) \\
\hline- & Batch & $\begin{array}{l}12.1(\mathrm{~g} \\
\mathrm{COD} / \mathrm{L})\end{array}$ & - & 0.41 & Anaerobic Sludge & $\begin{array}{l}\text { Seifert et. al. } \\
(2009)\end{array}$ \\
\hline
\end{tabular}

$\mathrm{pH}$ was found to have a great impact on hydrogen production by Silva-Illanes et al., who observed the highest molar yield of $0.41 \mathrm{~mol} \mathrm{H}_{2} / \mathrm{mol}$ glycerol was obtained at a pH of 5.5. Similarly, a molar yield of $0.40 \mathrm{~mol} \mathrm{H}_{2} / \mathrm{mol}$ glycerol was achieved at the same $\mathrm{pH}$ is a separate study (2015). The major difference between these two studies was that Silva-Illanes et al. operated at an OLR of $24.3 \mathrm{~g} \mathrm{COD/L-day,} \mathrm{while} \mathrm{Tapia-Venegas} \mathrm{et} \mathrm{al.} \mathrm{operated} \mathrm{at} \mathrm{an} \mathrm{OLR} \mathrm{of} 12.2 \mathrm{~g}$ COD/L-day (2015). Even though the OLRs between the two experiments were nearly $50 \%$ different, a similar molar hydrogen yield was achieved. The molar 
yield observed by Silva-Illanes et al. at a $\mathrm{pH}$ of 6.5 was ten times smaller than what was discovered at a pH of 5.5 (2015). At the lowest $\mathrm{pH}$ tested in this experiment, 6.15 , molar hydrogen yields only reached $0.02 \mathrm{~mol} \mathrm{H}_{2} / \mathrm{mol}$ glycerol, despite being run at a similar OLR and HRT to Silva-Illanes et al. (2015). It is possible that the yields found in this experiment at a $\mathrm{pH}$ of 6.15 were lower than what Silva-Illanes et al. and Tapia-Venegas et al. observed when operating at a $\mathrm{pH}$ of 5.5 because of the difference in $\mathrm{pH}$ may have selected for microorganisms in the anaerobic sludge that better fermented glycerol.

In addition to fermentation pathways and environmental conditions, the type of reactor used for fermentative hydrogen production also seems to influence molar hydrogen yields and production. Liu and Fang observed a molar hydrogen yield of $0.53 \mathrm{~mol} \mathrm{H} / \mathrm{mol}$ glycerol with an anaerobic sludge inoculum in a CSTR at an organic loading of $24.3 \mathrm{~g} \mathrm{COD/L-day} \mathrm{(2007).} \mathrm{Seifert} \mathrm{et} \mathrm{al.} \mathrm{observed} \mathrm{a} \mathrm{molar}$ hydrogen yield of $0.41 \mathrm{~mol} \mathrm{H}_{2} / \mathrm{mol}$ glycerol at an organic loading of $12.1 \mathrm{~g} \mathrm{COD} / \mathrm{L}$ (2009). Numerous studies utilize batch reactors to produce hydrogen from different organic wastes, yet like using pure cultures, batch reactors have some disadvantages that make their use less desirable (Batstone, Torrijos, Ruiz, Schmidt, 2004). To start, achieving similar results and products for each batch reaction may be difficult if mixed cultures are used as an inoculum. If the conditions inside the reactors are not the same as in the studies cited above. The time it takes to ferment the substrate in batch reactors is also longer than that of a continuous stirred tank reactor (Batstone et al., 2004). Continuous reactors are 
more desirable for larger scale fermentative hydrogen production because continuous production of hydrogen from a steady flow of substrate is achieved.

High hydrogen partial pressures in the liquid phase was found to be one of the main factors affecting hydrogen production (Mizuno et al., 2000). One study found that the digestion of glycerol was inhibited by dissolved hydrogen gas in the liquid phase because the metabolism of the microorganism involved in the fermentation process was inhibited (Dharmadi et al., 2006). Stripping the gas out of the liquid phase would therefore decrease the hydrogen partial pressure and allow for a greater amount of glycerol to be digested and converted into products like hydrogen gas. To increase the yields observed in $\mathrm{pH}, \mathrm{OLR}$, and HRT experiments, gas sparging of the digesters was tested.

The sparging of digesters with high purity nitrogen gas and biogas was found to nearly double the molar hydrogen yield in glycerol-fed digesters. The study showed that hydrogen yields differed by only $1.4 \%$ when sparged with nitrogen or biogas, indicating that the type of sparging gas does not influence the resulting hydrogen yields and production. The unsparged digesters operating at a $\mathrm{pH}$ of 6.39, OLR of $17.7 \pm 0.9010 \mathrm{~g} \mathrm{COD/L-day,} \mathrm{and} \mathrm{an} \mathrm{HRT} \mathrm{of} 12$ hours produced a molar hydrogen yield of $0.041 \pm 0.0055 \mathrm{~mol} \mathrm{H}_{2} / \mathrm{mol}$ glycerol. Nitrogen and biogas sparged digesters produced a molar yield of $0.071 \pm 0.0100 \mathrm{~mol} \mathrm{H}_{2} / \mathrm{mol}$ glycerol at an OLR of $18.7 \pm 2.046 \mathrm{~g} \mathrm{COD/L-day,} 12$ hour HRT, and $\mathrm{pH}$ of 6.49 .

Unsparged digesters produced only $4.1 \%$ of the theoretical hydrogen yield for glycerol, while sparged digesters produced $7.1 \%$ of the theoretical hydrogen 
yield. A useful comparison to the sparged molar hydrogen yields for glycerol are those observed with glucose substrate because glucose is, theoretically, the best substrate for fermentative hydrogen production. The theoretical molar hydrogen yield for glucose is $4 \mathrm{~mol} \mathrm{H}_{2} / \mathrm{mol}$ glucose. Kim et al. studied the effect of variable sparging rates of biogas, and nitrogen on molar hydrogen yields. Digesters were operated at a pH of 5.3, OLR of $40 \mathrm{~g} \mathrm{COD/L-day,} \mathrm{and} \mathrm{an} \mathrm{HRT} \mathrm{of} 12$ hours. The unsparged, control digester obtained a molar yield of $0.75 \mathrm{~mol} \mathrm{H}_{2} / \mathrm{mol}$ glucose, while digesters sparged with biogas and nitrogen gas achieved molar hydrogen yields of 0.84 , and $0.87 \mathrm{~mol} \mathrm{H}_{2} / \mathrm{mol}$ glucose respectively (Kim, Han, Kim, \& Shin, 2006). Sparging the digesters caused a $12 \%$ increase in molar hydrogen yields, and attained about $22 \%$ of the theoretical molar hydrogen yield for glucose.

In a separate experiment, glucose-fed digesters operating within a $\mathrm{pH}$ range of 6.0-6.40, an HRT of 12 hours, and an OLR of $19.2 \mathrm{~g} \mathrm{COD/L-day} \mathrm{produced} \mathrm{a}$ molar yield of $0.61 \mathrm{~mol} \mathrm{H}_{2} / \mathrm{mol}$ glucose. When sparged with $10.7 \mathrm{~L} \mathrm{~N} / \mathrm{hr}$, molar hydrogen yields increased to $3.08 \mathrm{~mol} \mathrm{H}_{2} / \mathrm{mol}$ glucose (Olivas, 2015). When sparged with $10.7 \mathrm{~L} \mathrm{~N} / \mathrm{hr}$, hydrogen yields increased by $500 \%$, producing roughly $77 \%$ of theoretical molar hydrogen yield for glucose. The differences between the yields obtained by Olivas and Kim et al. are likely attributed to the different OLRs, $\mathrm{pH}$ values, as well as sparging rates.

Sparging digesters in this experiment increased the overall molar hydrogen yield by $42 \%$, which is $7.1 \%$ of the theoretical molar hydrogen yield for glycerol. However, the highest sparging rate tested was $3.2 \mathrm{~mL} / \mathrm{min}$ per liter of digester, 
far less than the sparging rate of $10.7 \mathrm{~L} \mathrm{~N}_{2} / \mathrm{hr}$ tested by Olivas, and $6 \mathrm{~L} \mathrm{~N} / \mathrm{hr}$ tested by Kim et al. Sparging rates tested for glycerol-fed digesters were plotted against the molar hydrogen yields produced at each sparging rate to produce Equation 4-4. As stated earlier, it is likely that only $50 \%\left(0.5 \mathrm{~mol} \mathrm{H}_{2} / \mathrm{mol}\right.$ glycerol $)$ of the theoretical molar hydrogen yield for glycerol is actually attainable for fermentative hydrogen production. Assuming the relationship remains linear, 0.5 mol $\mathrm{H}_{2}$ /mol glycerol was substituted for $\mathrm{y}$ in Equation 4-4, and resulted in a sparging rate of $44 \mathrm{~mL} / \mathrm{min}$. At this sparging rate, it is estimated that $0.5 \mathrm{~mol}$ $\mathrm{H}_{2} /$ mol glycerol could be produced.

$y=0.003 x+0.0106$

Food waste-fed and nitrogen sparged digesters produced molar hydrogen yields that increased, almost linearly, with an increasing sparging rate. A linear regression was performed on sparging rates of $0 \mathrm{~L} \mathrm{~N} / \mathrm{hr}$ (unsparged), $0.5 \mathrm{~L}$ $\mathrm{N}_{2} / \mathrm{hr}$, and $1.0 \mathrm{~L} \mathrm{~N} / \mathrm{hr}$ for molar hydrogen yields resulting in an $R^{2}$ of 0.99 (Equation 4-5). The highest molar hydrogen yield was accomplished at a sparging rate of $1.0 \mathrm{~L} \mathrm{~N} / \mathrm{hr}$ and was $0.021 \pm 0.0013 \mathrm{~mol} \mathrm{H}_{2} / \mathrm{mol}$ COD. Compared to glycerol, food waste achieved molar hydrogen yields that were $5 \%$ greater than the maximum molar hydrogen yield for glycerol.

$y=0.0158 x+0.0054$

When sparged with nitrogen gas at $1.0 \mathrm{~L} \mathrm{~N}_{2} / \mathrm{hr}$, the molar hydrogen yield obtained in this experiment $\left(0.021 \pm 0.0013 \mathrm{~mol} \mathrm{H}_{2} / \mathrm{mol} \mathrm{COD}\right)$ was lower than what was found in other experiments (Table 8). It is important to note that $\mathrm{pH}$ and 
HRT optimization experiments were not performed for the food waste substrate, so while molar hydrogen yields obtained in this experiment may be low, there is a chance that hydrogen yields would increase once the optimal $\mathrm{pH}$ and HRT are found. One experiment, operating at a pH of 6.0 and OLR of $28 \mathrm{~g} \mathrm{COD/L-day,}$ obtained a molar hydrogen yield of $0.054 \mathrm{~mol} \mathrm{H}_{2} / \mathrm{mol}$ COD (Lee et al., 2010). The major differences between Lee's experiments were $\mathrm{pH}$ and inoculum. Lee et al. inoculated the reactors with enriched kitchen waste compost and maintained a $\mathrm{pH}$ of 6.0. It is possible that the microorganisms in the kitchen waste compost may have been better adapted to food waste fermentation. A separate experiment operated at an OLR of $50 \mathrm{~g} \mathrm{COD/L-day,} \mathrm{HRT} \mathrm{of} 2$ days, and $\mathrm{pH}$ of 5.5 , produced a molar hydrogen yield of $0.038 \mathrm{~mol} \mathrm{H}_{2} / \mathrm{mol} \mathrm{COD}$ (Li et al., 2008). The food waste sparging experiments likely produced lower hydrogen yields than those obtained by Li et al. because of the differences in HRT, OLR, and $\mathrm{pH}$.

Table 8. Molar hydrogen yields produced by food waste substrate at varying operational conditions and cultures.

\begin{tabular}{ccccccc}
\hline pH & Reactor & $\begin{array}{c}\text { Organic } \\
\text { Loading } \\
\text { Rate (g } \\
\text { COD/L-day) }\end{array}$ & $\begin{array}{c}\mathrm{HRT} \\
\text { (day) }\end{array}$ & $\begin{array}{c}\text { Yield (mol } \\
\mathrm{H}_{2} / \mathrm{mol} \\
\text { COD) }\end{array}$ & Culture & Source \\
\hline- & Batch & 4.6 & - & 0.135 & $\begin{array}{c}\text { Anaerobic } \\
\text { sludge }\end{array}$ & Chen et al. (2006) \\
5.5 & CSTR & 50 & 2 & 0.038 & $\begin{array}{c}\text { Acidogenic } \\
\text { sludge }\end{array}$ & Li et al. (2008b) \\
6.0 & CSTR & 28 & - & 0.054 & $\begin{array}{c}\text { Kitchen Waste } \\
\text { Compost }\end{array}$ & Lee et al. (2010a) \\
\hline
\end{tabular}

Molar hydrogen yields obtained in this experiment were, for the most part, lower than yields obtained in experiments (Table 7). Culture-type and $\mathrm{pH}$ are likely the reasons yields were so low. As stated earlier, glycerol can be fermented to 
various products: Escherichia coli, for example, can ferment glycerol to hydrogen gas, but only under acidic conditions and when hydrogen is not accumulating in the liquid phase (Yazdani \& Gonzalez, 2007; Dharmadi et al., 2006). On the other hand, the microorganism Propionibacteria acidipropioncic will ferment glycerol to propionic acid (Yazdani \& Gonzalez, 2007; Gonzales et al., 2004). It is unknown whether either of these microorganisms were present in the initial anaerobic sludge inoculum. However, experiments that used anaerobic wastewater sludge still produced higher molar yields. The major difference was $\mathrm{pH}$. Experiments yours or others? operating at the same OLR and HRT produced higher molar hydrogen yields when operating at a $\mathrm{pH}$ of 5.5 than were produced at a $\mathrm{pH}$ of 6.5. However, molar hydrogen yields produced in this experiment were highest at a pH of 6.5. Because molar hydrogen yields at 6.5 were consistently better than those obtained at a pH of $6.15, \mathrm{pH}$ values less than 6.15 were not tested. Future experiments using mixed cultures as a substrate should focus on testing a greater range of $\mathrm{pH}$ values to ensure the optimal $\mathrm{pH}$ is found.

Food waste-fed digesters also produced molar hydrogen yields that were lower than those found in other experiments. Unlike glycerol experiments, $\mathrm{pH}$ and HRT optimization experiments were not run for food waste substrate, rather the optimal $\mathrm{pH}$ and HRT from glycerol experiments were used. Therefore, food waste experiments were not run at the optimal $\mathrm{pH}$ and HRT. It is likely that the molar hydrogen yields for food waste would have been higher had $\mathrm{pH}$ and HRT optimization experiments been run. Future HRT and $\mathrm{pH}$ testing is necessary to determine all of the operational conditions for food waste. 


\section{CHAPTER 5: CONCLUSION}

A series of experiments were performed to individually optimize each of the major operational conditions affecting fermentative hydrogen production. The major operational conditions tested were $\mathrm{pH}, \mathrm{OLR}, \mathrm{HRT}$, and gas sparging rate. A range of values for each condition were tested, and those that produced the highest molar hydrogen yield and volumetric hydrogen production were deemed optimal and used in subsequent experiments. It was determined that the optimal

$\mathrm{pH}, \mathrm{OLR}, \mathrm{HRT}$, and gas sparging rate for glycerol substrate were $\mathrm{pH} 6.5,18.2 \mathrm{~g}$ COD/L-day, 12 hours, and $3.2 \mathrm{~mL} / \mathrm{min}$ per liter of digester. At these conditions, a molar hydrogen yield of $0.020 \pm 0.0029 \mathrm{~mol} \mathrm{H}_{2} / \mathrm{mol} \mathrm{COD}$ and volumetric hydrogen production of $0.281 \pm 0.0395 \mathrm{LH}_{2} / \mathrm{L}_{\text {Reactor-day were produced. Molar }}$ hydrogen yields obtained in this experiment were low compared to other experiments.

Separate experiments performed for food waste substrate established an optimal OLR of $33.9 \mathrm{~g} \mathrm{COD/L-day} \mathrm{and} \mathrm{nitrogen} \mathrm{sparging} \mathrm{rate} \mathrm{of} 1.0 \mathrm{~L} \mathrm{~N} / \mathrm{hr}$. pH and HRT optimization experiments were not performed for food waste substrate, though it is recommended they be performed in future experiments. Digesters fed food waste substrate produced a maximum molar hydrogen yield of $0.021 \pm 0.0013$ $\mathrm{mol} \mathrm{H}_{2} / \mathrm{mol} \mathrm{COD}$ and volumetric hydrogen production of $0.478 \pm 0.0280 \mathrm{~L}$ $\mathrm{H}_{2} / \mathrm{L}_{\text {Reactor-day }}$ at a pH of 6.5 and HRT of 12 hours.

Gas sparging of anaerobic digesters, a novel approach to increasing overall hydrogen yields and production, was examined for glycerol and food waste 
substrate. For all sparging rates examined, molar hydrogen yields and volumetric hydrogen production increased almost linearly with sparging rate. Relationships between gas sparging rate and molar hydrogen yields were produced for each of the substrates tested, resulting in coefficients of determination, or $\mathrm{R}^{2}$ values, greater than 0.92 . Assuming the relationships remain linear, future experiments can estimate, and examine the potential increase in molar hydrogen yields at increased sparging rates. Compared to unsparged digester, sparged digesters increased molar hydrogen yields and volumetric hydrogen production by at least $42 \%$. Most importantly, it was determined that the type of gas involved in sparging had very little, if any, effect on overall hydrogen production.

After performing numerous experiments on hydrogen optimization by means of anaerobic digestion, and analyzing their results, recommendations for future experiments come to light. One of the most promising applications for the anaerobic digestion of waste substrates, or any organic substrate for that matter, is two-phase anaerobic digestion. In this scenario, first phase digesters produce hydrogen, while the second phase digesters produce methane. Produced methane gas is sparged through the first phase, increasing hydrogen yields, and producing a gas mixture of hydrogen and methane that, when combusted in an IC engine, reduces the amount of nitrogen oxides emitted (TerMaath, Skolnik, Schefer, \& Keller, 2006).

In terms of digester operation, increased automation should be investigated. Gas sparging rate could potentially be automated to sustain consistent hydrogen 
yields, an important factor for large scale hydrogen production. Despite some of the drawbacks to automation, continuous monitoring and control of bench scale anaerobic digestion systems could provide steady conditions resulting in higher confidence in the obtained. At a larger scale, one issue that could be detrimental to overall hydrogen production is the attached growth of methanogenic bacteria to the reactor walls. Long-term experiments should be run to investigate the health of the culture over time, determining the effect of possible methanogenic attached growths, and options for removing the growth if necessary. The costliest aspect of digester operation in this experiment was the phosphate buffer system. New sources of alkalinity should be studied to reduce overall operational costs to the digestion system while maintaining an adequate buffering capacity.

As waste substrates become more desirable and feasible for their use in fermentative hydrogen production, recalcitrant waste substrates treated with biogas enzymes should be studied. Biogas enzymes have the potential to break down more difficult substrates, decrease retention times while maintaining the same rate of fermentation, increase the quality of biogas, and even increase biogas production while using less feedstock (DuPont, 2016). Studies have shown that digesters that are fed biogas enzyme-treated substrate have reduced digester operational costs by $10 \%$ (Dupont, 2016). However, the cost and energy effectiveness of bio enzymes should be further studied. 


\section{REFERENCES}

Agler, M. T., Wrenn, B. A., Zinder, S. H., \& Angenent, L. T. (2011). Waste to bioproduct conversion with undefined mixed cultures: the carboxylate platform. Trends In Biotechnology, 29(2), 70-78. doi:10.1016/j.tibtech.2010.11.006

Ahmadi, P., \& Kjeang, E. (2017). Realistic simulation of fuel economy and life cycle metrics for hydrogen fuel cell vehicles. International Journal Of Energy Research, 41(5), 714-727. doi:10.1002/er.3672

APHA. (2005). Standard Methods for the Examination of Water and Wastewater, 21st ed. Washington, D.C.: American Public Health Association.

Batstone, D. J., Torrijos, M., Ruiz, C., \& Schmidt, J. E. (2004). Use of an anaerobic sequencing batch reactor for parameter estimation in modelling of anaerobic digestion. Water Science \& Technology, 50(10), 295-303.

Beckers, L., Masset, J., Hamilton, C., Delvigne, F., Toye, D., Crine, M., \& ... Hiligsmann, S. (2015). Investigation of the links between mass transfer conditions, dissolved hydrogen concentration and biohydrogen production by the pure strain Clostridium butyricum CWBI1009. Biochemical Engineering Journal, 9818-28. doi:10.1016/j.bej.2015.01.008

Chen, W., Chen, S., Kumar Khanal, S., \& Sung, S. (2006). Kinetic study of biological hydrogen production by anaerobic fermentation. International Journal Of Hydrogen Energy, 31(15), 2170-2178. doi:10.1016/j.ijhydene.2006.02.020

Chong, M. L., Sabaratnam, V., Shirai, Y., \& Hassan, M. A. (2009). Biohydrogen production from biomass and industrial wastes by dark fermentation. International Journal of Hydrogen Energy, 34(8), 3277-3287.

Choudhuri, A. R., \& Gollahalli, S. R. (2000). Combustion characteristics of hydrogen hydrocarbon hybrid fuels. International Journal of Hydrogen Energy, 25, 451462. Retrieved from http://www.sciencedirect.com/science/article/pii/S0360319999000270\#

Cooke, R. (2014). Aerobic and Anaerobic Digestion and Types of Decompositon. Retrieved from http://water.me.vccs.edu/courses/env149/lesson4b.htm

Curry, N., \& Pillay, P. (2012). Biogas prediction and design of a food waste to energy system for the urban environment. Renewable Energy: An International Journal, 41200-209. doi:10.1016/j.renene.2011.10.019

Das, D., Khanna, N., \& Dasgupta, C. N. (2014). Biohydrogen production: fundamentals and technology advances. CRC Press. 
Dharmadi, Y., Murarka, A., \& Gonzalez, R. (2006). Anaerobic fermentation of glycerol by Escherichia coli: a new platform for metabolic engineering. Biotechnology and bioengineering, 94(5), 821-829.

Department of Energy. (2014). Alternative Fuels Data Center: Hydrogen Production and Distribution. Retrieved January 1, 2015, from http://www.afdc.energy.gov/fuels/hydrogen_production.html

DuPont. (2016). Enzyme Products for Biogas Production Solutions for anaerobic digesters[Pamphlet].

Florida Solar Energy Center. (2014). Hydrogen Basics - Production. Retrieved January 1, 2015, from http://www.fsec.ucf.edu/en/consumer/hydrogen/basics/production.htm

Gonzales, V. A., Pelayo-Ortiz, C., Bories, A., Jauregui, J. J. A., \& Himmi, E. (2004). Glycerol fermentation with Propionibacteria and optimisation of the production of propionic acid.

Gunaseelan, V. N. (1997). Anaerobic digestion of biomass for methane production: a review. Biomass and bioenergy, 13(1-2), 83-114.

Hallenbeck, P. C., \& Benemann, J. R. (2002). Biological hydrogen production; fundamentals and limiting processes. International Journal Of Hydrogen Energy, 27(11/12), 1185.

Han, W., Ye, M., Zhu, A. J., Huang, J. G., Zhao, H. T., \& Li, Y. F. (2016). A combined bioprocess based on solid-state fermentation for dark fermentative hydrogen production from food waste. Journal Of Cleaner Production, 1123744-3749. doi:10.1016/j.jclepro.2015.08.072

Heyndrickx, M., Vos, P. D., Vancanneyt, M., \& Ley, J. D. (1991). The fermentation of glycerol byClostridium butyricum LMG $1212 \mathrm{t} 2$ and $1213 \mathrm{t} 1 \mathrm{andC}$. pasteurianum LMG 3285. Applied microbiology and biotechnology, 34(5), 637-642.

Kim, S., Han, S., \& Shin, H. (2004). Feasibility of biohydrogen production by anaerobic co-digestion of food waste and sewage sludge. International Journal Of Hydrogen Energy, 29(15), 1607-1616. doi:10.1016/j.jhydene.2004.02.018

Kim, D., Han, S., Kim, S., \& Shin, H. (2006). Effect of gas sparging on continuous fermentative hydrogen production. International Journal Of Hydrogen Energy, 31(15), 2158-2169. doi:10.1016/j.ijhydene.2006.02.012 
Kornbluth, K., Greenwood, J., Jordan, E., McCaffrey, Z., \& Erickson, P. a. (2012). Economic feasibility of hydrogen enrichment for reducing $\mathrm{NO} x$ emissions from landfill gas power generation alternatives: A comparison of the levelized cost of electricity with present strategies. Energy Policy, 41(x), 333-339. http://doi.org/10.1016/j.enpol.2011.10.054

Kumar, G., Sivagurunathan, P., Pugazhendhi, A., Thi, N. D., Zhen, G., Chandrasekhar, K., \& Kadier, A. (2017). A comprehensive overview on light independent fermentative hydrogen production from wastewater feedstock and possible integrative options. Energy Conversion \& Management, 141390-402. doi:10.1016/j.enconman.2016.09.087

Kuruti, K., Begum, S., Ahuja, S., Anupoju, G. R., Juntupally, S., Gandu, B., \& Ahuja, D. K. (2017). Exploitation of rapid acidification phenomena of food waste in reducing the hydraulic retention time (HRT) of high rate anaerobic digester without conceding on biogas yield. Bioresource Technology, 22665-72. doi:10.1016/j.biortech.2016.12.005

Lamed, R. J., Lobos, J. H., \& Su, T. M. (1988). Effects of stirring and hydrogen on fermentation products of Clostridium thermocellum. Applied and Environmental Microbiology, 54(5), 1216-1221.

Lee, Z., Li, S., Kuo, P., Chen, I., Tien, Y., Huang, Y., \& ... Cheng, S. (2010). Thermophilic bio-energy process study on hydrogen fermentation with vegetable kitchen waste. International Journal Of Hydrogen Energy, 35(24), 13458-13466. doi:10.1016/j.ijhydene.2009.11.126

Li, S. L., Kuo, S. C., Lin, J. S., Lee, Z. K., Wang, Y. H., \& Cheng, S. S. (2008). Process performance evaluation of intermittent-continuous stirred tank reactor for anaerobic hydrogen fermentation with kitchen waste. International journal of hydrogen energy, 33(5), 1522-1531.

Liang, K., \& Pirnie, M. (2009). Regulatory Impacts of Biogas-fired Internal Combustion Engines. In CWEA Air, Water, \& Energy Conference: Sustainability for Wastewater Treatment Plants. Retrieved from https://www.cwea.org/sarbs/pdfs/AirWaterEnergyConf/BiogasEngineRegCWEAJ une112009.pdf

Liu, F., \& Fang, B. (2007). Optimization of bio-hydrogen production from biodiesel wastes by Klebsiella pneumoniae. Biotechnology journal, 2(3), 374-380.

Lo, Y., Chen, X., Huang, C., Yuan, Y., \& Chang, J. (2013). Dark fermentative hydrogen production with crude glycerol from biodiesel industry using indigenous hydrogen-producing bacteria. International Journal Of Hydrogen Energy, 38(35), 15815-15822. doi:10.1016/j.ijhydene.2013.05.083 
Maru, B., Bielen, A., Constantí, M., Medina, F., \& Kengen, S. (2013). Glycerol fermentation to hydrogen by Thermotoga maritima: Proposed pathway and bioenergetic considerations. International Journal Of Hydrogen Energy, 38(14), 5563-5572. doi:10.1016/j.ijhydene.2013.02.130

Masset, J., Calusinska, M., Hamilton, C., Hiligsmann, S., Joris, B., Wilmotte, A., \& Thonart, P. (2012). Fermentative hydrogen production from glucose and starch using pure strains and artificial co-cultures of Clostridium spp. Biotechnology For Biofuels, 5(1), 35-49. doi:10.1186/1754-6834-5-35

McCarty, P. L. (1964). Anaerobic Waste Treatment Fundamentals. Public Works, 95(9,10,11,12). Retrieved from http://www.seas.ucla.edu/stenstro/Anaerobic assignment.pdf

Mizuno, O., Dinsdale, R., Hawkes, F. R., Hawkes, D. L., \& Noike, T. (2000). Enhancement of hydrogen production from glucose by nitrogen gas sparging. Bioresource Technology, 73(1), 59-65.

Olivas, N. M. (2015). Two-Phase Anaerobic Digestion to Reduce the NOX Emission Potential of Biogas(Unpublished master's thesis). California Polytechnic State University.

Pakarinen, O., Kaparaju, P., \& Rintala, J. (2011). The effect of organic loading rate and retention time on hydrogen production from a methanogenic CSTR. Bioresource Technology, 102(19), 8952-8957. doi:10.1016/j.biortech.2011.07.020

Romm, J. (2006). CALIFORNIA'S HYDROGEN HIGHWAY RECONSIDERED. Golden Gate University Law Review, 36(3), 393-411.

Ruggeri, B., Tommasi, T., \& Sanfilippo, S. (2015). BioH2 \& BioCH4 Through Anaerobic Digestion: From Research to Full-scale Applications. Springer-Verlag London. http://doi.org/10.1007/978-1-4471-6431-9

Seifert, K., Waligorska, M., Wojtowski, M., \& Laniecki, M. (2009). Hydrogen generation from glycerol in batch fermentation process. International Journal Of Hydrogen Energy, 34(9), 3671-3678. doi:10.1016/j.jjhydene.2009.02.045

Sharma, Y., Parnas, R., \& Li, B. (2011). Bioenergy production from glycerol in hydrogen producing bioreactors (HPBs) and microbial fuel cells (MFCs). International Journal Of Hydrogen Energy, 36(6), 3853-3861. doi:10.1016/j.ijhydene.2010.12.040 
Silva-Illanes, F., Tapia Venegas, E., Marone, A., Trably, E., Ruiz-Filippi, G. (2015). Influence of $\mathrm{pH}$ and hydraulic retention time on hydrogen and ethanol coproduction by dark fermentation in a CSTR with glycerol as substrate. Presented at 14. World Congress on Anaerobic Digestion (AD14), Viña del Mar, CHL (2015$11-15$ - 2015-11-18).

Tapia-Venegas, E., Cabrol, L., Brandhoff, B., Hamelin, J., Trably, E., Steyer, J., \& Ruiz-Filippi, G. (2015). Adaptation of acidogenic sludge to increasing glycerol concentrations for biohydrogen production. Applied Microbiology \& Biotechnology, 99(19), 8295-8308. doi:10.1007/s00253-015-6832-6

TerMaath, C., Skolnik, E., Schefer, R., \& Keller, J. (2006). Emissions reduction benefits from hydrogen addition to midsize gas turbine feedstocks. International Journal Of Hydrogen Energy, 31(9), 1147-1158.

doi:10.1016/j.ijhydene.2005.10.002

Thompson, Reese S. "Hydrogen production by anaerobic fermentation using agricultural and food processing wastes utilizing a two-stage digestion system." (2008).

Valdez-Vazquez, I., \& Poggi-Varaldo, H. M. (2009). Hydrogen production by fermentative consortia. Renewable and Sustainable Energy Reviews, 13(5), 1000-1013. http://doi.org/10.1016/j.rser.2008.03.003

Wilson, R. P. (2012). Application of Hydrogen Assited Lean Operation to Biogas Fueled Reciprocating Engines (BioHALO). Retrieved from http://www.energy.ca.gov/2012publications/CEC-500-2012-064/CEC-500-2012064.pdf

Yazdani, S. S., \& Gonzalez, R. (2007). Anaerobic fermentation of glycerol: a path to economic viability for the biofuels industry. Current Opinion In Biotechnology, 18(3), 213-219. doi:10.1016/j.copbio.2007.05.002 